Aus der Poliklinik für Zahnärztliche Prothetik

(Prof. Dr. med. dent. R. Bürgers)

im Zentrum Zahn-, Mund- und Kieferheilkunde

der Medizinischen Fakultät der Universität Göttingen

\title{
Untersuchungen zu Herkunft und \\ Migrationsverhalten von chondrogenen \\ Progenitorzellen in den späten Stadien \\ der Osteoarthrose
}

\author{
INAUGURAL-DISSERTATION \\ zur Erlangung des Doktorgrades \\ der Medizinischen Fakultät der \\ Georg-August-Universität zu Göttingen
}

vorgelegt von

Regina Bunke (geb. Gerter)

aus

Celle 
Dekan:

I. Berichterstatter:

II. Berichterstatter:

III. Berichterstatter:
Prof. Dr. rer. nat. H.K. Kroemer

Prof. Dr. med. N. Miosge

Prof. Dr. med. R. Dressel

Prof. Dr. med. M. Oppermann

Datum der mündlichen Prüfung: 27. März 2018 
Hiermit erkläre ich, die Dissertation mit dem Titel "Untersuchungen zu Herkunft und Migrationsverhalten von chondrogenen Progenitorzellen in den späten Stadien der Osteoarthrose" eigenständig angefertigt und keine anderen als die von mir angegebenen Quellen und Hilfsmittel verwendet zu haben.

Göttingen, den

(Unterschrift) 


\section{Inhaltsverzeichnis}

Abbildungsverzeichnis .................................................................................. III

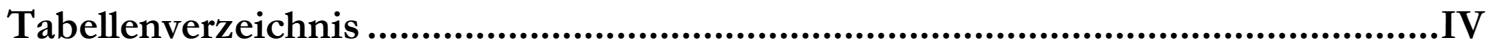

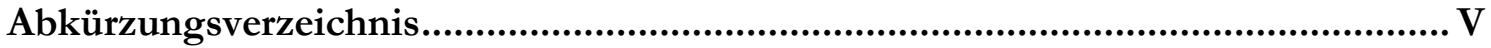

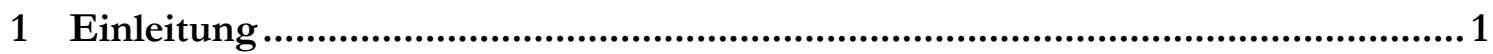

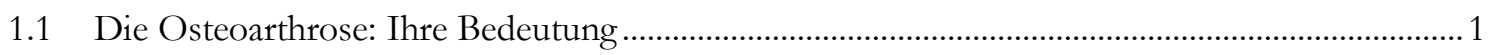

1.2 Histologische Veränderungen im Gelenkknorpel.................................................................... 1

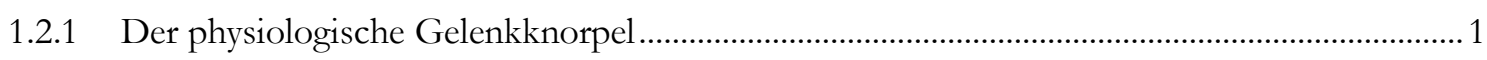

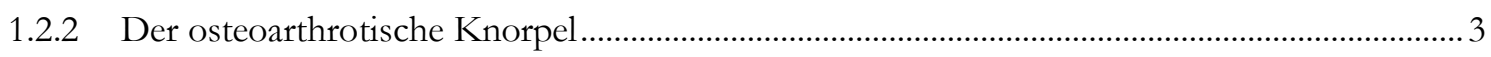

1.3 Zellbasierte Reparaturmechanismen ...........................................................................................

1.4 Mesenchymale Stammzellen und Perizyten …………..............................................................

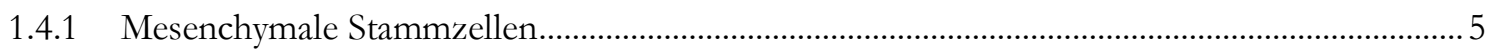

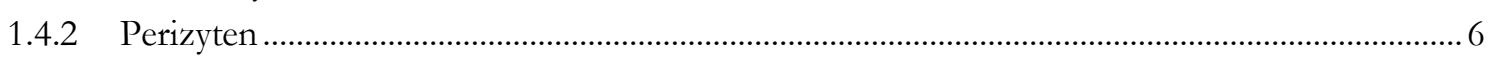

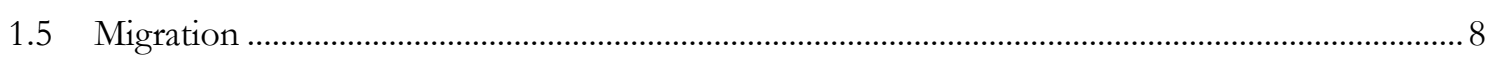

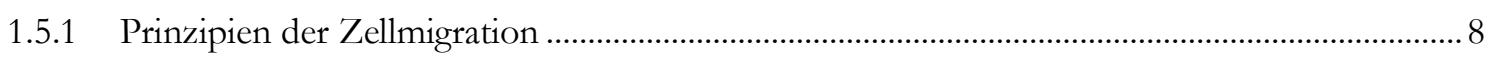

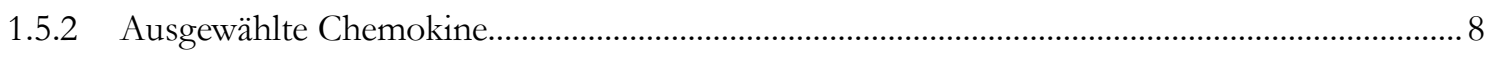

1.6 Aufgaben- und Fragestellung dieser Arbeit …………………………………………………....... 10

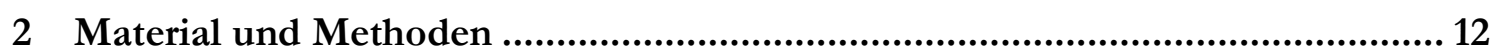

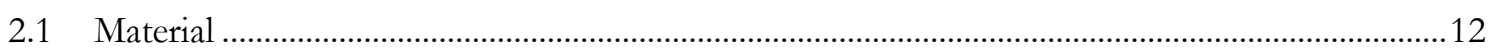

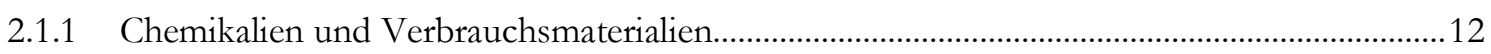

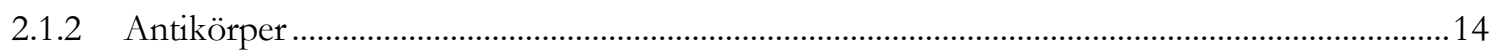

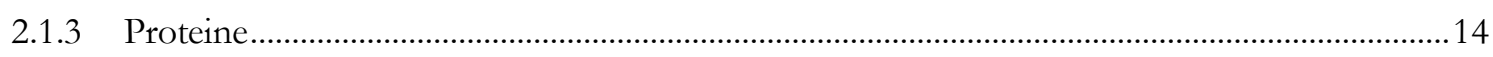

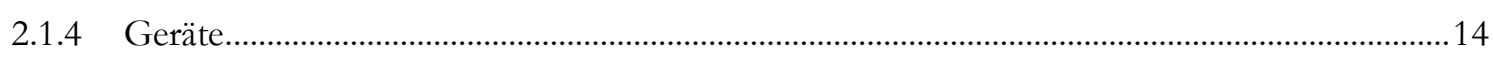

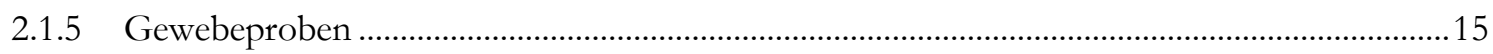

2.2 Immunhistochemische Untersuchung von Perizytenmarkern am Knorpelgewebe.....................16

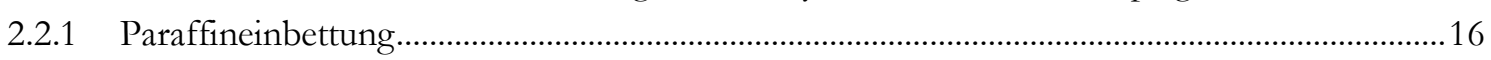

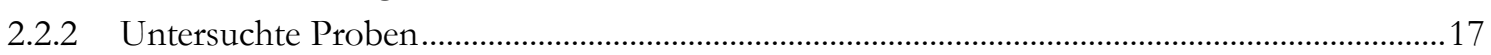

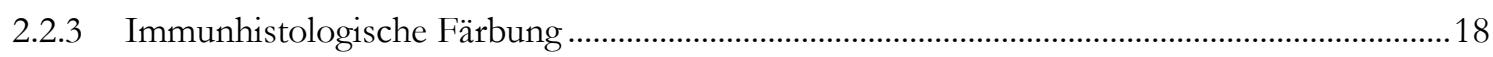

2.3 Untersuchung von CPCs in Hinblick auf Perizyten- und mesenchymale

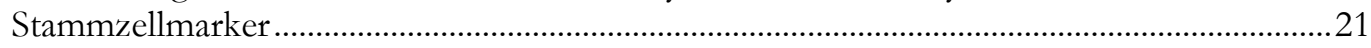

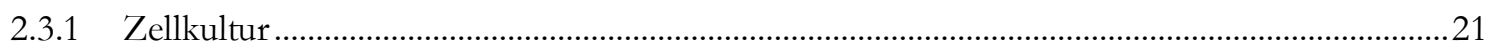

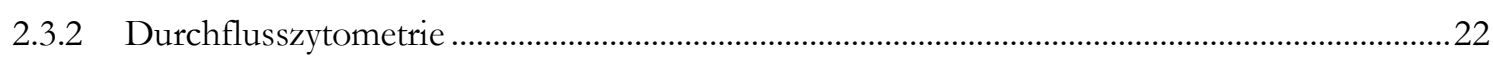

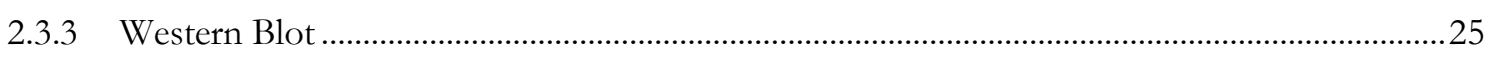

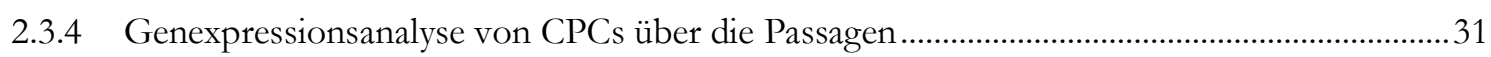

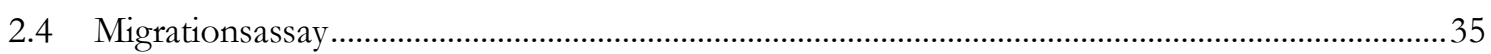




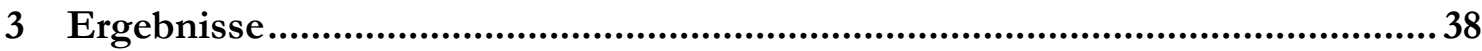

3.1 Immunhistochemische Untersuchung von Perizytenmarkern am Knorpelgewebe....................38

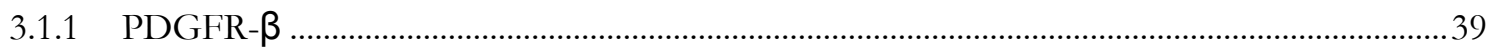

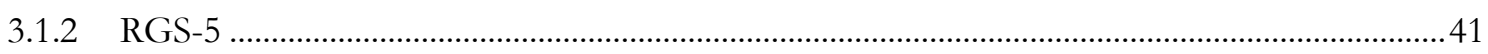

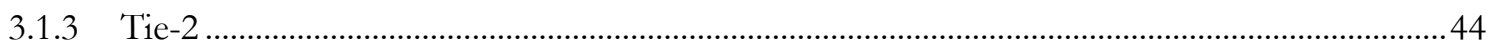

3.2 Untersuchung von CPCs in Hinblick auf Perizyten- und mesenchymale Stammzellmarker.............................................................................................................. 49

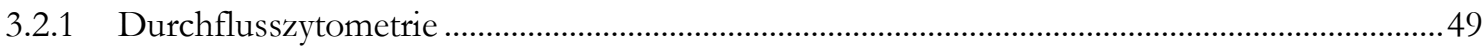

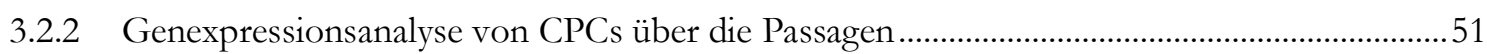

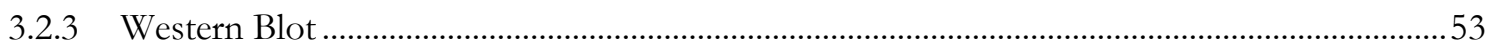

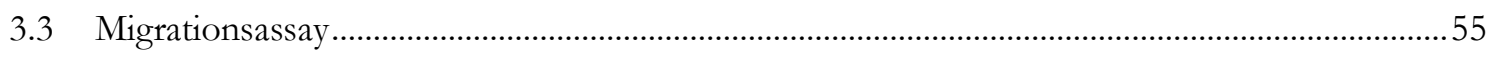

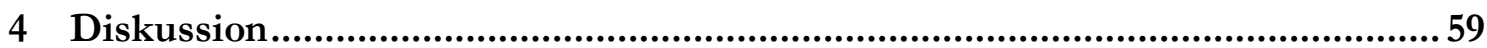

4.1 Osteoarthrose und Stammzellen - Histologische Beobachtungen..................................................59

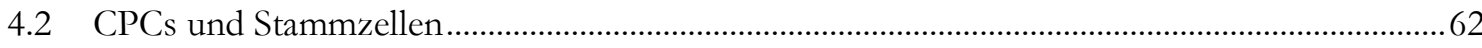

4.3 Migration - Was könnte der Antrieb sein? ...................................................................................

4.4 Einordnung der Ergebnisse dieser Arbeit in den biologischen und medizinischen Kontext mit Schlussbetrachtungen ............................................................................................. 67

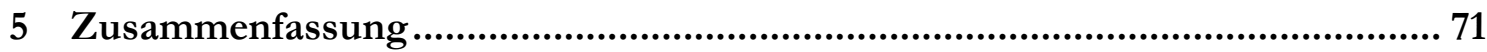

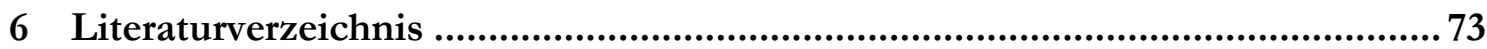




\section{Abbildungsverzeichnis}

Abbildung 1.1 Zoneneinteilung des gesunden hyalinen Knorpels ...................................... 3

Abbildung 1.2 CPCs $(*)$ migrieren aus einer Probe osteoarthrotischen Knorpels ............. 5

Abbildung 3.1 Untersuchung eines mikroskopisch gesunden Knorpels auf PDGFR- $\beta$ Expression

Abbildung 3.2 Immunhistochemische Untersuchung von PDGFR- $\beta$ im osteoarthrotischem Kniegelenksknorpel .................................................... 40

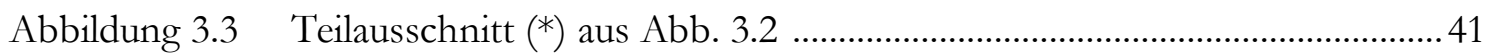

Abbildung 3.4 Teilausschnitt $(* *)$ aus Abb. 3.2 ................................................................... 41

Abbildung 3.5 Immunhistochemische Untersuchung auf RGS-5-Expression bei mikroskopisch gesundem Knorpel ............................................................... 42

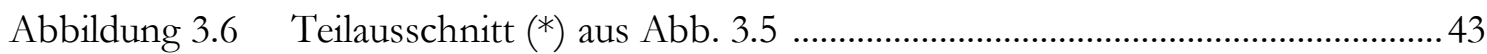

Abbildung 3.7 RGS-5-positive Einsprossungen in den Knorpel bei fortgeschrittener

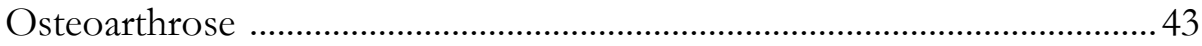

Abbildung 3.8 Kleines Blutgefäß mit RGS-5-positivem Stroma im subchondralen

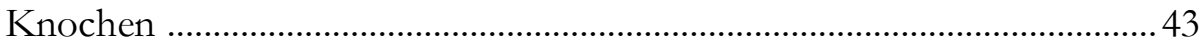

Abbildung 3.9 Gelenkknorpel mit vorangeschrittener Osteoarthrose und RGS-5positiven Zellclustern ..................................................................................... 44

Abbildung 3.10 Tie-2-Expression im gesunden Knorpel...................................................... 45

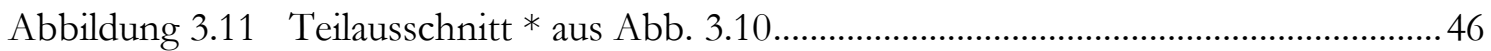

Abbildung 3.12 Tie-2-positive Zellen an der Knorpeloberfläche eines mikroskopisch gesunden Knorpels ....................................................................................... 46

Abbildung 3.13 Tie-2-Expression in der frühen Osteoarthrose ……………......................... 47

Abbildung 3.14 Untersuchung der Tie-2-Expression bei fortgeschrittener

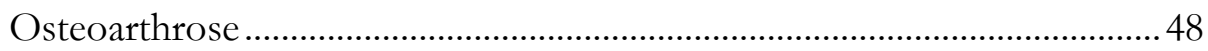

Abbildung 3.15 Tie-2-positive Einsprossung in den Knorpel................................................. 48

Abbildung 3.16 Tie-2-positive Cluster bei fortgeschrittener Osteoarthrose ......................... 49

Abbildung 3.17 Durchflusszytometrische Untersuchung der CPCs auf Perizytenund mesenchymale Stammzellmarker......................................................... 50

Abbildung 3.18 Durchflusszytometrische Untersuchung in Bezug auf die

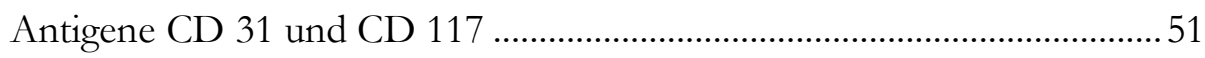

Abbildung 3.19 Passagenintervalle dreier CPC-Populationen................................................ 51

Abbildung 3.20 PCR-Untersuchung über die Passagen ......................................................... 52

Abbildung 3.21 Relative Expression der untersuchten Gene über die Passagen .................. 53

Abbildung 3.22 Western Blot-Untersuchung auf eine PDGFR- $\beta$-Exression hin ................ 54

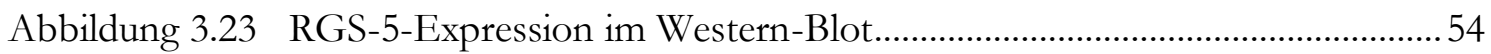

Abbildung 3.24 Western-Blot-Untersuchung mit dem Tie-2-Antikörper ............................. 54

Abbildung 3.25 Migrationsassay mit Entzündungsfaktoren als Chemokine.......................... 56

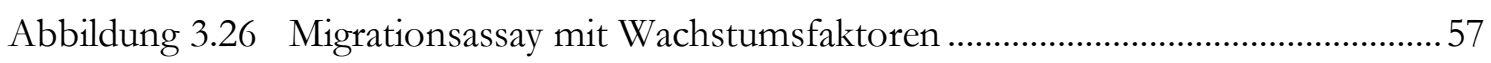

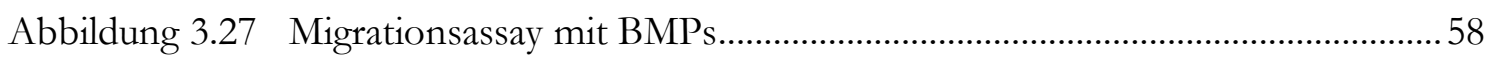




\section{Tabellenverzeichnis}

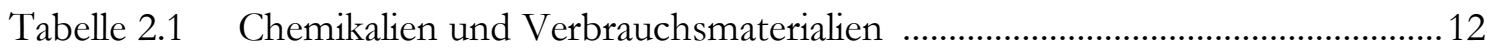

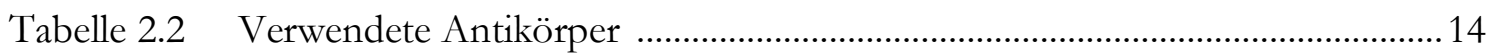

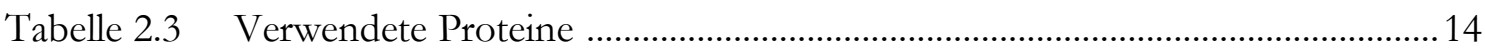

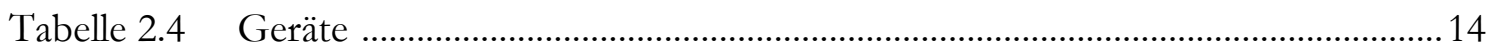

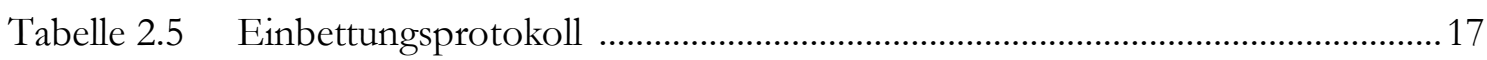

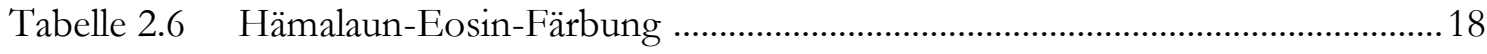

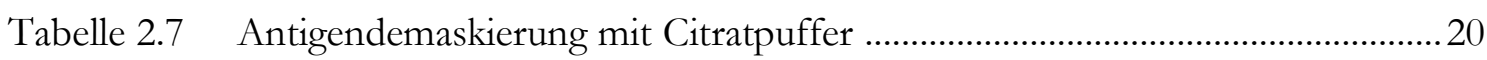

Tabelle 2.8 Immunhistologische Untersuchung mit dem DAKO REAL ${ }^{\mathrm{TM}}$

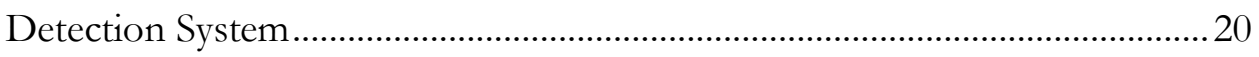

Tabelle 2.9 Für die Immunhistochemie verwendete Antikörper...........................................2 21

Tabelle 2.10 Antigenmarkierung oberflächlicher Antigene .................................................... 23

Tabelle 2.11 Antigenmarkierung intrazellulärer Antigene ......................................................2 24

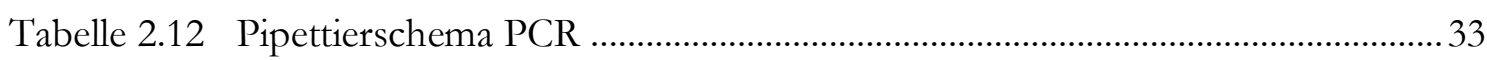

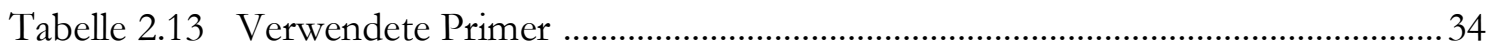

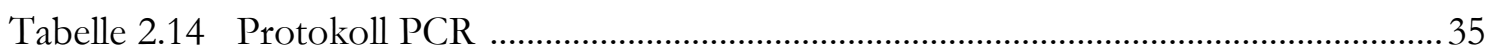

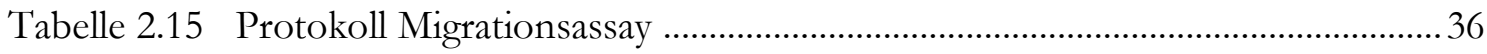

Tabelle 2.16 Untersuchte Zytokine............................................................................................. 37 


\section{Abkürzungsverzeichnis}

Im folgenden werden diejenigen Abkürzungen aufgelistet, die nicht zu den allgemein üblichen Abkürzungen oder zu den SI-Einheiten zählen.

\begin{tabular}{|c|c|}
\hline $\mathrm{AM}$ & Acetomethoxy \\
\hline aSMA & alpha-Smooth Muscle Actin \\
\hline APS & Ammoniumpersulfat \\
\hline Ang-1 und -2 & Angiopoetin-1 und -2 \\
\hline BMP & Bone Morphogenetic Protein \\
\hline BSA & Bovines Serumalbumin \\
\hline CPCs & Chondrogenic Progenitor Cells \\
\hline $\mathrm{CD}$ & Cluster of Differentiation \\
\hline cDNA & complementary $D N A$ \\
\hline DEPC & Diethylpyrocarbonate \\
\hline DMEM & Dulbecco's Modified Eagle Medium \\
\hline DNA & Desoxyribonukleinsäure \\
\hline EDTA & Ethylendiamintetraacetat \\
\hline EZM & Extrazellulärmatrix \\
\hline et al. & et alii \\
\hline FCS & Fetal Calf Serum (Fetales Kälberserum) \\
\hline FGF-2 & Fibroblast Growth Factor-2 \\
\hline FITC & Fluoreszeinisothiocyanat \\
\hline FSC & Forward Scatter \\
\hline FOXO1A & Forkhead Box Protein $01 A$ \\
\hline gDNA & genomische DNA \\
\hline GPCRs & G Protein-Coupled Receptors \\
\hline IGF-1 & Insulin-Like Growth Factor-1 \\
\hline IL & Interleukin \\
\hline MG & Molekulargewicht \\
\hline MMPs & Matrix-Metalloproteinasen \\
\hline MSCs & Mesenchymal Stem Cells \\
\hline mRNA & messenger-RNA \\
\hline OARSI & Osteoarthritis Research Society International \\
\hline PBS & Phosphate-Buffered Saline \\
\hline PCR & Polymerase Chain Reaction \\
\hline PDGF-B & Platelet-Derived Growth Factor-B \\
\hline PDGFR- $\beta$ & Platelet-Derived Growth Factor Receptor- $\beta$ \\
\hline RD-RT-PCR & Real-Time Detection-Reverse Transkription-PCR \\
\hline PVDF & Polyvinylidenfluorid \\
\hline RGS-5 & Regulator of $G$ Protein Signaling-5 \\
\hline RNA & Ribonukleinsäure \\
\hline rpm & rounds per minute \\
\hline
\end{tabular}


SDS-PAGE Sodium Dodecyl Sulfate Polyacrylamide Gel Electrophoresis

sf

SSC

TBS-T

TEMED

TEPS

TGF- $\beta$

Tie-2

$\mathrm{T}_{\mathrm{m}}$

TNF- $\alpha$

TRIS

VEGF serumfrei

Side Scatter

Tris Buffered Saline-Tween-Lösung

Tetramethylethylendiamin

Totalendoprothesen

Transforming Growth Factor- $\beta$

Tunica Internal Endothelial Kinase-2

Annealingtemperatur

Tumor Necrosis Factor-a

Trisaminomethan

Vascular Endothelial Growth Factor 


\section{Einleitung}

\subsection{Die Osteoarthrose: Ihre Bedeutung}

Bekannterweise zählt die Osteoarthrose zu den häufigsten chronischen Erkrankungen im höheren Patientenalter. Je nach Gelenkbeteiligung führt die Osteoarthrose über Jahre hinweg bis zur Arbeitsunfähigkeit. Dadurch und auf Grund jahrzehntelanger Therapiekosten entsteht ein erheblicher Schaden für die einzelnen Volkswirtschaften (Allen und Golightly 2015; Chen und Tuan 2008; Koskinen et al. 2008).

In frühen Stadien lindern Methoden wie Pridie drilling oder Microfracturing lediglich die Symptome (Pridie 1955; Simon und Jackson 2006), jedoch können diese und andere Therapieoptionen die Progression der Erkrankung nicht aufhalten. In den späteren Stadien werden in der Regel chirurgische Maßnahmen ergriffen, um ein gewisses Maß an Lebensqualität zu erhalten. Das Einsetzen von Totalendoprothesen (TEPs) wird dabei möglichst weit ins höhere Alter hinausgezögert (Debrunner 2005). Derzeitigen Daten aus Skandinavien zufolge sind Revisionsoperationen für zementierte TEPs in 90\% der Fälle nach circa 10-15 Jahren erforderlich (Koskinen et al. 2008) und da bei jeder Revisionsoperation ein nicht unerheblicher Teil Knochen verloren geht, die Komplikationsrate steigt und Folgeoperationen vom Ergebnis her nicht an die Primäroperationen heranreichen (Debrunner 2005), ist die Anzahl an TEP-Wechseln naturgemäß limitiert. Dieser Sachverhalt vor dem Hintergrund betrachtet, dass die Inzidenz der Osteoarthrose bei stetig steigender Lebenserwartung im höheren Alter zunimmt und weitere Risikofaktoren wie Adipositas vermehrt vorhanden sind, zeigt, dass die Forschung auf diesem Gebiet nach wie vor von großer Bedeutung ist.

\subsection{Histologische Veränderungen im Gelenkknorpel}

Ausgangspunkt der vorliegenden Arbeit sind die histologischen Veränderungen und zellbiologischen Prozessen im Gelenkknorpel, auf die im folgenden eingegangen wird.

\subsubsection{Der physiologische Gelenkknorpel}

Der physiologische Gelenkknorpel zeichnet sich durch ovale bis runde, oft in Gruppen liegende Chondrozyten aus, die von einer basophilen Matrix, dem sogenanntem Knorpelhof oder Territorium, umgeben sind. Eine isogene Gruppe von Chondrozyten mit dem sie 
umgebenden Territorium wird Chondron genannt (Bucher und Wartenberg 1997). Die interterritorial liegenden Kollagenfibrillen sind im physiologischen Knorpel unter dem Lichtmikroskop nicht sichtbar. Der Gelenkknorpel ist gefäßlos, die Ernährung erfolgt über die Synovialflüssigkeit per Diffusion im Rahmen der während einer Gelenkbewegung auftretenden Druck- und Scherbelastungen (Kuettner 1992).

Reife Chondrozyten teilen sich nicht mehr. Sie bestimmen im wesentlichen anabole und katabole Prozesse in der sie umgebenden Extrazellulärmatrix (EZM) und somit im ganzen Gelenkknorpel (Hidaka und Goldring 2008).

Die wesentlichen Funktionen des hyalinen Knorpels, Festigkeit und Druckelastizität, resultieren aus folgenden EZM-Bestandteilen: Kollagenfibrillen des Kollagen-Typs II, zu kleinen Anteilen auch Kollagen Typ IX und XI, und den polyanionischen Proteoglykanen, vor allem des Typs Aggrecan (Gebhard et al. 2004; Sandell 2007; Umlauf et al. 2010). Die Aggrecanmoleküle bilden mittels Hyaluron sehr große Proteoglykan-Aggregate. Kollagenfibrillen und Proteoglykane sind miteinander vernetzt, so dass die zugfesten Kollagenfibrillen eine gegenseitige Abstoßung der Proteoglykane und ein „Aufquellen“ der Proteoglykane auf Grund von Wasseranlagerung auf ein Minimum begrenzen (Aigner und McKenna 2002; Kuettner 1992). Die Festigkeit des Knorpels beruht auf dieser relativ hohen Spannung zwischen den Kollagenfibrillen und den auseinander strebenden Proteoglykanen, während die Druckelastizität darauf beruht, dass das Konstrukt aus Kollagenfibrillen und Proteoglykanen eine gewisse Komprimierung toleriert und nach dem Enden der Druckbelastung sich wieder ausdehnt (Bucher und Wartenberg 1997; Kuettner 1992).

Die Kollagenfibrillen sind arkadenartig im Gelenkknorpel angeordnet, daher ziehen sie tangential von der Knorpel-Knochengrenze zur Gelenkoberfläche und wieder im Bogen zur Knorpel-Knochengrenze zurück. Aus dem Verlauf der Kollagenfibrillen ergibt sich eine Zoneneinteilung des Gelenkknorpels (siehe Abbildung 1.1).

Zwischen der Radiärzone (Zone III) und der Zone des mineralisierten Knorpels (Zone IV), in der die Kollagenfibrillen verankert sind, liegt eine deutlich anfärbbare Grenzlinie (englisch tidemark) (Bucher und Wartenberg 1997).

Die im Hinblick auf die Pathophysiologie der Osteoarthrose wesentlichen Sachverhalte und die für diese Arbeit relevanten über die oben genannten Details hinausgehenden Aspekte des physiologischen Knorpels werden im Verlauf behandelt. 


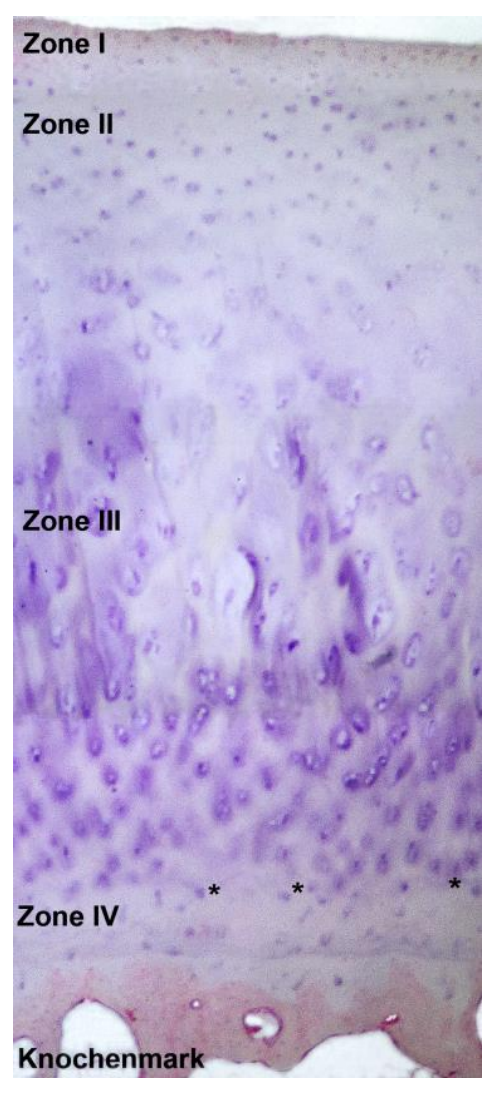

Abbildung 1.1: Zoneneinteilung des gesunden hyalinen Knorpels.

$*=$ Grenzlinie

\subsubsection{Der osteoarthrotische Knorpel}

Generell lässt sich sagen, dass im gesunden Gelenkknorpel ein Gleichgewicht zwischen anabolen und katabolen Prozessen vorliegt. Es gibt Hinweise darauf, dass im osteoarthrotischen Knorpel die katabolen Prozesse überwiegen, die sukzessive die Destruktion des hyalinen Gelenkknorpels bedingen können (Aigner et al. 2004; Hedbom und Hauselmann 2002). Diese Imbalance können verschiedene Faktoren begünstigen. Hier können genannt werden: ein höheres Alter, übermäßige Belastung durch Übergewicht oder unphysiologische Belastung nach Verletzungen, die das Gelenk als solches dauerhaft geschädigt haben (Sun 2010). Im höheren Lebensalter sezernieren alternde Chondrozyten zunehmend eher degradierte EZM-Moleküle oder reagieren im geringeren Maß auf anabolische Wachstumsfaktoren wie den Insulin-Like Growth Factor-1 (IGF-1) (Hidaka und Goldring 2008). Auf die veränderte EZM-Struktur reagieren die Knorpelzellen mit einer erhöhten Proliferation und EZM-Protein-Synthese, jedoch werden auch Proteinasen, wie Matrix-Metalloproteinasen (MMPs) und proinflammatorische Zytokine, wie Interleukin- (IL-) 1及, -6, -8 oder Tumor Necrosis Factor-a (TNF-a), sezerniert (Hidaka und Goldring 2008; Pelletier et al. 2001; Sun 2010). Die Sezernierung von proinflammatorischen Zytokinen setzt eine Art Teufelskreis in Gang (Aigner und McKenna 2002), da diese die Chondrozyten zur Sezernierung weiterer 
proinflammatorischer Zytokine und Proteinasen, die die Degeneration des Knorpels unterhalten, stimulieren (Goldring und Goldring 2004; Umlauf et al. 2010).

In zunehmender Weise wird die Osteoarthrose nicht nur als eine rein degenerative Erkrankung des höheren Alters betrachtet, sondern die Hinweise, dass in den frühen Stadien der Osteoarthrose Entzündungsreaktionen eine wesentliche Komponente der Pathogenese darstellen, verdichten sich (Fernandes et al. 2002; Hedbom und Hauselmann 2002; Hidaka und Goldring 2008; Pelletier et al. 2001).

Die zunehmende Destruktion des Gelenkknorpels führt letztendlich zu den auch in späteren Stadien sichtbaren Oberflächenfissuren, Tidemarkduplikaturen und -brüchen, Kapillareinsprossungen und zunehmendem Knorpelschwund mit radiologisch sichtbarer Gelenkspaltverschmälerung (Koelling et al. 2009; Stoppiello et al. 2014; Sun 2010).

\subsection{Zellbasierte Reparaturmechanismen}

Therapieoptionen wie Pridie drilling oder Microfracturing in frühen Stadien der Osteoarthrose eröffnen die Knochenmarkhöhle und fördern die Bildung von fibrokartilaginärem Reparaturgewebe (Pridie 1955; Simon und Jackson 2006). Dieses Reparaturgewebe ist jedoch nicht äquivalent zu hyalinem Gelenkknorpel und ist weniger fest und druckelastisch. Eine Ursache könnte sein, dass das Reparaturgewebe vornehmlich aus Kollagen Typ I statt des physiologisch vorkommenden Kollagen Typ II besteht, das wesentlich für die Funktionalität des Gelenkknorpels bestimmend ist (Miosge et al. 2004). Es treten auch endogene Reparaturmechanismen auf, die jedoch nicht die Pathogenese aufhalten können und ähnliches Ersatzgewebe wie das durch Pridie drilling oder Microfracturing induzierte Reparaturgewebe mit überwiegend Kollagen Typ I entstehen lassen (Miosge et al. 2004; Sandell und Aigner 2001).

Nach enzymatischem Verdauen von osteoarthrotischem Knorpel konnten mit Hilfe von charakterisierenden Oberflächenmarkern Zellen vergleichbar mit mesenchymalen Progenitorzellen identifiziert werden (Alsalameh et al. 2004; Fickert et al. 2004). Zusätzlich wurden an der Oberfläche des physiologischen Knorpels Chondrozyten mit Progenitorzellcharakter gefunden (Dowthwaite et al. 2004). Die Vermutung liegt nahe, dass bei den endogenen Reparaturmechanismen mesenchymale Progenitorzellen involviert sind. In der Arbeitsgruppe von Prof. Miosge wurde eine Zellpopulation isoliert und mit mesenchymalem Progenitorzellcharakter identifiziert, die im Folgenden als Chondrogenic Progenitor Cells (CPCs) bezeichnet wird (Koelling et al. 2009). 


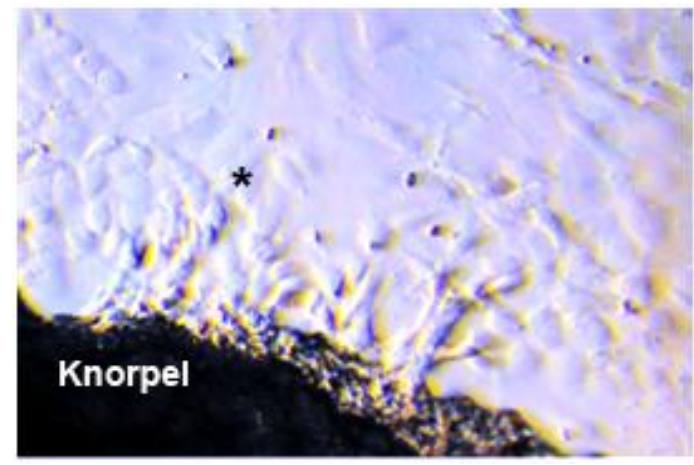

Abbildung 1.2: CPCs $\left(^{*}\right)$ migrieren aus einer Probe osteoarthrotischen Knorpels.

Diese Population zeigt ein hohes migratorisches Potential, ist abgrenzbar von Chondrozyten und Osteoblasten und lässt sich adipogen, osteogen und chondrogen differenzieren (Koelling et al. 2009). Ferner konnten elektronenmikroskopisch durch die Tidemark migrierende Zellen gezeigt werden (Koelling et al. 2009).

\subsection{Mesenchymale Stammzellen und Perizyten}

\subsubsection{Mesenchymale Stammzellen}

Erste Hinweise auf die heutigen Mesenchymal Stem Cells (MSCs) gehen bereits in die 70er Jahre im letzten Jahrhundert des vergangenen Jahrtausends auf Friedenstein et al. zurück. In zahlreichen Versuchen konnten MSCs aus vielen Geweben, insbesondere aus dem Fettgewebe und dem Knochenmark, isoliert werden und trotz der heterogenen Populationen zeigten sich Gemeinsamkeiten in Bezug auf Oberflächenmarker und In-vitroDifferenzierbarkeit, beispielsweise zu Adipozyten, Chondrozyten und Osteozyten (da Silva Meirelles et al. 2006; Jones et al. 2002; Jones und McGonagle 2008; Mackay et al. 1998).

Stro-1, einer der bekanntesten Oberflächenmarker von MSCs (Kolf et al. 2007), wurde 1991 von Simmons und Torok-Storb beschrieben und seitdem mit MSCs in Verbindung gebracht (Dennis et al. 2002; Lin et al. 2011; Simmons und Torok-Storb 1991). Der Name „Stro-1“ stellt hierbei keine Abkürzung dar (Chopra et al. 2013). Bisher wurde Stro-1 noch nicht genauer identifiziert, eine Publikation gibt Hinweise darauf, dass es sich um ein $75 \mathrm{kDa}$ schweres endotheliales Antigen handele (Ning et al. 2011). CPCs zeigen eine niedrige Stro-1-Expression (Koelling et al. 2009). Im Rahmen dieser Arbeit wurde der Stro-1Antikörper in manchen Versuchen parallel zu den weiter unten aufgeführten Perizytenmarkern getestet. 
Caplan veröffentlichte in den letzten Jahren mehrere Artikel mit der These, dass alle MSCs Perizyten, jedoch nicht alle Perizyten im Umkehrschluss MSCs seien. Indizien für diese These bezieht er unter anderem aus den Sachverhalten, dass man MSCs aus beinahe jedem Gewebe isolieren kann, diese Gewebe vaskularisiert sind und Fluorescent Activated Cell Sorting- (FACS-) Analysen eine Co-Lokalisierung von Perizyten- und MSC-Markern aufwiesen (Caplan 2008; Caplan 2010; Crisan et al. 2009). Ferner ließen sich in Versuchen verschiedene Perizyten-Populationen aus unterschiedlichen Geweben chondrogen, osteogen und adipogen differenzieren (Brachvogel et al. 2005; Crisan et al. 2008).

Wie unter 1.2.2 erwähnt, treten in den späteren Stadien der Kniegelenksosteoarthrose Gefäßeinsprossungen auf, die unweigerlich von perivaskulären Zellen begleitet sind.

\subsubsection{Perizyten}

\subsubsection{Morphologie und Vorkommen}

Perizyten oder nach ihrem Entdecker früher Ronget-Zellen genannt wurden ursprünglich als Zellen beschrieben, die im perivaskulären Raum Kleinstgefäße und Kapillaren umgeben und in Zellkontakt mit den Endothelzellen stehen (Diaz-Flores et al. 2009; Bergers und Song 2005).

Während der Angiogenese sind die Interaktionen zwischen Endothelzellen und Perizyten von großer Wichtigkeit. Nach einer Aktivierung von Endothelzellen und Perizyten erfolgt ein Remodelling der Basalmembran, so dass im Anschluss die Migration der Endothelzellen und der Perizyten erfolgen kann. Daraufhin bildet sich ein neues Gefäßlumen aus, Perizyten wandern in den neuen perivaskulären Raum ein, und es bildet sich eine neue Basalmembran aus (Diaz-Flores et al. 2009).

Neben ihrer Rolle in der Angiogenese werden Perizyten weitere Funktionen zugeschrieben, darunter Gefäßstabilisierung, Regulation des vaskulären Tonus und der Gewebshomöostase, Matrix-Protein-Synthese und ein mesenchymales Differenzierungspotential, das die Funktion von Perizyten als sogenannte Vorläuferzellen für regeneratorische Prozesse in Frage kommen lässt (Diaz-Flores et al. 2009).

Eine eindeutige Identifizierung der Perizyten im perivaskulären Raum wird durch die Heterogenität der Perizytenpopulationen erschwert. Das gilt insbesondere dann, wenn verschiedene Perizyten-Typen im selben perivaskulären Raum auftreten (Diaz-Flores et al. 2009; Kurz et al. 2008). In der Forschung mit Perizyten hat sich etabliert, mehrere Marker parallel zu verwenden, mit der Einschränkung, dass es keinen spezifischen Marker gibt, der auch 
alle Perizyten-Populationen erkennen lässt (Armulik et al. 2005; Edelman et al. 2006). Bei der Wahl der Perizytenmarker müssen unter anderem die Spezies, das zu untersuchende Gewebe, eine womöglich bestehende Pathologie und der Zustand des Gefäßes in Ruhe beziehungsweise im Stadium der Angiogenese berücksichtigt werden (Diaz-Flores et al. 2009; Dvorak und Feng 2001; Gerhardt et al. 2000).

\subsubsection{Ausgewählte Perizytenmarker}

Im Rahmen dieser Arbeit wurden die folgenden Perizytenmarker für die nachfolgenden Untersuchungen ausgewählt:

- Platelet-Derived Growth Factor Receptor- $\beta$ (PDGFR- $\beta$ )

- Regulator of G Protein Signaling-5 (RGS-5)

- Tunica Internal Endothelial Kinase-2 (Tie-2)

- alpha-Smooth Muscle Actin (aSMA)

PDGFR- $\beta$ ist einer der verbreitetsten Marker bei Perizyten-Untersuchungen (Allt und Lawrenson 2001; Hellström et al. 1999; Howson et al. 2005). Er ist für die nachfolgenden Migrationsversuchen von Relevanz, da Perizyten vermittelt durch den Rezeptor PDGFR- $\beta$ (Westermark et al. 1990) als Antwort auf von Endothelzellen sezerniertes PDGF-B entlang der expandierenden Endothel-Sprossungen migrieren und proliferieren (Armulik et al. 2005).

Das Molekül RGS-5 ist von besonderem Interesse, da sein Gen eines der frühesten ist, das in Perizyten während der Angiogenese aktiviert wird (Bondjers et al. 2003) und als ein möglicher positiver Regulator der Chondrogenese beschrieben wurde (Appleton et al. 2006). Signalwege, die über G-Protein-gekoppelte Rezeptoren (englisch G Protein-Coupled Receptors, GPCRs) verlaufen, sind an zellulären Antworten auf extrazelluläre Reize beteiligt und benötigen eine genaue Regulation (De Vries et al. 2000). RGS-Proteine wirken intrazellulär und sind ein wichtiger Negativ-Regulator von GPCRs (De Vries et al. 2000).

Tie-2 ist kein klassischer Perizytenmarker im eigentlichen Sinne, vielmehr wurde Tie-2 bei Endothelzellen und Perizyten-Vorläuferzellen beschrieben (Howson et al. 2005). Die Expression von Tie-2, dem Rezeptor von Angiopoetin-1 und -2 (Ang-1 und -2), wurde auch bei Perizyten beschrieben (Diaz-Flores et al. 2009).

Während die bisher genannten Perizytenmarker Rezeptoren oder rezeptorassoziierte Antigene darstellen, werden in der Forschung auch kontraktile Proteine als Marker herangezogen. aSMA ist neben Desmin einer der gängigsten Marker bei Perizyten (Diaz-Flores et al. 
2009) und ist in den Mikrofilamenten der Perizyten zu finden (Diaz-Flores et al. 2009; Skalli et al. 1989).

\subsection{Migration}

\subsubsection{Prinzipien der Zellmigration}

Die Zellmigration ist eine der wichtigsten und grundlegendsten Zellfunktionen im menschlichen Körper und wird auch im Rahmen der Osteoarthrose beobachtet (Koelling et al. 2009). Der Vorgang der Zellmigration ist ein kleinschrittiger und fein auf einander abgestimmter Prozess (Lauffenburger und Horwitz 1996; Ridley et al. 2003). Als Antwort auf die Rezeption eines Attractant findet eine Polarisation innerhalb der Zelle statt und es bilden sich Filo- und/oder Lamellipodien in Migrationsrichtung aus (Khalil und Friedl 2010). Diese binden an die EZM oder benachbarte Zellen über Transmembran-Rezeptoren, die mit dem Aktin des Zytoskeletts verbunden sind (Horwitz und Webb 2003; Ridley et al. 2003). Über diese Bindungen erfolgt die Traktion des Zellkörpers, bei gleichzeitigen Ablösungen von Adhäsionen am anderen Pol der Zelle (Horwitz und Webb 2003; Ridley et al. 2003).

Gerichtete Zellmigration als Antwort auf einen spezifischen chemischen Reiz hin wird Chemotaxis genannt (Mishima und Lotz 2008).

\subsubsection{Ausgewählte Chemokine}

\section{Platelet-Derived Growth Factor-BB}

In Versuchen wurden Indizien für die Wichtigkeit eines intakten Platelet-Derived Growth Factor-B (PDGF-B)-/PDGFR- $\beta$-Signalweges für die Perizyten-Migration und PericytenProliferation entlang von Gefäßeinsprossungen gefunden (Hellström et al. 1999). Die Untersuchungen von Hellström zeigten, dass PDGF-B -/- und PDGFR- $\beta$-/- defiziente Mäuse Gefäßmalformationen und einen Verlust an Perizyten aufwiesen (Hellström et al. 1999).

PDGF treten als Dimere, über Disulfid-Brücken verbunden, in homologer (PDGF-AA, PDGF-BB, PDGF-CC, PDGF-DD) oder heterologer (PDGF-AB) Form auf (Mishima und Lotz 2008; Rönnstrand et al. 2001). Der Rezeptor PDGFR-a bindet die Ketten A, B und C und PDGFR- $\beta$ die Ketten B und D mit hoher Affinität (Mishima und Lotz 2008). PDGF-AA, PDGF-AB und vor allem PDGF-BB zeigten einen signifikanten chemotaktischen Effekt auf MSCs (Mishima und Lotz 2008). 
Vascular endothelial growth factor

Die Genfamilie des Glykoproteins Vascular Endothelial Growth Factor (VEGF) umfasst neben den Subtypen A, B, C und D ebenfalls das Protein Placental Growth Factor (Herbert und

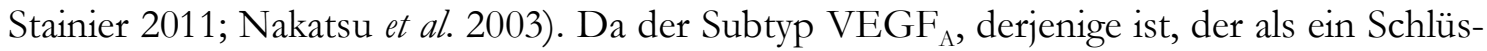
selfaktor der Blutgefäßbildung gilt, während zum Beispiel $V_{E G F}$ und $V_{E G F}$ die lymphatische Angiogenese regulieren (Dai und Rabie 2007; Ferrara et al. 2003), wurde für diese Arbeit das Augenmerk auf den Subtyp $\mathrm{VEGF}_{\mathrm{A}}$ gelegt, so dass im folgenden die Bezeichnung VEGF als $V_{E G F}$ zu verstehen ist. Derzeit sind folgende Splicevarianten von VEGF bekannt: $\mathrm{VEGF}_{121}, \mathrm{VEGF}_{145}, \mathrm{VEGF}_{165}, \mathrm{VEGF}_{189}$ und $\mathrm{VEGF}_{206}$ (Carlevaro et al. 2000; Ferrara et al. 2003; Pufe et al. 2001). Die vorherrschende Variante im menschlichen Körper ist VEGF $_{165}$ (Ferrara et al. 2003; Lamalice et al. 2007). Vermittelt über die VEGF-Rezeptoren-1 und -2 führt VEGF zu einer erhöhten Gefäßpermeabilität und initiiert über Proliferation und Migration bei Endothelzellen und Perizyten eine Neoangiogenese (Diaz-Flores et al. 2009; Witmer et al. 2004).

Während Hypoxie einer der Hauptsekretionsstimuli ist, können bei einem bestehenden Entzündungsprozess die Mediatoren IL-1, IL-6, IL-8 und TNF- $\alpha$, wie sie auch in der Osteoarthrose auftreten, die Genexpression von VEGF im Gewebe hochregulieren (Angelo und Kurzrock 2007). Dies ist konkordant zum Nachweis von VEGF im osteoarthrotischem Knorpel, während im physiologischen Gelenkknorpel keine VEGF-Sekretion beobachtet werden konnte (Pufe et al. 2001). In weiteren Studien wurden ein mobilisierender Effekt von VEGF auf aus dem Knochenmark stammende Endothelvorläuferzellen (Kalka et al. 2000) und Monozyten (Barleon et al. 1996) beobachtet.

\section{Angiopoietin-1 und -2}

Die beiden untersuchten Liganden von Tie-2, Ang-1 (Davis et al. 1996) und Ang-2 (Maisonpierre et al. 1997), zeigen in Bezug auf die Gefäßphysiologie unterschiedliche Wirkungen. Ang-1 wirkt auf das Gefäß stabilisierend und setzt die Gefäßpermeabilität herab (Diaz-Flores et al. 2009; Singh et al. 2011).

Ang-2 kann eine Dissoziation von Perizyten und Endothelzellen herbeiführen, was in der frühen Phase der Angiogenese von Bedeutung ist, und kann in Gegenwart von VEGF Gefäßsprossungen unterstützen (Diaz-Flores et al. 2009). Partiell kann auch Ang-2 auf Grund seiner höheren Bindungsneigung zu Tie-2 als Antagonist von Ang-1 wirken (Maisonpierre et al. 1997; Singh et al. 2011). 


\section{Entzündungsmediatoren: TNF- $\alpha$, IL- $6,-8$ und -17}

Im Abschnitt 1.2.2 wurden bereits Entzündungsreaktionen innerhalb des osteoarthrotischen Knorpels als wesentlicher Aspekt der Pathophysiologie genannt. Von den eingangs genannten Entzündungsmediatoren wurden im Rahmen dieser Arbeit die Zytokine TNF- $\alpha$, IL-6, IL-8 und IL-17 ausgewählt, um ihre Wirkung als Chemokine auf CPCs zu untersuchen. TNF- $\alpha$ und IL-8 wurden als positive Regulatoren der Angiogenese beschrieben (Ferrara et al. 2003). In Versuchen zeigte sich parallel dazu, dass IL-17 als Chemokin Migration induzieren kann (Moran et al. 2011).

\section{$\underline{\text { Bone morphogenetic proteins }}$}

Die Familie der Transforming Growth Factor- $\beta$ (TGF- $\beta$ )-Zytokine lässt sich in zwei Subfamilien unterteilen: die TGF- $\beta$ /activin- und die Bone Morphogenetic Proteins (BMPs)-Subfamilie. Beide Subfamilien sind gemäß ihrer genetischen Sequenz und ihren aktivierenden Signalwegen charakterisiert worden (Krauss 2008). In Tierversuchen wurde in den letzten Jahrzehnten die Rolle der BMPs als Wachstumsfaktoren im Rahmen der embryonalen Entwicklung und in zellulären Prozessen der heranwachsenden und adulten Tiere untersucht. Eine nicht zu unterschätzende Rolle spielen BMPs, daher auch die Namensgebung, bei der Osteo- und Chondrogenese (Chen et al. 2004).

In Versuchen zeigte sich, dass BMP-2 die chondrogene Differenzierung von MSCs induzieren kann (Palmer et al. 2005). BMP-2, -4, -7 und -14 fördern bei ChondrozytenVorläuferzellen die Proliferation und Differenzierung (Goldring et al. 2006). Interessanterweise zeigten mit BMP-4 transduzierte Stammzellen in einem Osteoarthrose-Modell ein erhöhtes chondrogenes Potential (Matsumoto et al. 2009).

Bobacz et al. beschrieben 2003 die endogene Expression von BMP-6 sowohl im gesunden als auch im osteoarthrotischem Knochen. Parallel dazu wurde auch eine erhöhte Expression von BMP-2 im osteoarthrotischem Knorpel beschrieben (Fukui et al. 2003). Auf MSCs können BMP-2, -4 und -7 als Chemokine wirken (Mishima und Lotz 2008).

\subsection{Aufgaben- und Fragestellung dieser Arbeit}

Im Rahmen der vorliegenden Arbeit sollte untersucht werden, ob die in der Osteoarthrose auftretenden chondrogenen Progenitorzellen (CPCs) sich von Perizyten bzw. mesenchymalen Stammzellen ableiten lassen und inwiefern ausgewählte Chemokine, die in Bezug auf das pathophysiologische Geschehen im osteoarthrotischen Knorpel relevant sind, chemotaktische Auswirkungen auf das Migrationsverhalten der CPCs zeigen würde. 
Da es sich bei den CPCs um Progenitorzellen handelt, die aus osteoarthrotischen Knorpelproben auf Grund ihres hohen migratorischen Potentials isoliert werden können und die ein hohes mesenchymales Differenzierungspotential aufweisen (siehe Kapitel 1.3), wurde die Frage nach dem Ursprung der CPCs aufgeworfen. Hierzu wurden bereits Hinweise veröffentlicht, dass die CPCs aus dem Knochenmarksraum durch Brüche in der Tidemark in den osteoarthrotischen Knorpel migriert sein könnten (Koelling et al. 2009). Um diesen Sachverhalt weiter aufzuklären und Hinweise zu erlangen, von welchen Zellpopulationen CPCs abstammen könnten, wurden histologische Untersuchungen an mikroskopisch gesunden und osteoarthrotischen Knorpelproben mit den Perizyten- bzw. mesenchymalen Stammzellmarkern PDGFR- $\beta$, RGS-5 und Tie-2 durchgeführt. In weitergehenden immunzytologischen und molekularbiologischen Untersuchungen wurde das Vorkommen dieser und weiterer Stammzellmarker auch bei den CPCs direkt untersucht.

Darüber hinaus sollte mittels eines Migrationsassays geprüft werden, ob Entzündungsfaktoren und Wachstumsfaktoren, wie sie im osteoarthrotischen Knorpel nachgewiesen wurden (siehe Kapitel 1.2.2 und 1.5.2), chemotaktische Auswirkungen auf CPCs besitzen und damit eine Erklärung für die Migration von CPCs in den osteoarthrotischen Knorpel liefern könnten. Zusätzlich wurden weitere Wachstumsfaktoren auf ihre chemotaktische Wirkung hin geprüft, die einen positiven Einfluss auf CPCs im Rahmen zellbiologischer Therapieansätze nehmen könnten.

Über die Erkenntnisse in dieser Arbeit sollte ein besseres Verständnis über die Herkunft der CPCs und ihre Rolle bei endogenen Reparaturmechanismen im Rahmen der Osteoarthrose gewonnen werden. Zusätzlich sollten die Ergebnisse Hinweise für eine Weiterentwicklung von Strategien im Rahmen von zellbiologischen Therapien liefern. 


\section{Material und Methoden}

\subsection{Material}

\subsubsection{Chemikalien und Verbrauchsmaterialien}

Tabelle 2.1: Chemikalien und Verbrauchsmaterialien.

\begin{tabular}{|c|c|}
\hline Produkt & Hersteller \\
\hline Acrylamid & Roth (3029.2) \\
\hline Ammoniumperoxodisulfat & Roth (9592.2) \\
\hline Biopur ${ }^{\circledR}$ Safe-Lock-Tube & Eppendorf (0030121589) \\
\hline Bromphenolblau & Roth (T116.1) \\
\hline Calcein AM & BD Pharmingen $^{\mathrm{TM}}(564061)$ \\
\hline Coomassie briliant blue R250 Powder & Serva (1752b) \\
\hline DAKO REAL ${ }^{\mathrm{TM}}$ Detection Sytem & Dako (K5005) \\
\hline Dinatriumhydrogenphosphat & Roth \\
\hline Dulbecco's Modified Eagle Medium mit GlutaMax ${ }^{\mathrm{TM}}$ & Gibco (21885) \\
\hline ECL Prime Western Blotting Detection System & Amersham (RPN2232) \\
\hline Eosin & AppliChem (A0822,0025) \\
\hline Essigsäure 100\% (Eisessig) & AppliChem (A0662) \\
\hline Ethanol absolut p.a. & AppliChem (2005786) \\
\hline Ethyldiamintetraacetat (EDTA) & Sigma-Aldrich (E5134) \\
\hline Eukitt & Sigma-Aldrich (03989) \\
\hline Fix\&Perm & Dianova \\
\hline Formalin & Merck (3997) \\
\hline Glycerin & Roth (3783.1) \\
\hline Glycin & Applichem (A3707) \\
\hline Hämalaun & Merck (1.09249) \\
\hline Isopropylalkohol & Roth (9866.5) \\
\hline Kalialaun & Roth (P724.2) \\
\hline Kaliumchlorid & Merck (104936) \\
\hline Kaliumdihydrogenphosphat & Roth (P018.2) \\
\hline Mercaptoethanol & Sigma-Aldrich (63689) \\
\hline
\end{tabular}


Fortsetzung Tabelle 2.1

\begin{tabular}{|c|c|}
\hline Produkt & Hersteller \\
\hline Methanol & Roth (4627.2) \\
\hline Milchpulver & Roth (T145.2) \\
\hline Natriumchlorid & Roth (9265.2) \\
\hline Natriumdodecylsulfat & Fuka (71999) \\
\hline Natriumhydroxid & Roth (6771.1) \\
\hline Natriumjodat & Roth (HN17.1) \\
\hline Paraplast Plus $52^{\circ} \mathrm{C}$ & Sigma-Aldrich (327204) \\
\hline Paraplast Plus $56^{\circ} \mathrm{C}$ & Sigma-Aldrich (P3683) \\
\hline Penicillin/Streptomycin & PAN Biotech (P06-07100) \\
\hline Phosphate-Buffered Saline (PBS) & Sigma-Aldrich (4417-100TAB) \\
\hline Proteinleiter für Western Blot & Fermentas (SM0671) \\
\hline Qiashredder & Qiagen (79656) \\
\hline Quanti-Tect-Reverse-Transcription-Kit & Qiagen (205310) \\
\hline RLT-Lysis-Puffer & Qiagen (79216) \\
\hline RNeasy-Mini-Kit & Qiagen (74106) \\
\hline RNeasy-Mini-Säule & Qiagen (74106) \\
\hline RPE-Puffer & Qiagen (1018013) \\
\hline RW1-Puffer & Qiagen (1015763) \\
\hline Safe-Lock Tube & Eppendorf (Hamburg,Deutschland) \\
\hline Salzsäure & Roth (6792.1) \\
\hline Streptomycin & PAN Biotech \\
\hline SYBR-Green-Mix & Qiagen (204141) \\
\hline Tetramethylethylendiamin (TEMED) & Roth (2367.3) \\
\hline ThinCert $^{\mathrm{TM}}, 8 \mu \mathrm{m}$ (Migrationseinsätze) & Greiner Bio-one (662 638) \\
\hline tri-Natriumcitrat Dihydrat & Roth (4088.3) \\
\hline Trisaminomethan (TRIS) & Roth (5429.3) \\
\hline Tris-Buffered Saline (TBS) & Roth (Karlsruhe, Deutschland) \\
\hline Trypsin & PAN (P10-024100) \\
\hline Tween-20 & Roth (9127.2) \\
\hline Xylol & Roth (CN 80.2) \\
\hline Zellkulturflaschen & Sarstedt (83.1813.002) \\
\hline Zitronensäuremonohydrat & Merck (100244) \\
\hline
\end{tabular}




\subsubsection{Antikörper}

Tabelle 2.2: Verwendete Antikörper.

\begin{tabular}{ll}
\hline Produkt & Hersteller \\
\hline Anti-Kaninchen-IgG-Peroxidase gekoppelt & Sigma (A0545) \\
Anti-Maus-IgG-Peroxidase gekoppelt & Sigma (A9917) \\
Anti-Cluster of Differention (CD) 117 & BD Pharmingen (555713) \\
Anti-Platelet-Derived Growth Factor Receptor- $\beta$ (PDGFR- $\beta$ ) & BD Pharmingen (610114) \\
Anti-Regulator of G-Protein Signaling-5 (RGS-5) & Sigma (HPA001821) \\
Anti-human Stro-1 & R\&D Systems (MAB1038) \\
Anti-Tunica Internal Endothelial Kinase-2 (Tie-2)/H-176 & Santa Cruz (sc-9026) \\
\hline
\end{tabular}

\subsubsection{Proteine}

Tabelle 2.3: Verwendete Proteine.

\begin{tabular}{ll}
\hline Produkt & Hersteller \\
\hline Angiopoietin-1 & R\&D Systems (923-AN/CF) \\
Angiopoietin-2 & R\&D Systems (623-AN/CF) \\
Bone Morphogenetic Proteins 2, 4, 6, 9, 12, 13 & Freundliche Bereitstellung von Fr. Prof. \\
& V. Rosen, University of Harvard, USA \\
Bovine Serum Albumin (BSA) & Sigma (A9647-100G) \\
Calcein-AM & PromoKine (PK-CA707-80011) \\
Fetal Calf Serum (FCS) & Invitrogen \\
Interleukin-6 & Sigma (H7416-10UG) \\
Interleukin-8 & Sigma (I1645-10UG) \\
Interleukin-17 & R\&D Systems (5194-IL) \\
Tumor Necrosis Factor-alpha & Sigma (H8916-10UG) \\
Platelet-Derived Growth Factor -BB & Promokine (C-63022) \\
Vascular Endothelial Growth Factor ${ }_{165}$ & PromoKine (C-64423) \\
\hline
\end{tabular}

\subsubsection{Geräte}

Tabelle 2.4: Geräte.

\begin{tabular}{ll}
\hline Produkt & Hersteller \\
\hline Biophotometer & Eppendorf (Hamburg, Deutschland) \\
Cellometer ${ }^{\mathrm{TM}}$ Cell Viability Counter & Nexcelom (Lawrence, USA) \\
Einbettungsautomat & Duplex Processer, Shandon Elliot (GB)
\end{tabular}




\begin{tabular}{ll} 
Fortsetzung Tabelle 2.4 & \\
\hline Produkt & Hersteller \\
\hline Durchflusszytometer & Becton Dickinson (Mountain View, USA) \\
HerasafeTM KS12 & Thermo Fisher (Wilmington, USA) \\
Jung Biocut 2035-Mikrotom & Leica (Nussloch, Deutschland) \\
Labotect C200 Inkubator & Labotect (Göttingen, Deutschland) \\
Lichtmikroskop „PrimoStar“ & Zeiss (Göttingen, Deutschland) \\
Mastercycler ${ }^{\circledR}$ ep gradient S realplex ${ }^{2}$ & Eppendorf (Hamburg, Deutschland) \\
Nikon D90 & Nikon (Düsseldorf, Deutschland) \\
Zentrifugen & Eppendorf (Hamburg, Deutschland) \\
\hline
\end{tabular}

\subsubsection{Gewebeproben}

Es wurden Gewebeproben untersucht, die aus Kniegelenksknorpeln mit einem späten Stadium einer Osteoarthrose entstammen und im Rahmen von KniegelenksersatzOperationen Patienten entnommen wurden. Bei allen Patienten wurde vor der Operation nach den Klassifikationskriterien des American College of Rheumatology (Altman et al. 1986) eine Gonarthrose diagnostiziert. Die Patienten gaben vor der Operation nach entsprechender Aufklärung ihr schriftliches Einverständnis, dass ihre Gewebeproben für die Studie verwendet werden durften. Die Studie wurde von der Ethikkommission der Medizinischen Fakultät der Georg-August-Universität Göttingen genehmigt. Das Alter der Patienten war im Durchschnitt 67,1 Jahre, dabei betrug die Spannbreite 44 bis 85 Jahre. Die Proben wurden der seitlichen Knie-Gelenks-Kondyle in unmittelbarer Nachbarschaft zum Hauptdefekt entnommen. Die Defekte entsprachen den Graden 4,0 bis 4,5 nach Pritzker (Pritzker et al. 2006). Zusätzlich wurden Proben gewonnen, die möglichst weit vom Defekt entfernt lagen und einem makroskopisch betrachtet möglichst intakten Knorpel entsprachen. Nach der Entnahme wurden die Gewebeproben in einer 1:1 Lösung aus Phosphate-Buffered-SalineLösung (PBS-Lösung) und Dulbecco's Modified Eagle Medium (DMEM) gekühlt aufbewahrt und unmittelbar weiterverwendet.

\section{Stammlösung 10xPBS}

$\begin{array}{ll}81,8 \mathrm{~g} & \text { Natriumchlorid } \\ 2 \mathrm{~g} & \text { Kaliumchlorid } \\ 16 \mathrm{~g} & \text { Dinatriumhydrogenphosphat } \\ 2 \mathrm{~g} & \text { Kaliumdihydrogenphosphat } \\ 11 & \text { Aqua destillata }\end{array}$


Ergänzender Hinweis zur PBS-Stammlösung: Der pH-Wert ist zu überprüfen und gegebenenfalls mit Salzsäure oder Natronlauge auf den pH 7,4 einzustellen.

Für 1xPBS: 10xPBS 1:10 mit Aqua destillata verdünnen

\title{
2.2 Immunhistochemische Untersuchung von Perizytenmarkern am Knorpelgewebe
}

\subsubsection{Paraffineinbettung}

Für die immunhistochemischen Untersuchungen wurden von den Gewebeproben geeignete Bereiche des Knorpels inklusive des darunterliegenden Knochens mittels eines Skapells in circa 1 bis 1,5 cm große Würfel geschnitten und jeweils in einem Probenröhrchen mit gepufferter Formalin-Lösung über Nacht bei $\mathrm{pH} 7,4$ und $4{ }^{\circ} \mathrm{C}$ im Kühlschrank fixiert.

\section{Gepufferte Formalin-Lösung nach Lillie, pH 7,4}

$100 \mathrm{ml}$ Formalin (37\%)

$333 \mathrm{ml}$ Sørensen-Puffer $(0,3 \mathrm{M})$

$567 \mathrm{ml}$ Aqua destillata

\section{Sorensen Puffer (0,3 M)}

$18,2 \mathrm{ml}$ Kaliumdihydrogenphosphat-Lösung (41,37 $\mathrm{g}$ in 11 Aqua destillata)

$566 \mathrm{ml}$ Dinatriumhydrogenphosphat-Lösung (42,58 g in 11 Aqua destillata)

Im Anschluss an die Fixierung erfolgte die Entkalkung des Knochenanteils der Probe in 20\%iger Ethylendiamintetraacetat-Lösung (EDTA-Lösung) bei pH 7,4 unter Lichtausschluss und Raumtemperatur für vier Wochen und täglichem Wechsel der EDTA-Lösung.

\author{
20\% EDTA-Lösung, $p H$ 7,4 \\ $895 \mathrm{ml}$ Aqua destillata \\ $105 \mathrm{ml}$ Natriumhydroxid (5 M) \\ $200 \mathrm{~g} \quad$ EDTA
}


Für die darauffolgende Einbettung wurden die Proben in 70\%ige Ethanol-Lösung für mindestens $24 \mathrm{~h}$ bei $4{ }^{\circ} \mathrm{C}$ zwischengelagert. Mittels eines Einbettungsautomaten und dem nachfolgendem Schema (siehe Tabelle 2.5) wurden die Gewebeproben dehydriert und in Paraffin eingebettet.

Tabelle 2.5: Einbettungsprotokoll.

\begin{tabular}{lll}
\hline 1 & Ethanol $70 \%$ & $3 \mathrm{~h}$ \\
\hline 2 & Ethanol $80 \%$ & $1 \mathrm{~h}$ \\
\hline 3 & Ethanol $90 \%$ & $1 \mathrm{~h}$ \\
\hline 4 & Ethanol $96 \%$ & $1 \mathrm{~h}$ \\
\hline 5 & Ethanol absolut & $2 \mathrm{~h}$ \\
\hline 6 & Isopropylalkohol & $2 \mathrm{~h}$ \\
\hline 7 & Isopropylalkohol & $1,5 \mathrm{~h}$ \\
\hline 8 & Xylol & $0,5 \mathrm{~h}$ \\
\hline 9 & Xylol & $0,5 \mathrm{~h}$ \\
\hline 10 & Xylol & $0,75 \mathrm{~h}$ \\
\hline 11 & Paraplast Plus $\left(52{ }^{\circ} \mathrm{C}\right)$ & $0,5 \mathrm{~h} \mathrm{bei} 60{ }^{\circ} \mathrm{C}$ \\
\hline 12 & Paraplast Plus $\left(56^{\circ} \mathrm{C}\right)$ & $7 \mathrm{~h} \mathrm{bei} 60{ }^{\circ} \mathrm{C}$ \\
\hline
\end{tabular}

Nach der Paraffineinbettung wurden die Proben einzeln als Blöcke in Paraffin eingegossen und katalogisiert. Für die weiterführenden immunhistologischen Untersuchungen wurden die Präparate mit einem Mikrotom in Schnitte mit einer Schnittdicke von 2-6 $\mu \mathrm{m}$ weiterverarbeitet und nach einem kurzen Wasserbad bei $45^{\circ} \mathrm{C}$ auf Objektträger übertragen, die über Nacht bei $37^{\circ} \mathrm{C}$ trockneten.

\subsubsection{Untersuchte Proben}

Die Gewebe-Teilproben der untersuchten Patienten wurden nach dem Schnitt und nach einer jeweils exemplarischen Hämalaun-Eosin-Übersichtsfärbung in mikroskopisch gesunden oder defekten Knorpel klassifiziert. Als mikroskopisch gesund galt: Keine offensichtlichen Oberflächenfissuren, vom Aussehen her physiologischer Knorpelaufbau, keine Tidemarkbrüche und vor allem keine Kapillareinsprossungen im Knorpelbereich.

\section{Hämalaun-Eosin-Färbung}

Die Färbung wurde nach folgendem Protokoll durchgeführt: 
Tabelle 2.6: Hämalaun-Eosin-Färbung.

\begin{tabular}{lll}
\hline 1 & Xylol & $5 \mathrm{~min}$ \\
\hline 2 & Xylol & $5 \mathrm{~min}$ \\
\hline 3 & Ethanol absolut & $2 \mathrm{~min}$ \\
\hline 5 & Ethanol $96 \%$ & $2 \mathrm{~min}$ \\
\hline 6 & Ethanol $80 \%$ & $2 \mathrm{~min}$ \\
\hline 7 & Ethanol $60 \%$ & $2 \mathrm{~min}$ \\
\hline 8 & Aqua destillata & $2 \mathrm{~min}$ \\
\hline 9 & Hämalaun (nach Mayer) & $4 \mathrm{~min}$ \\
\hline 10 & Fließendes Wasser & $1 \mathrm{~min}$ \\
\hline 11 & Eosin & $15 \mathrm{~min}$ \\
\hline 12 & Aqua destillata & $7 \mathrm{~min}$ \\
\hline 13 & Ethanol 60\% & $1 \mathrm{~min}$ \\
\hline 14 & Ethanol $80 \%$ & $1 \mathrm{~min}$ \\
\hline 15 & Ethanol $96 \%$ & $1 \mathrm{~min}$ \\
\hline 16 & Ethanol absolut & $1 \mathrm{~min}$ \\
\hline 17 & Ethanol absolut & $2 \mathrm{~min}$ \\
\hline 18 & Xylol & $2 \mathrm{~min}$ \\
\hline
\end{tabular}

\section{Hämalaun-Färbelösung}

$1 \mathrm{~g} \quad$ Hämalaun

11 Aqua destillata

$0,2 \mathrm{~g}$ Natriumjodat

$50 \mathrm{~g}$ Kalialaun

$50 \mathrm{~g}$ Chloralhydrat

$1 \mathrm{~g} \quad$ Zitronensäure

Eosinlösung

$1 \mathrm{~g}$ Eosin

\section{Aqua destillata}

Vor der Färbung ein bis zwei Tropfen Eisessig hinzugeben.

\subsubsection{Immunhistologische Färbung}

Immunhistologische Verfahren sind etablierte Methoden zur Darstellung sowohl oberflächlicher als auch intrazellulärer Antigene. Das allgemeine Prinzip der immunhistologischen Färbungen besteht in der Bindung eines spezifischen Antikörpers an eine Antigenstruktur und der Sichtbarmachung der Antigen-Antikörper-Reaktion zum Nachweis der 
stattgefundenen Bindung. Über die Färbung erhält man Hinweise zum Vorkommen der zu untersuchenden Antigene und deren Verteilung im Gewebe.

Der Nachweis der Reaktion erfolgt in der Immunhistochemie typischerweise über Chromogene. Chromogenanfärbungen beinhalten eine Aktivierung des Farbstoffes über eine enzymatische Umsetzung. Hierzu haben sich unter anderem auf Peroxidase bzw. auf Alkalische Phosphatase basierende Systeme etabliert.

Jedes Antigen kann aus einem oder mehreren Epitopen bestehen. Es gibt formalinsensitive Epitope, die nach einer Formalinfixierung signifikante Konformitätsänderungen aufweisen. Grundlage für eine formalinbedingte Konformitätsänderung ist das Auftreten von intraund intermolekularen Quervernetzungen, die einen völligen Verlust der Immunreaktivität hervorrufen können („Maskierung des Epitops“).

Über die letzten Jahrzehnte wurden verschiedene Protokolle entwickelt, die die „Demaskierung“ der Epitope erzielen sollten. Eine Methode findet in dieser Arbeit Verwendung, die das Erhitzen des Präparates für 45 min bei $95^{\circ} \mathrm{C}$ in Citratpuffer und bei $\mathrm{pH} 6$ vorsieht. Durch die Hitzebehandlung und die Inkubation mit Citrat-Ionen sollen die durch das Formalin bedingten Veränderungen rückgängig gemacht und die Immunreaktivität der Epitope wieder erlangt werden.

\section{Citratpuffer}

Lösung A: $\quad$ 4,2 g Zitronensäuremonohydrat werden in $200 \mathrm{ml}$ Aqua destillata gelöst Lösung B: $\quad$ 26,4 g Trinatriumcitrat werden in 11 Aqua destillata gelöst.

Für einen Liter Citratpuffer werden $18 \mathrm{ml}$ von Lösung A und $82 \mathrm{ml}$ von Lösung B mit $900 \mathrm{ml}$ Aqua destillata versetzt. Der $\mathrm{pH}$-Wert der Lösung soll bei 6,0 liegen. Bei $\mathrm{pH}<6,0$ kann mit einer geeigneten Zugabe von Lösung B der pH-Wert angehoben werden.

Die Citratpuffer-Behandlung der Schnitte erfolgte nach dem folgenden Protokoll (Tabelle 2.7). Wenn nicht anders angegeben, wurden bei diesem Protokoll und auch bei allen anderen Versuchen die jeweiligen Zwischenschritte bei Raumtemperatur durchgeführt.

Nach der Citratpuffer-Behandlung schloss sich die immunologische Färbung an. Hierzu wurde das DAKO REAL ${ }^{\text {TM }}$ Detection System verwendet, das einen mehrfach biotinylierten Sekundär-Antikörper verwendet, der sowohl an einen Primär-Antikörper von einem Kaninchen als auch von einer Maus binden kann. Die im Kit verwendete Alkalische Phosphatase wurde mit Streptavidin gekoppelt. Streptavidin bindet an die Biotin-Moleküle des 
Sekundär-Antikörpers, so dass über die Mehrfach-Biotinylierung des Sekundär-Antikörpers eine Signalverstärkung bei der anschließenden Reaktion der Alkalischen Phosphatase mit dem Chromogen Fast Red aus dem Kit stattfand.

Tabelle 2.7: Antigendemaskierung mit Citratpuffer.

\begin{tabular}{|c|c|c|c|}
\hline 1 & \multicolumn{3}{|c|}{ Citratpuffer in einem geeigneten Gefäß auf $95^{\circ} \mathrm{C}$ erwärmen. } \\
\hline 2 & Xylol & $10 \mathrm{~min}$ & Entparaffinierung der Schnitte \\
\hline 3 & Ethanol absolut & $3 \mathrm{~min}$ & \multirow{5}{*}{$\begin{array}{l}\text { Absteigende Alkoholreihe zur } \\
\text { Rehydrierung der Schnitte }\end{array}$} \\
\hline 4 & Ethanol 96\% & $3 \min$ & \\
\hline 5 & Ethanol $80 \%$ & $3 \mathrm{~min}$ & \\
\hline 6 & Ethanol 60\% & $3 \min$ & \\
\hline 7 & Ethanol 50\% & $3 \min$ & \\
\hline 8 & 1xPBS (pH 7,4) & $10 \min$ & Waschvorgang \\
\hline 9 & \multicolumn{3}{|c|}{$\begin{array}{l}\text { Die Objektträger werden mit dem } 95^{\circ} \mathrm{C} \text { heißen, jedoch nicht kochendem Citratpuf- } \\
\text { fer für } 30 \text { min bei } 95^{\circ} \mathrm{C} \text { inkubiert. }\end{array}$} \\
\hline 10 & \multicolumn{3}{|c|}{$\begin{array}{l}\text { Nach der Citratpufferbehandlung die Schnitte in der Lösung auf Raumtemperatur } \\
\text { abkühlen lassen. }\end{array}$} \\
\hline 11 & $1 \times \mathrm{PBS}(\mathrm{pH} 7,4)$ & $10 \mathrm{~min}$ & Waschvorgang \\
\hline
\end{tabular}

In Vorversuchen wurden für die verwendeten Primär-Antikörper jeweils die geeignete Inkubationsdauer, Temperatur und Verdünnung ermittelt (siehe Tabelle 2.9). Zur Vermeidung einer unspezifischen Hintergrundfärbung auf Grund hydrophober Bindungen wurden die Schnitte vor der Applikation des Primär-Antikörpers mit einer 1\%igen Bovine Serum Albumin (BSA)/ PBS-Lösung inkubiert.

Die immunhistologische Untersuchung erfolgte nach folgendem Protokoll (Tabelle 2.8).

Tabelle 2.8: Immunhistologische Untersuchung mit dem DAKO REAL ${ }^{\mathrm{TM}}$ Detection System.

\begin{tabular}{|c|c|c|c|}
\hline 1 & $\begin{array}{l}\text { 1\%ige PBS/BSA-Lösung, } 100 \mu \mathrm{l} \text { je } \\
\text { Schnitt }\end{array}$ & $10 \mathrm{~min}$ & Blocken \\
\hline 2 & $\begin{array}{l}\text { Inkubation mit dem Primär- } \\
\text { Antikörper (siehe auch Tabelle 2.8) }\end{array}$ & $\begin{array}{l}\text { Über Nacht bei } \\
37^{\circ} \mathrm{C}\end{array}$ & $\begin{array}{l}\text { Die Negativkontrolle } \\
\text { wurde ohne Primär- } \\
\text { Antikörper inkubiert. }\end{array}$ \\
\hline 3 & $1 \times \mathrm{PBS}$ & $10 \mathrm{~min}$ & Waschvorgang \\
\hline 4 & $\begin{array}{l}\text { Biotinylierter Sekundär-Antikörper: } \\
\text { 2-3 Tropfen je Schnitt }\end{array}$ & $15 \mathrm{~min}$ & \\
\hline 5 & $1 \mathrm{xPBS}$ & $10 \mathrm{~min}$ & Waschvorgang \\
\hline
\end{tabular}


Fortsetzung Tabelle 2.8

\begin{tabular}{|l|l|l|l|}
\hline 6 & $\begin{array}{l}\text { Chromogenlösung*: 2-3 Tropfen je } \\
\text { Schnitt }\end{array}$ & 10 min & \\
\hline 7 & $1 \times P B S$ & 10 min & Waschvorgang \\
\hline 8 & $\begin{array}{l}\text { Hämalaun nach Meyer 1:4 verdünnt } \\
\text { in Aqua destillata }\end{array}$ & 1 min & Gegenfärbung \\
\hline 9 & Objektträger in einer Küvette 10 min unter fließendem Leitungswasser spülen. \\
\hline 10 & $\begin{array}{l}\text { In einer aufsteigenden Alkoholreihe dehydrieren (siehe Tabelle 2.7, Schritte 2-7 in } \\
\text { umgekehrter Reihenfolge) }\end{array}$ \\
\hline 11 & Präparate mit Objektträgergläschen und Einbettmedium Eukitt eindecken. \\
\hline
\end{tabular}

* Chromogenlösung

$30 \mu \mathrm{l}$ Chromogen Red 1-Lösung mit $30 \mu \mathrm{l}$ Chromogen Red 2-Lösung versetzen und gut mischen. Weitere $30 \mu \mathrm{l}$ Chromogen Red 3-Lösung zupipettieren, gut durchmischen und mit $750 \mu$ A AP-Buffer verdünnen.

Tabelle 2.9: Für die Immunhistochemie verwendete Antikörper.

\begin{tabular}{|l|l|l|l|l|}
\hline Antigen & Quelle & Konzentration & Anwendung & Hersteller \\
\hline PDGFR- $\beta$ & Maus & $1: 100$ & Über Nacht $/ 37^{\circ} \mathrm{C}$ & BD Pharmingen \\
\hline RGS-5 & Kaninchen & $1: 50$ & Über Nacht $/ 37^{\circ} \mathrm{C}$ & Sigma-Aldrich \\
\hline Tie-2 & Kaninchen & $1: 125$ & Über Nacht $/ 37^{\circ} \mathrm{C}$ & Santa Cruz \\
\hline
\end{tabular}

\subsection{Untersuchung von CPCs in Hinblick auf Perizyten- und mesenchymale Stammzellmarker}

\subsubsection{Zellkultur}

Die für diese Dissertation untersuchten CPCs wurden unter zur Hilfenahme ihres hohen eigenmigratorischen Potentials nach Laborstandard isoliert. Hierzu wurden in einer Sterilbank mit einem Skalpell Gewebeproben aus Knorpelarealen, die einen makroskopischen Defekt im Sinne einer Osteoarthrose aufwiesen, in Millimeter große Stückchen geschnitten und in $75 \mathrm{~cm}^{2}$ Zellkulturflaschen mit $10 \mathrm{ml}$ Kulturmedium kultiviert (siehe Koelling et al. 2009). Dort verblieben die Knorpelstückchen unter Sichtkontrolle für sieben bis zehn Tage und wurden nach hinreichender Anzahl ausgewanderter CPCs mit sterilem PBS aus den Zellkulturflaschen herausgespült, und die Zellkulturflaschen wurden anschließend mit $10 \mathrm{ml}$ Kulturmedium aufgefüllt. Bei Stellen mit einer sehr dichten Besiedelung von CPCs 
wurden vorsichtig mit einem Zellschaber die Zellen vom Flaschenboden gelöst und mit dem in der Zellkulturflasche sich befindenden Kulturmedium gleichmäßig vermischt.

\title{
Kulturmedium
}

\author{
$500 \mathrm{ml}$ DMEM mit GlutaMax ${ }^{\mathrm{TM}}$ \\ $50 \mathrm{ml}$ Fetal Calf Serum (FCS) \\ $5 \mathrm{ml} \quad$ Penicillin/Streptomycin (50.000 units/50 mg)
}

Die Kultivierung der Zellen erfolgte bei $37{ }^{\circ} \mathrm{C}, 5 \% \mathrm{CO}_{2}$ und 95\% Luftfeuchtigkeit im Zellkulturschrank. Das Kulturmedium wurde alle 3 Tage gewechselt, und es erfolgte ein Passagieren der Zellen bei optisch geschätzten 80\%iger Konfluenz.

In Vorbereitung der Passagierung wurden die Zellkulturflaschen zunächst mit PBS gespült, um die Rückstände von FCS zu minimieren. FCS inaktiviert Trypsin, das in Lösung mit EDTA zum Ernten der Zellen verwendet wurde. Nach dem Ablösen der Zellen wurde durch Zugabe von Zellkulturmedium das Trypsin inaktiviert und der Überstand in ein Röhrchen gegeben zur Zentrifugation bei 300 g. Der Überstand wurde verworfen und das Zellpellet in $1 \mathrm{ml}$ PBS resuspendiert, um gemäß Laborstandard die Zellzahl mit einem Zählautomaten (Cellometer ${ }^{\mathrm{TM}}$ Zählkammer) zu bestimmen und in die Zellkulturflaschen circa 75.000 Zellen zur weiteren Kultur zu geben.

\subsubsection{Durchflusszytometrie}

Mit Hilfe der Durchflusszytometrie lassen sich Zellen, die einzeln von einem Laser getroffen werden, anhand ihrer Emission von optischen Signalen vermessen. Die Quantität der optischen Signale, auch Vorwärts- und Seitwärts-Streulicht (englisch Forward Scatter (FSC) und Side Scatter (SSC)) genannt, korrelieren im Falle des FSC-Detektors mit dem Volumen der Zelle und im Falle des SSCs mit der Granularität der Zelle. Neben dem allgemeinen Streulicht können auch Fluoreszenzsignale vermessen werden, wenn die zu untersuchenden Antigene vorab Fluoreszenzfarbstoff-gekoppelte-Antikörper gebunden haben. Durch Verwendung teildurchlässiger Spiegel, die Signale bestimmter Wellenlängen zu den jeweiligen Detektoren leiten können, können auch mehrere Fluoreszenzen parallel gemessen werden. Als Weiterentwicklung können die Zellen auf Grund der optischen Emissionen auch nach bestimmten gewünschten Parametern sortiert werden. An dieser Stelle soll Herrn Prof. Wulff (Klinik für Hämatologie und Onkologie) und seinen Mitarbeitern für die 
freundliche Unterstützung und die Möglichkeit zur Durchführung der Messungen herzlich gedankt werden!

In der vorliegenden Arbeit wurden mittels der Durchflusszytometrie bei neun Patienten in einer frühen Passage die Expression folgender Antigene untersucht: PDGFR- $\beta$, RGS-5, Tie-2, Stro-1 und Cluster of Differentiation (CD) 117.

CD 117 (cKit) wird von Progenitorzellen aus dem Knochenmark und auch von Herzstammzellen exprimiert, wobei letztere von MSCs über eine Stammzell-Faktor/CD 117Signalkaskade zur Migration und Proliferation stimuliert werden können (Fish 2016; Hatzistergos et al. 2010; Suzuki et al. 2011). Als Kontrolle, ob womöglich Endothelzellen in der Probe vorhanden sein könnten, wurde in zwei Passagen der Anteil an CD 31-positiven Zellen gemessen. Der verwendete CD 117-Antikörper ist bereits mit dem Fluoreszenzfarbstoff Fluoreszeinisothiocyanat (FITC) gekoppelt. Bei den anderen Primär-Antikörpern wurden als Sekundär-Antikörper Ziege-Anti-Maus-FITC-IgG und Ziege-Anti-KaninchenFITC-IgG verwendet.

Bei der Markierung der Zellen ist auch zu berücksichtigen, ob sich die Antigene auf der Oberfläche der Zellen oder im Intrazellularraum befinden und ob die Antikörper bereits mit einem Fluoreszenz-Farbstoff gekoppelt sind oder nicht.

PDGFR- $\beta$, Tie-2, Stro-1 und CD 117 sind oberflächlich sitzende Antigene, während RGS5 ein intrazelluläres Antigen ist. Die Antigenmarkierungen erfolgten jeweils nach folgenden Protokollen.

\section{Tabelle 2.10: Antigenmarkierung oberflächlicher Antigene.}

1 Die Zellen werden geerntet, in ein Probenröhrchen überführt und bei $300 \mathrm{~g}$ abzentrifugiert.

2 Je Probe werden mindestens 10.000 Zellen in jeweils $100 \mu$ PBS gelöst und in ein spezielles Durchflusszytometrieröhrchen überführt.

3 Bei jeder Messreihe wurde stets zusätzlich zu den zu untersuchenden Antigenen ein Röhrchen mit mindestens 10.000 Zellen in $500 \mu \mathrm{l}$ PBS zum Eichen angesetzt.

$4 \quad \mathrm{Zu}$ den Proben für die Antigenmarkierung werden $2 \mu \mathrm{l}$ Antikörper-Lösung (EndMischungsverhältnis 1:50) hinzupipettiert und 30 min bei $37^{\circ} \mathrm{C}$ inkubiert.

$5 \quad$ Anschließend wird $1 \mathrm{ml}$ PBS in die Röhrchen gegeben, vermischt und die Probe bei $300 \mathrm{~g}$ abzentrifugiert. Der Überstand wird entfernt, um die überschüssigen Antikörper zu entfernen.

$6 \quad$ Das Zellpellet wird in $500 \mu \mathrm{l}$ PBS resuspendiert. 
Fortsetzung Tabelle 2.10

\begin{tabular}{|l|l|}
7 & $\begin{array}{l}\text { Bei Primär-Antikörpern, die nicht bereits mit einem Fluoreszenzfarbstoff } \\
\text { markiert sind, wird ein Fluoreszenz-gekoppelter-Sekundär-Antikörper im Verhältnis }\end{array}$ \\
$\begin{array}{l}\text { 1:100 hinzupipettiert und } 30 \mathrm{~min} \text { bei Raumtemperatur unter Lichtausschluss inku- } \\
\text { biert. Parallel wird eine Isokontrolle ohne Primär-Antikörper nur mit dem Sekundär- } \\
\text { Antikörper angesetzt. }\end{array}$ \\
\hline 8 & $\begin{array}{l}\text { Anschließend wird } 1 \mathrm{ml} \text { PBS in die Röhrchen gegeben, vermischt und die Probe bei } \\
300 \mathrm{~g} \text { abzentrifugiert. Der Überstand wird entfernt, um die überschüssigen Antikör- } \\
\text { per zu entfernen. Das Zellpellet wird in } 500 \mu \mathrm{PBS} \text { resuspendiert. }\end{array}$ \\
\hline
\end{tabular}

Bei der Markierung intrazellulärer Antigene muss die Zellmembran permeabilisiert werden, damit die Antikörper die Zellmembran passieren können. Hierfür wurde ein zusätzliches Kit (Fix\&Perm von Dianova) benötigt. Das Medium A des Kits fixierte die Zellen, während Medium B die Zellmembran permeabilisierte. Durch die Fixierung waren die Zellen nicht mehr vital.

Tabelle 2.11: Antigenmarkierung intrazellulärer Antigene.

\begin{tabular}{|c|c|}
\hline 1 & $\begin{array}{l}\text { Die Zellen werden geerntet, in ein Probenröhrchen überführt und bei } 300 \mathrm{~g} \text { abzentri- } \\
\text { fugiert. }\end{array}$ \\
\hline 2 & $\begin{array}{l}\text { Probe werden mindestens } 10.000 \text { Zellen in jeweils } 100 \mu \text { von Medium A des Kits } \\
\text { x\&Perm gelöst, in ein spezielles Durchflusszytometrieröhrchen überführt, } 15 \text { min } \\
\text { i Raumtemperatur inkubiert und nach der Zugabe von } 1 \mathrm{ml} \text { PBS bei } 300 \mathrm{~g} \text { abzent- } \\
\text { ugiert. Der Überstand wird verworfen. }\end{array}$ \\
\hline 3 & $\begin{array}{l}\text { Bë jeder Messreine wurde stets zusatzllch zu den zu } \\
\text { Rörchen mit mindestens } 10.000 \text { Zellen in } 500 \mu \mathrm{PBS}\end{array}$ \\
\hline 4 & $\begin{array}{l}\text { Die Proben für die Antigenmarkierung werden in } 100 \mu \text { l Medium B gelöst, } 2 \mu \mathrm{l} \text { Anti- } \\
\text { körper-Lösung (End-Mischungsverhältnis 1:50) hinzupipettiert, vorsichtig mit der } \\
\text { Pipette vermischt und } 30 \text { min bei } 37^{\circ} \mathrm{C} \text { unter Lichtausschluss inkubiert. Parallel wird } \\
\text { eine Isokontrolle für den Sekundär-Antikörper ohne Zugabe des Primär-Antikörpers } \\
\text { jedoch unter Zugabe des Mediums B angesetzt. }\end{array}$ \\
\hline 5 & $\begin{array}{l}\text { Anschließend wird } 1 \mathrm{ml} \text { PBS in die Röhrchen gegeben, vorsichtig vermischt und die } \\
\text { Probe bei } 300 \mathrm{~g} \text { abzentrifugiert. Der Überstand wird entfernt, um Mediumreste und } \\
\text { die überschüssigen Antikörper zu entfernen. }\end{array}$ \\
\hline 6 & Das Zellpellet wird in $500 \mu \mathrm{l}$ PBS resuspendiert. \\
\hline 7 & $\begin{array}{l}\text { Bei Primär-Antikörpern, die nicht bereits mit einem Fluoreszenzfarbstoff } \\
\text { markiert sind, wird ein Fluoreszenz-gekoppelter-Sekundär-Antikörper im Verhältnis } \\
\text { 1:100 hinzupipettiert und } 30 \mathrm{~min} \text { bei Raumtemperatur unter Lichtausschluss inku- } \\
\text { biert. Die Isokontrolle ohne Primär-Antikörper aus Schritt } 4 \text { wird mit dem Sekundär- } \\
\text { Antikörper angesetzt. }\end{array}$ \\
\hline
\end{tabular}


Fortsetzung Tabelle 2.11

$8 \quad$ Anschließend wird $1 \mathrm{ml}$ PBS in die Röhrchen gegeben, vermischt und die Probe bei $300 \mathrm{~g}$ abzentrifugiert. Der Überstand wird entfernt, um Mediumreste und die überschüssigen Antikörper zu entfernen. Das Zellpellet wird in $500 \mu \mathrm{l}$ PBS resuspendiert.

Die Proben wurden mittels eines Durchflusszytometers (von Becton Dickinson) gemessen. Dabei wurden je Probe mindestens 10.000 Zellen analysiert. Die Daten wurden mit Hilfe der Software WinMDIv2.9 und Cell Quest Pro 2000 erfasst und ausgewertet.

\subsubsection{Western Blot}

Nach Auftrennung einer Proteinprobe entsprechend der Größe und Ladung der Proteine mittels einer Gelelektrophorese können über einen Elektrotransfer die polyanionisch geladenen Proteine auf eine Membran (z.B. Nitrocellulose oder Polyvinylidenfluorid (PVDF)) übertragen werden. In unserem Labor erfolgt die Auftrennung der Proteine im 5 bis $250 \mathrm{kDa}$-Bereich über eine Sodium Dodecyl Sulfate Polyacrylamide Gel Electrophoresis (SDSPAGE) nach Ulrich K. Laemmli (1970), die auf einem diskontinuierlichen PolyacrylamidGel basiert, das den Vorteil einer höheren Bandenschärfe aufweist. Das im Überschuss zur Probe hinzugegebene Anion des Natriumdodecylsulfats (SDS) lagert sich in dichten, regelmäßigen Abständen an die Aminosäuren des durch Hitzeeinwirkung und durch Zugabe des Thiols $\beta$-Mercaptoethanol denaturierten Proteins und führt über elektrostatische Abstoßungskräfte zu einer Linealisierung des Proteins. Nach Anlegen einer Spannung führt dies zu einer Auftrennung der Proteine entsprechend der Kettenlänge und des Molekülsgewicht, wobei die kleineren Moleküle eine höhere Laufgeschwindigkeit als die großen Moleküle aufweisen. Um den Antikörpern einen Zugang zu den aufgetrennten Proteinen zu ermöglichen, erfolgt im Anschluss an die SDS-PAGE ein Elektrotransfer auf eine Membran mittels einer Tank-Blot-Kammer, das Muster der elektrophoretischen Auftrennung bleibt dabei erhalten. Die Proteine können nun mit Hilfe von Antikörpern und über Immunkonjugate vermittelte Farb- oder Chemilumineszenzreaktionen detektiert werden.

\subsubsection{Vorbereitung der Gele}

Das Gel für die SDS-PAGE besteht aus zwei Phasen: dem Sammelgel und dem Trenngel. Im Sammelgel konzentrieren sich die Proteine der Proben an der Trenngelkante, bevor die eigentliche Auftrennung erfolgt. Nachfolgend erfolgt eine Aufstellung der vorzubereitenden Teilkomponenten: 


\section{Sammelpuffer}

$15,1 \mathrm{~g}$ Trisaminomethan (TRIS) $(=0,5 \mathrm{M})$

Mit Salzsäure auf pH 6,8 einstellen und mit Wasser auf $250 \mathrm{ml}$ auffüllen.

\section{Trenngelpuffer}

$45,4 \mathrm{~g}$ TRIS $(=1,5 \mathrm{M})$

Mit Salzsäure auf pH 8,9 einstellen und mit Wasser auf $250 \mathrm{ml}$ auffüllen.

$\underline{10 \% S D S}$

$100 \mathrm{~g} \quad$ SDS in 11 Wasser

\section{0\% Ammoniumperoxodisulfat (APS)}

$1 \mathrm{~g} / 10 \mathrm{ml}$ Wasser

Während das Sammelgel bei allen Gelen gleichermaßen zusammengesetzt ist, sollte beim Trenngel die Molekülgröße mit ins Kalkül gezogen werden. Nach Laborstandard werden im Bereich $<30 \mathrm{kDa}$ 15\% Trenngele, im Bereich $50 \mathrm{kDa} 10 \%$ Trenngele und im Bereich $120 \mathrm{kDa}$ 8\% Trenngele verwendet. Die Prozentangabe steht, auch im Folgenden, für den Gehalt an Acrylamid am Gesamtgewicht. Auf Grund der angegebenen Molekulgrößen in der Literatur wurde für PDGFR- $\beta$ - und Tie-2-Immundetektionen Gele mit 8\% AcrylamidAnteil und für RGS-5 Gele mit 15\% Acrylamid-Anteil gewählt.

\section{Sammelgel (5\%)}

$1,25 \mathrm{ml}$ Sammelpuffer

$50 \mu \mathrm{l} \quad \operatorname{SDS}(=10 \%)$

$5 \mu \mathrm{l} \quad$ Tetramethylethylendiamin (TEMED)

$0,8 \mathrm{ml} \quad$ Acrylamid

$2,7 \mathrm{ml}$ Aqua destillata

$0,2 \mathrm{ml} \quad$ APS $(=10 \%)$ 
Trenngel $(8 \%)$

$1,4 \mathrm{ml}$ Trenngelpuffer

$55 \mu \mathrm{l} \quad \mathrm{SDS}(=10 \%)$

$5 \mu \mathrm{l} \quad$ TEMED

$1,5 \mathrm{ml}$ Acrylamid

2,3 $\mathrm{ml}$ Aqua destillata

$0,25 \mathrm{ml}$ APS

Trenngel (15\%)

1,4 $\mathrm{ml}$ Trenngelpuffer

$55 \mu \mathrm{l} \quad$ SDS $(=10 \%)$

$5 \mu \mathrm{l}$ TEMED

2,8 $\mathrm{ml}$ Acrylamid

$1,0 \mathrm{ml}$ Aqua destillata

$0,25 \mathrm{ml}$ APS

Zur Vorbereitung des Gelgießens wurden die Glasplatten mit 100\%igem Ethanol gereinigt. Je zwei Glasplatten wurden dann an drei Kanten gegeneinander mit einer Gummidichtung abgedichtet und mit Klammern fixiert. Es wurde mit einem wasserfesten Stift eine Markierung im Abstand von $6 \mathrm{~cm}$ von dem unteren Rand der Glasplatten aus vorgenommen. Nun wurden zunächst die Komponenten des gewünschten Trenngels gemischt und bis in Höhe der Markierung zwischen die beiden Glasplatten gegossen. Das Gel wurde sogleich mit Ethanol überschichtet, sodass bei der nachfolgenden Polymerisierung sich eine glatte Kante bildet. Währenddessen wurde das Sammelgel angemischt. Das Ethanol wurde vorsichtig entfernt und das Sammelgel auf das polymerisierte Trenngel gegossen. Zur Herstellung der benötigten Geltaschen wurde ein Kamm in das flüssige Sammelgel gesteckt.

\subsubsection{Probenvorbereitung und Elektrophorese}

Die zu untersuchenden CPCs wurden in den Zellkulturflaschen 1 min mit PBS gespült um Kulturmediumrückstände zu entfernen. Danach wurden $2 \mathrm{ml}$ Trypsin/EDTA-Lösung in jede Flasche gegeben und unter Sichtkontrolle bei $37^{\circ} \mathrm{C}$ für circa 10 min im Brutschrank inkubiert. Sobald sich alle Zellen vom Flaschenboden gelöst hatten, wurden in jede Flasche $3 \mathrm{ml}$ Kulturmedium pipettiert, um das Trypsin zu inaktivieren. Die Flüssigkeit aus den Flaschen wurde in ein $10 \mathrm{ml}$ Röhrchen überführt und $10 \mathrm{~min}$ bei $300 \mathrm{~g}$ zentrifugiert. Der Überstand wurde vorsichtig abgesaugt und das Zellpellet in $1 \mathrm{ml}$ PBS resuspendiert. Es 
wurde anschließend mit dem Zählautomaten nach Laborstandard die Zellkonzentration der einzelnen Proben ermittelt. Nach dem Zählen wurden je Probe die circa 300.000 Zellen entsprechende Menge PBS entnommen und in ein $2 \mathrm{ml}$ Eppendorf-Cup pipettiert. Die Probe wurde 10 min bei $300 \mathrm{~g}$ zentrifugiert und der Überstand verworfen. Das Zellpellet wurde in $30 \mu \mathrm{l}$ reduzierendem Probenpuffer gelöst. Dabei galt je $10 \mu \mathrm{l}$ Probenpuffer eine Anzahl von circa 100.000 Zellen. Die Proben wurden für 3 min auf $95^{\circ} \mathrm{C}$ erhitzt.

\section{Reduzierender Probenpuffer}

$0,9 \mathrm{ml} \quad 3 x S D S-P r o b e n p u f f e r$

$0,1 \mathrm{ml} \quad \beta$-Mercaptoethanol

Frisch ansetzen.

\section{3x SDS-Probenpuffer}

$3,6 \mathrm{~g}$ TRIS $(=0,3 \mathrm{M})$

$9,0 \mathrm{~g} \quad \operatorname{SDS}(=9 \%)$

$22,5 \mathrm{~g} \quad$ Glycerin $(=22,5 \%)$

Vor der Zugabe von SDS mit Salzsäure auf pH 6,7 einstellen, 100 ml Wasser und eine Spatelspitze Bromphenolblau hinzufügen.

Die Elektrophorese wurde in einem Eigenbau-Tank-Blot in Anlehnung an die BiometraElektrophoresekammer durchgeführt. Zunächst wurde die untere Elektrophoresekammer mit Laufpuffer aufgefüllt und das Gel in den Laufpuffer gestellt.

\section{Laufpuffer}

$$
\begin{array}{ll}
30,3 \mathrm{~g} & \text { TRIS }(=0,25 \mathrm{M}) \\
142,6 \mathrm{~g} & \text { Glycin }(=1,9 \mathrm{M}) \\
50 \mathrm{ml} & \operatorname{SDS}(=10 \%)
\end{array}
$$

Mit Wasser auf $1000 \mathrm{ml}$ auffüllen.

Dabei war zu beachten, dass zuvor die Gummidichtung zwischen den Glasplatten entfernt wurde und sich keine Blasen unter dem Gel bildeten, die eine elektrische Isolation darstellen würden. Mit Hilfe von Klammern wurde das Gel fixiert und die obere Elektrophoresekammer wurde nun auch mit Laufpuffer aufgefüllt. 
Die Proben zu $35 \mu \mathrm{l}$ je Tasche wurden in die Taschen pipettiert. Zusätzlich wurden auch in mindestens eine Tasche $5 \mu \mathrm{l}$ einer Proteinleiter hineinpipettiert. Die Konzentration der Proben im Sammelgel erfolgte bei 10 bis $15 \mathrm{~mA}$, während die Auftrennung im Trenngel bei 20 bis $25 \mathrm{~mA}$ stattfand.

\subsubsection{Der Nassblot}

Nach der Auftrennung der Proteine im Gel wurden sie in einer Tank-Blot-Kammer auf eine PVDF-Membran transferiert. Dazu wurde eine Spannung senkrecht zur Membran angelegt, so dass das Auftrennungsmuster der Elektrophorese erhalten blieb.

In Vorbereitung zum Nassblot wurden eine PVDF-Membran und sechs Filterpapiere (Whatman ${ }^{\circledR}$ für Blotting) zurecht geschnitten, so dass die Filterpapiere eine etwas größere Fläche als die Membran aufwiesen. Die PVDF-Membran wurde zur Aktivierung $15 \mathrm{~s}$ in Methanol geschwenkt und dann 2 min in Wasser gewaschen. Im Anschluss wurden die Filterpapiere, die PVDF-Membran und die Schwämme der Blotkassette in kaltem Transferpuffer mindestens 15 min getränkt.

\section{Transferpuffer, pH 8,3}

$6,05 \mathrm{~g} \quad$ TRIS $(=25 \mathrm{mM})$

$28,8 \mathrm{~g} \quad$ Glycin $(=192 \mathrm{mM})$

$400 \mathrm{ml}$ Methanol $(=20 \%(\mathrm{v} / \mathrm{v}))$

$1600 \mathrm{ml}$ Aqua destillata

In einer ausreichend großen Schale, die mit gekühltem Transferpuffer gefüllt wurde, wurde die Kassette für den Blot zusammengesetzt. Die Reihenfolge der einzelnen Komponenten setzte sich wie folgt zusammen: (Kathodenseite) Schwamm - drei Filterpapiere - Gel Membran - drei Filterpapiere - Schwamm (Anodenseite). Wichtig war, dass sich keine Luftblasen zwischen Membran und Gel bildeten. Die Kassette wurde mit Gummibändern fixiert und unter Berücksichtigung der Kassettenorientierung in den Blot-Tank gestellt. Der Tank wurde mit gekühltem Transferpuffer aufgefüllt und für 90 min bei $350 \mathrm{~mA}$ erfolgte der Elektrotransfer.

\subsubsection{Proteinfärbung auf der PVDF-Membran}

Um den Erfolg des Transfers zu beurteilen, wurde eine unspezifische Färbung der Proteine auf der Membran mit Coomassie-Blau-Lösung vorgenommen. 
Coomassie-Blau-Lösung

0,1 g Coomassie briliant blue R250 Powder

$100 \mathrm{ml} \quad$ Aqua destillata

Die Membran wurde unter leichtem Schwenken 2 min in die Coomassie Blau-Lösung gelegt. Danach wurde die Membran 2 min bis 5 min im Entfärber 1 und anschließend im Entfärber 2 geschwenkt, bis die Hintergrundfärbung der Membran verblichen war und die Proteinbanden deutlich angefärbt waren. Die Membran wurde eingescannt und anschlieBend zweimal in TRIS Buffered Saline-Lösung mit 0,05\%igem Tween-Lösung-Anteil (TBS-T) gewaschen. Anschließend stand sie für die Immundetektion zur Verfügung.

\section{Entfärber 1}

$5 \mathrm{ml}$ Methanol

$7 \mathrm{ml}$ Essigsäure

mit Wasser auf $100 \mathrm{ml}$ auffüllen

\section{Entfärber 2}

$90 \mathrm{ml}$ Methanol

$10 \mathrm{ml}$ Essigsäure

10xTBS (pH 7,4)

$24,2 \mathrm{~g} \quad$ TRIS $(=200 \mathrm{mM})$

$87,6 \mathrm{~g}$ Natriumchlorid (= 1,5 M)

In 11 Wasser auflösen.

$\underline{T B S-T}$

$100 \mathrm{ml}$ 10xTBS

$0,5 \mathrm{~g} \quad$ Tween-20 (=0,5\%)

Mit Wasser auf einen Liter auffüllen, bei Raumtemperatur verwenden. 


\subsubsection{Die Immundetektion}

Um unspezifische Antikörperbindungen auf Grund freier Proteinbindungsstellen auf der Membran zu vermeiden, wurde die Membran mindestens eine Stunde bei Raumtemperatur in folgender Blocklösung inkubiert.

\section{Blocklösung}

$5 \%$ Milchpulver-Anteil in TBS-T, immer frisch ansetzen.

Im Anschluss wurde in die Blocklösung der Primär-Antikörper in der gewünschten Verdünnung hinzupipettiert und die jeweiligen Membranen auf einer Wippe unter Schwenken bei $4{ }^{\circ} \mathrm{C}$ über Nacht inkubiert. Für die einzelnen Primär-Antikörper wurden folgende Verdünnungen gewählt: PDGFR- $\beta$ 1:250, RGS-5 1:250 und Tie-2 1:200.

Nach der Inkubation wurden die Membranen fünfmal mit TBS-T gewaschen, um nicht gebundene Primär-Antikörper zu entfernen. Je nachdem aus welchem Tier der PrimärAntikörper stammt, wurde als Sekundär-Antikörper Anti-Maus-IgG-Peroxidase (Sigma) in der Verdünnung 1:40.000 oder Anti-Kaninchen-IgG-Peroxidase (Sigma) in der Verdünnung 1:100.000 verwendet. Der Sekundär-Antikörper wurde wie auch der PrimärAntikörper mit der Blocklösung verdünnt und $1 \mathrm{~h}$ bei Raumtemperatur unter Schwenken inkubiert. Im Anschluss wurden die Membranen erneut mit TBS-T gewaschen.

Für die Chemilumineszenz-Reaktion mit dem Enzym Peroxidase wurde nun die Lösung ECL Prime Western Blotting Detection System (Amersham) nach dem empfohlenen Prozedere des Herstellers auf die Membranen pipettiert und 5 min unter Lichtausschluss bei Raumtemperatur inkubiert. Bei dieser Reaktion wird Licht freigesetzt und mit Hilfe von Röntgenkassetten in einer Dunkelkammer bei Rotlicht konnte jeweils ein zugeschnittener spezieller Film (Amersham Hyperfilm) belichtet werden. Nach der Belichtung wurden die Filme entwickelt und fixiert und konnten nach dem Trocknen eingescannt werden.

\subsubsection{Genexpressionsanalyse von CPCs über die Passagen}

Mit Hilfe der in den 80er Jahren des 20. Jahrhunderts entwickelten Polymerase Chain ReactionMethode (PCR-Methode) lassen sich Proben von Desoxyribonukleinsäuren (DNA) logarithmisch amplifizieren. Als DNA-Ausgangsproben (englisch template) lassen sich genomische DNA (gDNA) als auch in DNA umgeschriebene Ribonukleinsäuren (RNA) verwenden. In dieser Arbeit wurde in DNA umgeschriebene Boten-RNA (mRNA) untersucht, so 
dass sich Hinweise auf die Genexpression der untersuchten Gensequenzen ergaben. Bei der reversen Transkription (englisch reverse transkription) von mRNA erhält man eine zur mRNA komplementäre einzelsträngige DNA (cDNA), die bei Folgereaktionen in eine doppelsträngige überführt werden kann.

Das PCR-Programm umfasst im Grunde genommen eine zyklische Abfolge dreier Schritte: einen Denaturierungsschritt (bei $95{ }^{\circ} \mathrm{C}$ ), einen Annealingschritt (zwischen circa $53-65^{\circ} \mathrm{C}$ ) und einen Elongationsschritt $\left(72^{\circ} \mathrm{C}\right)$. Die Annealingtemperatur $\left(\mathrm{T}_{\mathrm{m}}\right)$ hängt von der Basenzusammensetzung der Primer und dem zu amplifizierenden Fragment der DNA ab (siehe auch Rychlik et al. 1990). Zwar kann man über verschiedene Näherungsgleichungen die $T_{m}$ eines Primers berechnen, die Ermittlung der optimalen $\mathrm{T}_{\mathrm{m}}$ über eine Gradienten-PCR ist jedoch genauer und wird Standardmäßig in unserem Labor bei der Etablierung eines Primers durchgeführt.

Durch die Verwendung von Fluoreszenzfarbstoffen, die an DNA binden und deren Signalstärke proportional zur DNA-Konzentration in der Probe ist, kann man nach jedem Zyklus den Gehalt an DNA quantifizieren (englisch Real-Time Detection). In dieser Arbeit findet der Farbstoff SYBR Green I Verwendung, der doppelsträngige als auch einzelsträngige DNA bindet, dabei fällt das Signal deutlich stärker aus, wenn doppelsträngige DNA gebunden worden ist. Zur Quanifizierung wird nach jedem Zyklus mittels eines Lasers der SYBR Green-DNA-Komplex im blauen Lichtbereich angeregt und die emittierten grünen Lichtsignale gemessen. Während des Denaturierungsschrittes sinkt die Intensität der Fluoreszenzsignale auf ein Minimum, wenn der Schmelzpunkt der DNA, also der Zeitpunkt zu dem die Trennung der Doppelstränge vollzogen ist, erreicht wird.

Eine korrekte Abkürzung für die in dieser Arbeit verwendete Real-Time Detection-Reverse Transkription-Polymerase Chain Reaction würde RD-RT-PCR lauten, aus Gründen der Vereinfachung wird jedoch im folgenden PCR mit RD-RT-PCR gleich gesetzt.

\subsubsection{1 mRNA-Isolation aus Zellen}

Für die mRNA-Isolation aus CPCs mit dem RNeasy-Mini-Kit von Qiagen wurde das Kulturmedium aus den Zellkulturflaschen entfernt und die Zellen mit PBS gewaschen. Im Anschluss wurden $700 \mu$ RLT-Lysis-Puffer und $7 \mu$ Mercaptoethanol direkt auf die Zellen pipettiert und 2 min inkubiert. Danach wurden $700 \mu \mathrm{l}$ der Lösung auf einen QIAshredder pipettiert und $2 \mathrm{~min}$ bei $15.000 \mathrm{~g}$ zentrifugiert. Dem Durchfluss wurden $700 \mu \mathrm{l}$ 70\%Ethanol zugesetzt, auf eine RNeasy-mini-Säule pipettiert und erneut 2 min bei $15.000 \mathrm{~g}$ zentrifugiert. Der Durchfluss wurde verworfen. Die auf Grund ihrer Affinität in der Säule 
zurückgebliebene mRNA wurde erst mit $700 \mu \mathrm{l}$ RW1-Puffer und dann mit $500 \mu \mathrm{l}$ REEPuffer für $30 \mathrm{~s}$ bei $8.000 \mathrm{~g}$ gewaschen. Anschließend wurde die Säule in ein neues Sammelröhrchen überführt und 1 min bei $15.000 \mathrm{~g}$ zentrifugiert, um restliche Pufferbestandteile zu entfernen. Auf die Membran der Säule wurden $30 \mu \mathrm{l}$ RNAse-freies Wasser pipettiert, die Säule in ein 1,5 ml Biopur ${ }^{\circledR}$ Safe-Lock Tube umgesteckt und nach einer Ruhezeit von 5 min wurde die Säule $1 \mathrm{~min}$ bei $15.000 \mathrm{~g}$ zentrifugiert. Das Eluat enthielt die präparierte mRNA. Die Konzentrationsbestimmung der eluierten mRNA erfolgte photometrisch (Spektralphotometer von Eppendorf) bei 260 und 280 nm. Es wurde nach Herstellerangaben vorgegangen.

\subsubsection{2 cDNA-Synthese und PCR-Protokoll}

Für die anschließende PCR wurde die präparierte mRNA mittels des Quanti-Tect-ReverseTranskription-Kits in cDNA umgeschrieben. Nach der Elimination der Reste genomischer DNA aus den Proben mit einem gDNA-Wipeout-Buffer wurden die reversen Transkriptase, eine RNA-abhängige DNA-Polymerase, ein Puffer und im Überschuss Primer zur Probe hinzufügt und 15 min bei $42{ }^{\circ} \mathrm{C}$ inkubiert. Die Enzymaktivität wurde durch Erhitzen der Reaktionsansätze auf $95^{\circ} \mathrm{C}$ für 3 min gestoppt. Unter Annahme eines vollständigen Umsatzes der mRNA-Matrize in cDNA wurde die Probe basierend auf die gemessenen mRNA-Konzentrationen der jeweiligen Proben auf eine Endkonzentration von $1 \mathrm{ng} / \mu \mathrm{l}$ verdünnt. Für die Verdünnung wurde mit Diethylpyrokarbonat (englisch Diethylpyrocarbonate, DEPC) behandeltes Wasser verwendet, das durch den DEPC-Einsatz bei sorgfältigem Umgang als RNasenfrei gilt.

\section{PCR-Protokoll}

Die Reaktionsansätze für die PCR wurden nach den Angaben in Tabelle 2.11 angesetzt. Es empfahl sich jedoch eine geringfügig höhere Menge als „Puffer“ anzusetzen, um exakt $10 \mu \mathrm{l}$ Reaktionsansatz je Well gewährleisten zu können.

Tabelle 2.12: Pipettierschema PCR.

\begin{tabular}{|l|l|l|}
\hline Substanz & Pro Well & Mastermix (3 Well) \\
\hline cDNA & $10 \mathrm{ng}$ & $30 \mathrm{ng}$ \\
Primer (forward+reverse) & je 20 pmol & je 60 pmol \\
SYBR-Green-Mix & $5 \mu \mathrm{l}$ & $15 \mu \mathrm{l}$ \\
Wasser & Auffüllen auf $10 \mu \mathrm{l}$ & Auffüllen auf $30 \mu \mathrm{l}$ \\
\hline
\end{tabular}


Die verwendeten Primer lassen sich aus Tabelle 2.13 entnehmen. Da das für Stro-1 kodierende Gen beziehungsweise die Gene noch nicht identifiziert werden konnten (Ning et al. 2011), wurde in der PCR-Untersuchung das Gen alpha-Smooth Muscle Actin (aSMA) untersucht. aSMA ist eines der am häufigsten verwendeten Perizytenmarker (Diaz-Flores et al. 2009).

Tabelle 2.13: Verwendete Primer.

\begin{tabular}{|l|l|l|}
\hline Target & Sequenz & Annealing-Temperatur \\
\hline$\beta 2-$ Mikroglobulin & $\begin{array}{l}\mathrm{Fw}^{1}: \text { tgctgtctccatgttgatgtatct } \\
\mathrm{Rv}^{2}: \text { tctctgctccccactctaa }\end{array}$ & $61^{\circ} \mathrm{C}$ \\
\hline PDGFR- $\beta$ & $\begin{array}{l}\text { Fw: actgttgggcgaaggt } \\
\text { Rv: caggcagggggatgatatagtc }\end{array}$ & $53^{\circ} \mathrm{C}$ \\
\hline Tie-2 & $\begin{array}{l}\text { Fw: gccttcaccaggctgatagt } \\
\text { Rv: tcacacgtccttccataaac }\end{array}$ & $53^{\circ} \mathrm{C}$ \\
\hline RGS-5 & $\begin{array}{l}\text { Fw: ctctccacgttccttgagtaa } \\
\text { Rv: tcttaatctaacccaaccctaac }\end{array}$ & $60{ }^{\circ} \mathrm{C}$ \\
\hline aSMA & $\begin{array}{l}\text { Fw: aatggctctgggctctgtaa } \\
\text { Rv: gccatgttctatcgggtactt }\end{array}$ & $63{ }^{\circ} \mathrm{C}$ \\
\hline
\end{tabular}

$1=\mathrm{Fw}$ entspricht dem forward Primer. $\quad 2=\mathrm{Rv}$ entspricht dem reverse Primer.

Sowohl die Substanzen des Reaktionsansatzes als auch die 96-Well-Platte für die PCR wurden während des Pipettiervorganges gekühlt. In jedes Well wurden $10 \mu \mathrm{l}$ Master-Mix pipettiert, drei Wells je Zielgen und Patient, und mit optical flat caps verschlossen. Danach wurden die Platten für $10 \mathrm{~s}$ bei $1.200 \mathrm{rpm}$ abzentrifugiert, um ein Konzentrierung des PCRAnsatzes auf dem Wellboden zu erzielen. Jede PCR wurde dreimal an unterschiedlichen Tagen wiederholt, so dass je Probe neun Werte vorliegen.

Unter Verwendung des Mastercycler ${ }^{\circledR}$ ep gradient S realplex (Eppendorf) wurde die PCR nach dem Protokoll in Tabelle 2.14 durchgeführt. Die statistische Auswertung und Normalisierung der PCR-Daten erfolgte nach Pfaffl (2001) unter Heranziehung des HouskeepingGens $\beta 2$-Mikroglobulin ( $\beta 2-\mathrm{M})$, das bei den Patienten vergleichbare ct-Werte aufwies. 
Tabelle 2.14: Protokoll PCR.

\begin{tabular}{|l|l|l|}
\hline 1. Initiale Denaturierung & 3 min bei $95^{\circ} \mathrm{C}$ & \\
\cline { 1 - 2 } 2. Denaturierung & $20 \mathrm{~s}$ bei $95^{\circ} \mathrm{C}$ & \multirow{2}{*}{$\begin{array}{c}\text { Schritt } 2-4 \text { werden in } \\
45 \text { Zyklen wiederholt }\end{array}$} \\
\cline { 1 - 2 } 3. Annealing & $20 \mathrm{~s}$ bei $53-63^{\circ} \mathrm{C}$ & \\
\cline { 1 - 2 } $\begin{array}{l}\text { 4. DNA-Synthese/ } \\
\text { Fluoreszenzmessung }\end{array}$ & $20 \mathrm{~s}$ bei $72{ }^{\circ} \mathrm{C}$ & \\
\hline 5. Letzter Synthesezyklus & 10 min bei $72^{\circ} \mathrm{C}$ & \\
\hline
\end{tabular}

Die Annealing-Temperatur hängt wie eingangs beschrieben vom verwendeten Primer ab (siehe auch Tabelle 2.13).

\subsection{Migrationsassay}

In den letzten Jahrzehnten haben sich verschiedene Versuchsdesigns etabliert, um die Migration vor allem als Antwort auf einen mechanischen oder chemischen Reiz hin zu untersuchen. Neben dem scratch assay gibt es das 3D-Invasion-Assay und ein Invasions-Assay durch eine Membran hindurch. Das scratch assay stellt gewisse Anforderungen an die Reproduzierbarkeit der künstlichen „Wunde“ und man sollte berücksichtigen, dass beim Kratzen Zellen verletzt werden, die chemotaktisch wirksame Zytokine freisetzen können. Beim 3D-Invasion-Assay migrieren Zellen, die in eine Matrix eingebettet sind, in einen angrenzenden Matrixbereich mit oder ohne Einfluss eines Zytokins. In diesen Matrices finden unterschiedliche Kollagene Verwendung, die einen eigenen Einfluss auf die Migration nehmen können.

1962 beschrieb Stephen Boyden die Verwendung einer Membran, durch die Zellen aus einer oberen Kammer zu einer Probe mit einem Zytokin in einer unteren Kammer migrieren können. In die Migrationseinsätze mit der Membran (obere Kammer) wird die Zellsuspension pipettiert. Dabei ist darauf zu achten, dass durch regelmäßiges Durchmischen ein höchstmöglicher Grad an Homogenität der Zellsuspension gewähr leistet wird, da die Zahl der gewanderten Zellen proportional zur Anzahl der Zellen ist, die in die obere Kammer pipettiert wurde. Auch dürfen sich keine Luftblasen unter der Membran bilden, da dies einen erheblichen Störfaktor für eine mögliche Zellmigration darstellt. In dieser Arbeit wurden die Migrationseinsätze ThinCert ${ }^{\mathrm{TM}}$ von Greiner bio-one verwendet, deren Membran eine Porengröße von $8 \mu \mathrm{m}$ aufwies. 
Zur Quantifizierung kann man die Zahl an gewanderten Zellen je nach Versuchdesign optisch auszählen oder über photometrische oder fluoreszenzbasierte Methoden bestimmen. In dieser Arbeit wurde der Fluoreszenzfarbstoff Calcein verwendet, der durch die Kopplung mit dem hydrophoben Acetomethoxy (AM) die Zellmembran von Zellen passieren kann. In lebenden Zellen spaltet eine Esterase den Calcein-AM-Komplex, und das Calcein wird quasi in der lebenden Zelle „gefangen“, so dass durch den Farbstoff eine Unterscheidung lebender von toten Zellen getroffen werden kann. Das gemessene Fluoreszenzsignal ist dabei proportional zur Zellzahl.

Tabelle 2.15: Protokoll Migrationsassay.

\begin{tabular}{|c|c|}
\hline 1 & $\begin{array}{l}\text { Bei einer ausreichenden Anzahl Zellkulturflaschen wird das Kultivierungsmedium } \\
\text { abpipettiert und die Zellkulturflaschen werden mit sterilem PBS gespült. }\end{array}$ \\
\hline 2 & $\begin{array}{l}\text { Das PBS wird verworfen und } 10 \mathrm{ml} \text { serumfreies (sf) Kulturmedium mit } 0,2 \% \text { iger } \\
\text { BSA auf die Zellen gegeben. Die Zellen „hungern“ über Nacht im Zellkultur- } \\
\text { schrank. }\end{array}$ \\
\hline 3 & $\begin{array}{l}\text { Das sf Medium wird abpipettiert und die Zellen mit Trypsin-EDTA geerntet (siehe } \\
\text { 2.3.1). Die Zellen werden mit sterilem PBS gewaschen und bei } 300 \text { g zentrifugiert. }\end{array}$ \\
\hline 4 & $\begin{array}{l}\text { Das Zellpellet wird in } 1 \mathrm{ml} \text { sf Medium resuspendiert und die Zellzahl bestimmt. } \\
\text { Die Zellsuspension wird unter Zugabe von sf Medium auf } 5 \times 10^{5} \text { Zellen } / \mathrm{ml} \text { ver- } \\
\text { dünnt. }\end{array}$ \\
\hline 5 & $\begin{array}{l}\text { Die Migrationeinsätze werden in 24-Well-Platten eingesetzt. Je Probe werden vier } \\
\text { Migrationseinsätze angesetzt. }\end{array}$ \\
\hline 6 & $\begin{array}{l}\text { In jedes Well werden } 600 \mu \mathrm{l} \text { sf Medium mit Zusatz (siehe Tabelle 2.15) oder ohne } \\
\text { (Negativkontrolle) pipettiert. }\end{array}$ \\
\hline 7 & $\begin{array}{l}\text { In jedes Insert werden } 200 \mu \mathrm{l} \text { Zellsuspension, ohne dabei die Membran zu verlet- } \\
\text { zen (!), pipettiert. }\end{array}$ \\
\hline 8 & Die Ansätze werden $12 \mathrm{~h}$ im Zellkulturschrank inkubiert. \\
\hline 9 & $\begin{array}{l}\text { Das Medium aus den Wells wird entfernt, durch } 450 \mu \mathrm{l} \text { sf Medium mit } 8 \mu \mathrm{M} \text { Cal- } \\
\text { cein-AM ersetzt und für } 45 \text { min im Zellkulturschrank inkubiert. }\end{array}$ \\
\hline 10 & Im Anschluss wird das Medium aus den Inserts entfernt. \\
\hline
\end{tabular}


Fortsetzung Tabelle 2.15

\begin{tabular}{|l|l|}
\hline 11 & $\begin{array}{l}\text { Die Migrationseinsätze werden in eine frisch vorbereitete } 24-\text { Well-Platte überführt, } \\
\text { die je Well } 500 \mu \text { l vorgewärmte Trypsin-EDTA-Lösung enthält. }\end{array}$ \\
\hline 12 & $\begin{array}{l}\text { Die Ansätze werden } 10 \text { min im Zellkulturschrank inkubiert, dabei werden die Plat- } \\
\text { ten regelmäßig vorsichtig gerüttelt. }\end{array}$ \\
\hline 13 & $\begin{array}{l}\text { Die Migrationeinsätze werden verworfen und } 200 \mu \text { der Trypsin-EDTA-Lösung } \\
\text { mit den markierten Zellen in ein Well einer schwarzen } 96-\text { Well-Mikrotiterplatte mit } \\
\text { transparentem Boden überführt. }\end{array}$ \\
\hline 14 & $\begin{array}{l}\text { Die Proben werden bei einer Exzitationswellenlänge } 495 \mathrm{~nm} \text { und bei einer Emis- } \\
\text { sionwellenlänge von } 515 \mathrm{~nm} \text { in einem Fluoreszenzplattenleser gemessen. }\end{array}$ \\
\hline
\end{tabular}

Der folgenden Tabelle lassen sich die untersuchten Zytokine entnehmen. Es wurden die ausgewählten Zytokine in einer niedrigen Konzentration mit $5 \mathrm{ng} / \mathrm{ml}_{\text {sfMedium }}$ bzw. $10 \mathrm{ng} / \mathrm{ml}_{\mathrm{sfMedium}}$ und in einer höheren Konzentration mit $40 \mathrm{ng} / \mathrm{ml}_{\mathrm{sfMedium}}$ auf ihre chemotaktische Wirkung bei sieben Patienten hin untersucht. Die CPCs der Patienten befanden sich in einer frühen Passage bis Passage P4. Pro Versuchsdurchlauf wurden als Positivkontrolle 10\% FCS und als Negativkontrolle serumfreies Medium gewählt und je Probe drei Ansätze untersucht. Ein herzlicher Dank gilt an dieser Stelle Frau Prof. Rosen von der University of Harvard für die freundliche Bereitstellung der in dieser Arbeit untersuchten BMPs. Die ermittelten Mittelwerte wurden mit dem t-Test für zwei verbundene Stichproben und der Software SPSS statistics (25.0, IBM, USA) statistisch geprüft.

Tabelle 2.16: Untersuchte Zytokine.

\begin{tabular}{|l|l|}
\hline Zytokin & Hersteller \\
\hline Angiopoietin-1 & R\&D Systems \\
\hline Angiopoietin-2 & R\&D Systems \\
\hline BMP-2,-4,-6,-9,-12,-13 & $\begin{array}{l}\text { Fr. Prof. V. Rosen, University } \\
\text { of Harvard }\end{array}$ \\
\hline FCS & Invitrogen \\
\hline IL-6 & Sigma \\
\hline IL-8 & Sigma \\
\hline IL-17 & R\&D Systems \\
\hline PDGF-BB & Promokine \\
\hline TNF- $\alpha$ & Sigma \\
\hline VEGF & Promokine \\
\hline
\end{tabular}




\section{Ergebnisse}

\subsection{Immunhistochemische Untersuchung von Perizytenmarkern am Knorpelgewebe}

Es wurden Gewebeproben von vier Patienten (\#7, \#28, \#260, \#262) untersucht, deren Teilgewebeproben, wie unter 2.2.2 beschrieben, in sogenannte mikroskopisch gesunden und defekten Knorpel unterschieden worden waren. Die Fallnummern in der Klammer entsprechen auch im Folgenden den Fallbezeichnungen der anonymisierten Patienten der AG Orale Biologie und Geweberegeneration.

Beim sogenannten mikroskopisch gesundem Knorpel wurden noch frühe Grade der Osteoarthrose (OARSI Grad 1,0 bis 2,0, siehe Pritzker et al. 2006) eingeschlossen. Wichtig für die Unterscheidung in mikroskopisch (noch) gesunden Knorpel und in einen von einer fortgeschrittenen Osteoarthrose gezeichneten defekten Knorpel war die Intaktheit der Tidemark.

Zusammenfassend lässt sich sagen, dass beim mikroskopisch gesunden Knorpel keine PDGFR- $\beta$ - und RGS-5-positiven Zellen im Knorpel beobachtet wurden. Im Gegensatz dazu zeigten sich Tie-2-positive Zellen in den oberflächennahen Knorpelschichten, während im darunterliegenden Knorpel keine Tie-2-positiven Zellen beobachtet wurden.

Bei fortgeschrittener Osteoarthrose und bei von Einssprossungen durchbrochener Tidemark zeigten sich sowohl PDGFR- $\beta$-, RGS-5- und Tie-2-positive Zellen als auch Zellcluster, die von Chondrozyten zu unterscheiden waren. Klassische Chondrozyten, die sich basophil anfärbten und sich mikroskopisch eindeutig als solche bestimmen ließen, waren im mikroskopisch gesunden als auch im defekten Knorpel weder PDGFR- $\beta$-, RGS-5- noch Tie-2-positiv. Ebenfalls wurden PDGFR- $\beta$-, RGS-5- und Tie-2-positive Einsprossungen vom subchondralen Knochen ausgehend in den Knorpel beobachtet. Es fiel auf, dass bei fortgeschrittener Osteoarthrose das Stroma zwischen den Knochentrabekeln an Dichte zugenommen hatte. Das Stroma zwischen den Knochentrabekeln zeigte sich PDGFR- $\beta$-, RGS-5- und Tie-2-positiv. 


\subsubsection{PDGFR- $\beta$}

Im mikrospisch gesunden Knorpel zeigten sich keine PDGFR- $\beta$-positiven Zellen. Im Bereich des subchondralen Knochens fanden sich PDGFR- $\beta$-positive Zellen im Bereich des Knochenmarks (Abbildung 3.1).

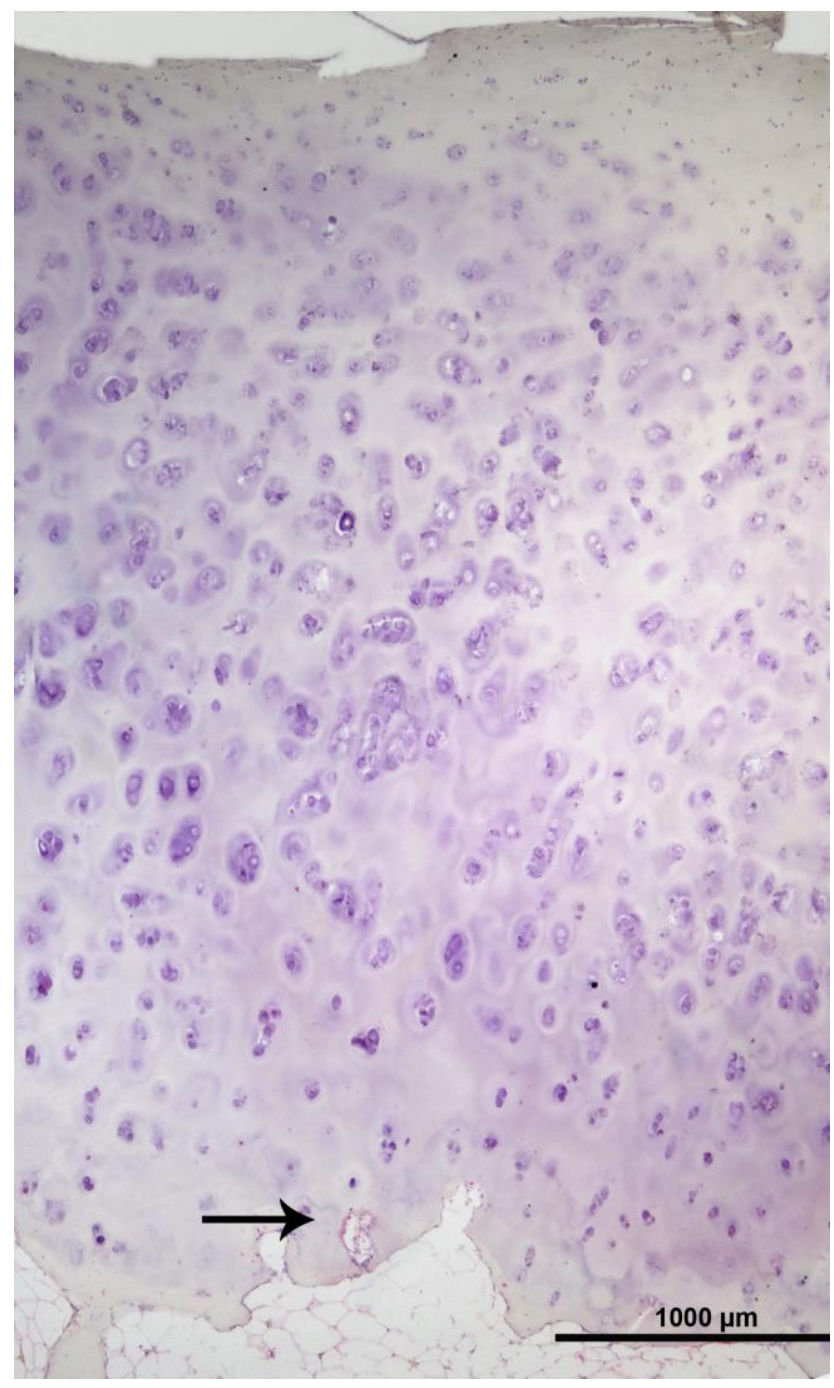

Abbildung 3.1: Untersuchung eines mikroskopisch gesunden Knorpels auf PDGFR$\boldsymbol{\beta}$-Expression. Vierzigfache Vergrößerung und Hämalaun-Gegenfärbung. Im Knorpel zeigt sich ein teilweise noch intakter Knorpelaufbau ohne Tidemarkbrüche. Die ersten Zeichen einer Osteoarthrose wie Hypertrophie und Desorientierung der Chondrozyten sind sichtbar. Im Bereich des Knorpels sind keine PDGFR- $\beta$-positiven Zellen zu beobachten. Im Bereich des subchondralen Knochens zeigen sich im Knochenmarksbereich PDGFR- $\beta$ positive Zellen und Bereiche mit erhöhter Anzahl PDGFR- $\beta$-positiver Zellen am Knochen-Knorpel-Übergang (Pfeil).

In Knorpelproben mit einer fortgeschrittenen Osteoarthrose und Tidemarkbrüchen mit Einsprossungen fanden sich PDGFR-ß-positive Zellen nahe der Knorpeloberfläche (siehe 
Abbildung 3.2 und 3.3), in Clustern, vereinzelt zwischen nicht positiven Zellen (siehe Abbildung 3.3) und im Bereich der Tidemarkbrüche. Im Bereich des Knochenmarks zeigte sich eine erhöhte Dichte an PDGFR- $\beta$-positivem Stroma im Vergleich zu Gewebeproben mit einer sehr frühen Osteoarthrose (vergleichbar Abbildung 3.1 und 3.2). Auch bei einer fortgeschritteneren Osteoarthrose konnten klassische Chondrozyten im Knorpel beobachtet werden, die sich basophil anfärbten, die eindeutige Morphologie aufwiesen und in den typischen Gruppen lagen.

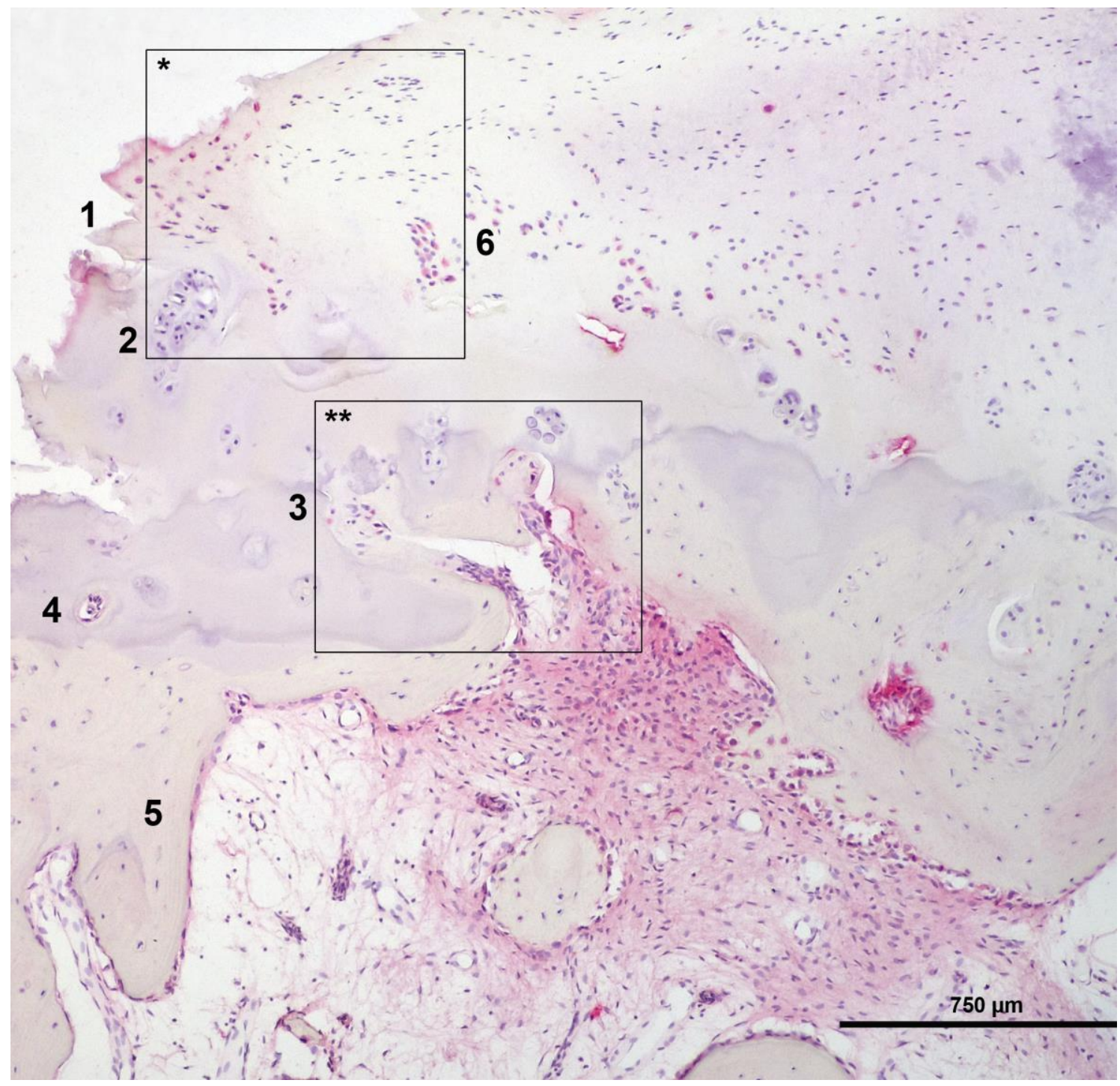

Abbildung 3.2: Immunhistochemische Untersuchung von PDGFR- $\beta$ im osteoarthrotischem Kniegelenksknorpel. Hundertfache Vergrößerung mit HämalaunGegenfärbung. Entsprechend einer fortgeschrittenen Osteoarthrose zeigen sich Oberflächenfissuren (1), Chondrozytencluster (2), Tidemarksbrüche (3) und Kapillareinsprossungen im Knorpel (4). Es zeigt sich eine deutlich erhöhte Dichte an Rotanfärbung von PDGFR- $\beta$-positiven Zellen im Knochenmarksbereich (5). Im Knorpelbereich fanden sich ebenfalls PDGFR- $\beta$-positive Zellen (6). Die mit $\left(^{*}\right)$ und $\left(^{* *}\right)$ gekennzeichneten Bereiche werden in den Abb. 3.3 und 3.4 näher beschrieben. 
Abbildung 3.3: Teilausschnitt $*$ aus Abb. 3.2. Es zeigen sich PDGFR- $\beta$ positive Zellen angeordnet in Gruppen (1), an der Knorpeloberfläche (2) und in verschiedenen anderen Bereichen

(*). Chondrozytencluster, gezeichnet von der Osteoarthrose durch Hypertrophie und Proliferation, zeigen sich nicht PDGFR- $\beta$-positiv.

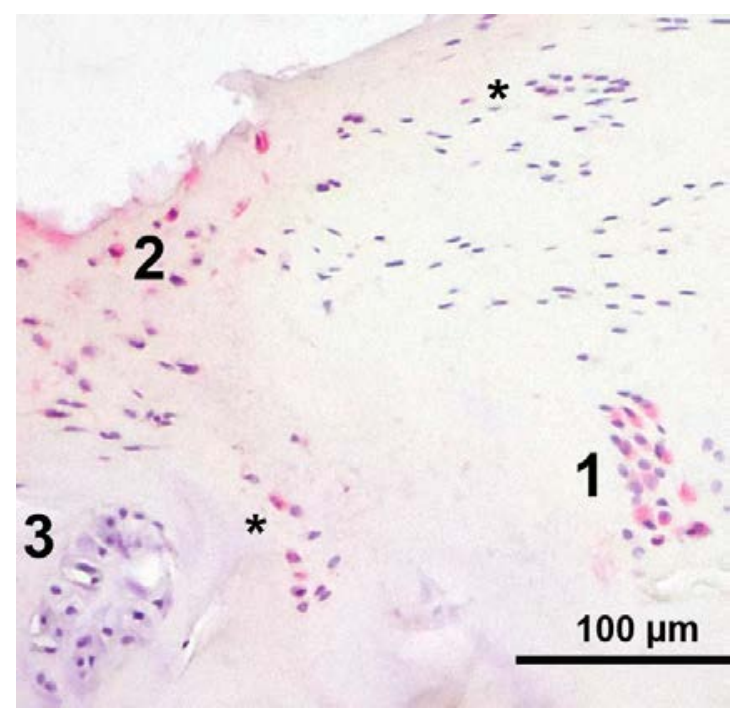

Abbildung 3.4: Teilausschnitt ** aus Abb. 3.2. Der Ausschnitt zeigt einen Bereich mit Tidemarkbrüchen (*). PDGFR- $\beta$-positive Zellen aus dem Knochenmark (1) reichen bis in die Tidemarkbrüche heran (Pfeile). Mit (2) wurde ein Chondrozytencluster gekennzeichnet.

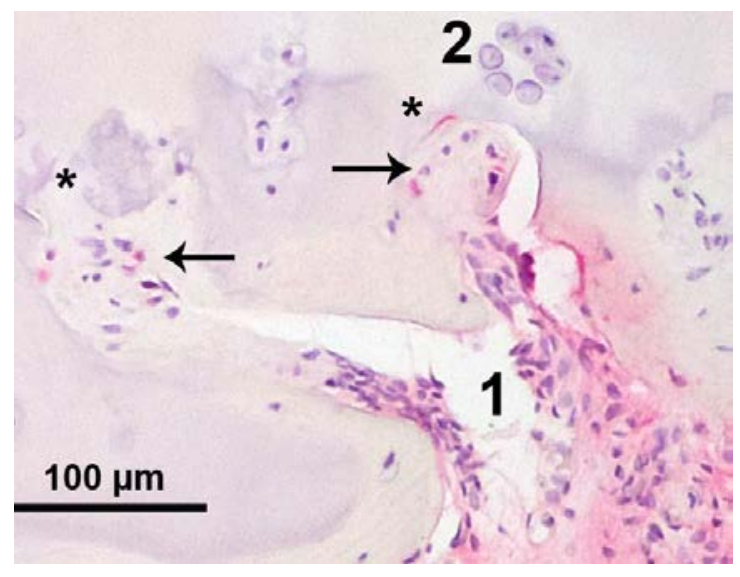

Bereits im Knorpel mit einer frühen Osteoarthrose wiesen die Chondrozyten pathologische Veränderungen im Zuge der Pathophysiologie auf, wie Hypertrophie, Proliferation und Desorientierung, die sich im Verlauf verstärkten (Abbildung 3.1 und 3.2). Die Chondrozyten zeigten sich weder im mikroskopisch gesunden noch im defekten Knorpel PDGFR- $\beta$ positiv.

\subsubsection{RGS-5}

Ähnlich zu PDGFR- $\beta$ zeigte sich auch bei RGS-5 ein deutlicher Unterschied zwischen einem weitestgehend intakten und einem von einer fortgeschrittenen Osteoarthrose gezeichneten Knorpel. Im mikroskopisch intakten Knorpel zeigten sich im Bereich des Gelenkknorpels keine RGS-5-positiven Zellen (Abbildung 3.5). Im Bereich des subchondralen Knochens gab es, ähnlich zu den Untersuchungen mit dem PDGFR- $\beta$-Antikörper, Bereiche mit einer erhöhten Anzahl RGS-5-positiver Zellen (Abbildung 3.5 und 3.6). In Knor- 
pelproben mit einer fortgeschritteneren Osteoarthrose zeigten sich deutlich RGS-5-positive Einsprossungen in den Knorpel und RGS-5-positives Stroma zwischen den Knochentrabekeln (Abbildung 3.7). In Bereichen, in denen deutliche Einsprossungen in den Knorpel vorgefunden wurden, konnte eine erhöhte Dichte an RGS-5-positiven Zellen im Zwischenraum der Knochentrabekeln beobachtet werden (vergleichbar Abbildung 3.5 und 3.7). Ähnliche Beobachtungen wurden auch bei der Untersuchung von Gewebeproben mit PDGFR- $\beta$ getroffen (siehe oben).

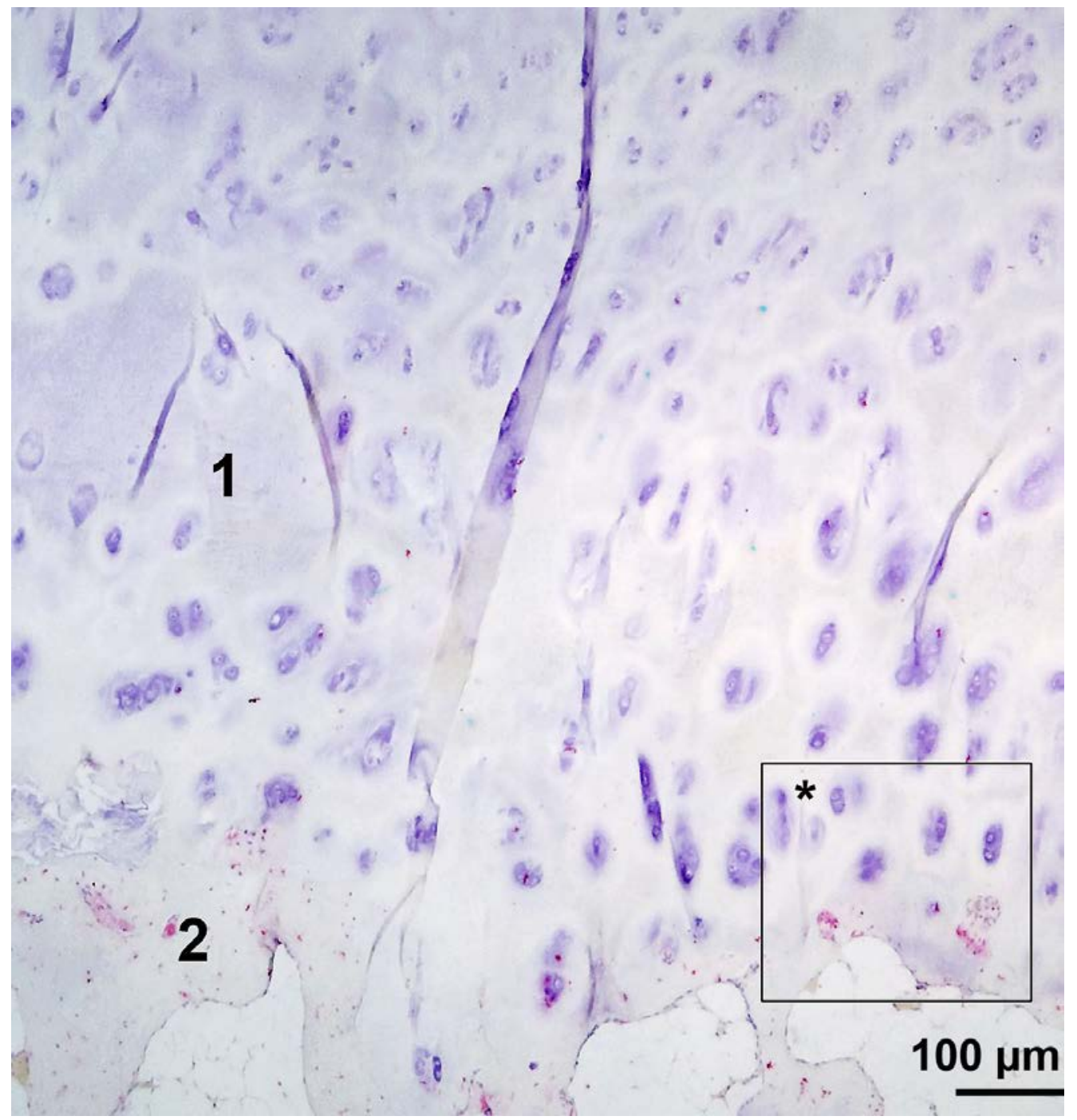

Abbildung 3.5: Immunhistochemische Untersuchung auf RGS-5-Expression bei mikroskopisch gesundem Knorpel. Hundertfache Vergrößerung mit HämalaunGegenfärbung. Im Knorpelbereich zeigen sich keine RGS-5-positiven-Zellen (1). Im subchondralem Knorpel finden sich Bereiche mit RGS-5-positiven Zellen, die zum Teil vereinzelt, aber zum Teil auch in größeren Knochenlakunen auftreten (2). Der mit (*)gekennzeichnete Bereich wird in Abbildung 3.6 erläutert. 
Abbildung 3.6: Teilausschnitt * aus Abb. 3.5. Die beiden Pfeile zeigen auf Bereiche mit RGS-5-positiven Zellen im subchondralen Knochen. Der linke Pfeil zeigt eine potentiell frühe Einsprossung. Mit $\left(^{*}\right)$ wurden RGS-5negative Chondrozyten im kalzifizierten Knorpel markiert.

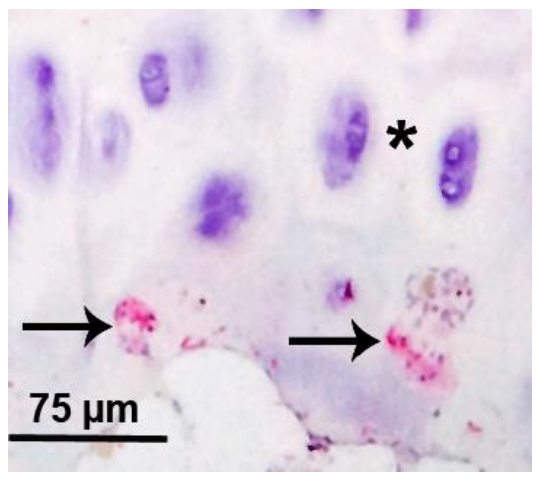

Abbildung 3.7: RGS-5-positive Einsprossungen in den Knorpel bei einer fortgeschrittener Osteoarthrose. Hundertfache Vergrößerung mit Hämalaun-Gegenfärbung. Es zeigen sich RGS-5-positive Einsprossungen (1). Im subchondralen Knochen finden sich vereinzelte RGS-5-positive Zellen und Kapillaren mit RGS-5-positivem Stroma (2). Im Knochenmark (3) zeigen sich am subchondralen Knochen eine erhöhte Dichte an RGS-5positiven Zellen mit zum Teil sehr deutlicher Reaktion (Pfeile) Mit (*)

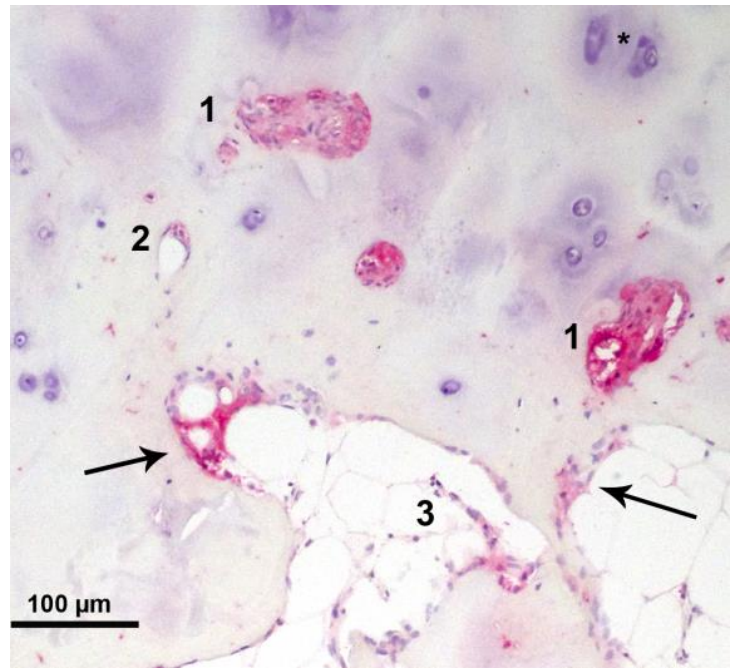
wurden RGS-5-negative Chondrozyten markiert.

Die kleinen Blutgefäße im subchondralen Knochen zeigten ein angrenzendes deutlich RGS-5-positives Stroma, während die Endothelzellen RGS-5-negativ waren (Abbildung $3.8)$.

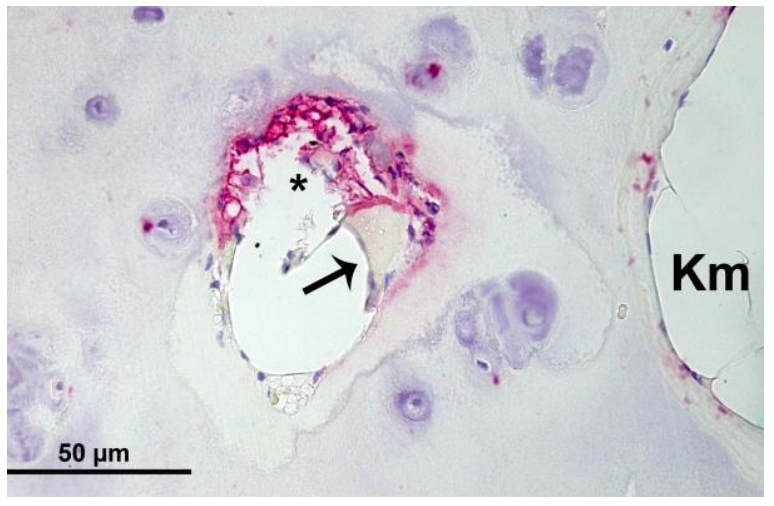

Abbildung 3.8: Kleines Blutgefäß mit RGS-5-positivem Stroma im subchondralen Knochen. Vierhundertfache Vergrößerung mit Hämalaun-Gegenfärbung. An das kleine Blutgefäß grenzt RGS-5-positives Stroma (*). Der Pfeil zeigt auf das RGS-5-negative Endothel. Rechts im Bild sieht man den Knochenmarksbereich $(\mathbf{K m})$. 
Im Knorpel mit vorangeschrittener Osteoarthrose zeigten sich, wie auch bei der Untersuchung mit dem PDGFR- $\beta$-Antikörper, RGS-5-positive Cluster sowohl an der Knorpeloberfläche als auch in tieferen Schichten des Knorpels (Abbildung 3.9). Abbildung 3.12a zeigt zum Vergleich die Knorpeloberfläche eines weitestgehend intakten Gelenkknorpels. Hier wurden keine RGS-5-positiven Zellen beobachtet.

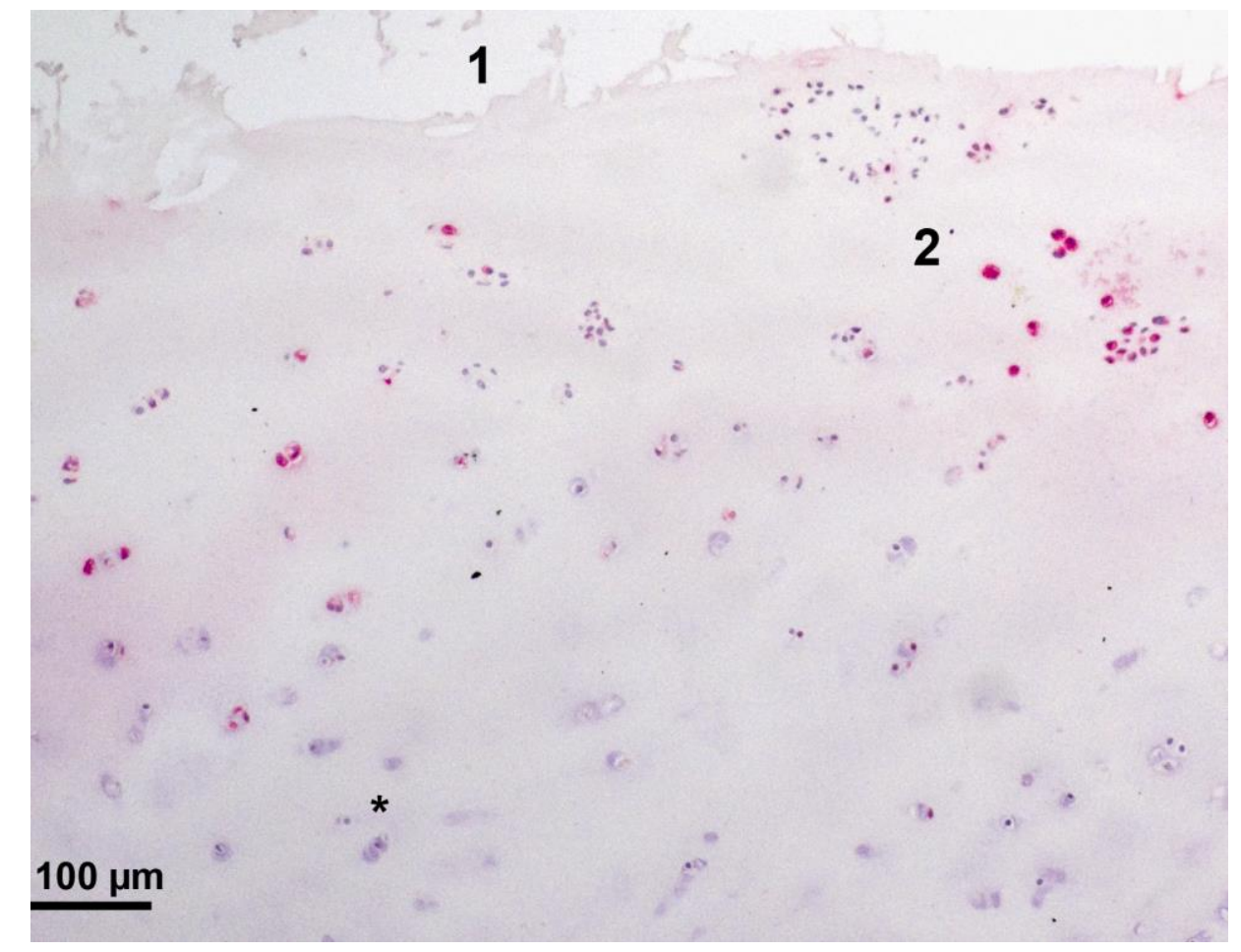

Abbildung 3.9: Gelenkknorpel mit vorangeschrittener Osteoarthrose und RGS-5positiven Zellclustern. Hundertfache Vergrößerung und Hämalaun-Gegenfärbung. Die Knorpeloberfläche weist Fissuren auf (1). Sowohl an der Oberfläche als auch in den tieferen Schichten des Knorpels können RGS-5-positive Zellcluster beobachtet werden (2). Mit (*) wurden RGS-5-negative Knorpelzellen markiert.

\subsubsection{Tie-2}

Im mikroskopisch gesunden Knorpeln zeigte sich an der Knorpeloberfläche, im Gegensatz zu den Untersuchungen mit den Antikörpern PDGFR- $\beta$ und RGS-5, Zellen, die Tie-2positiv waren (siehe Abbildung 3.10 und 3.12). 


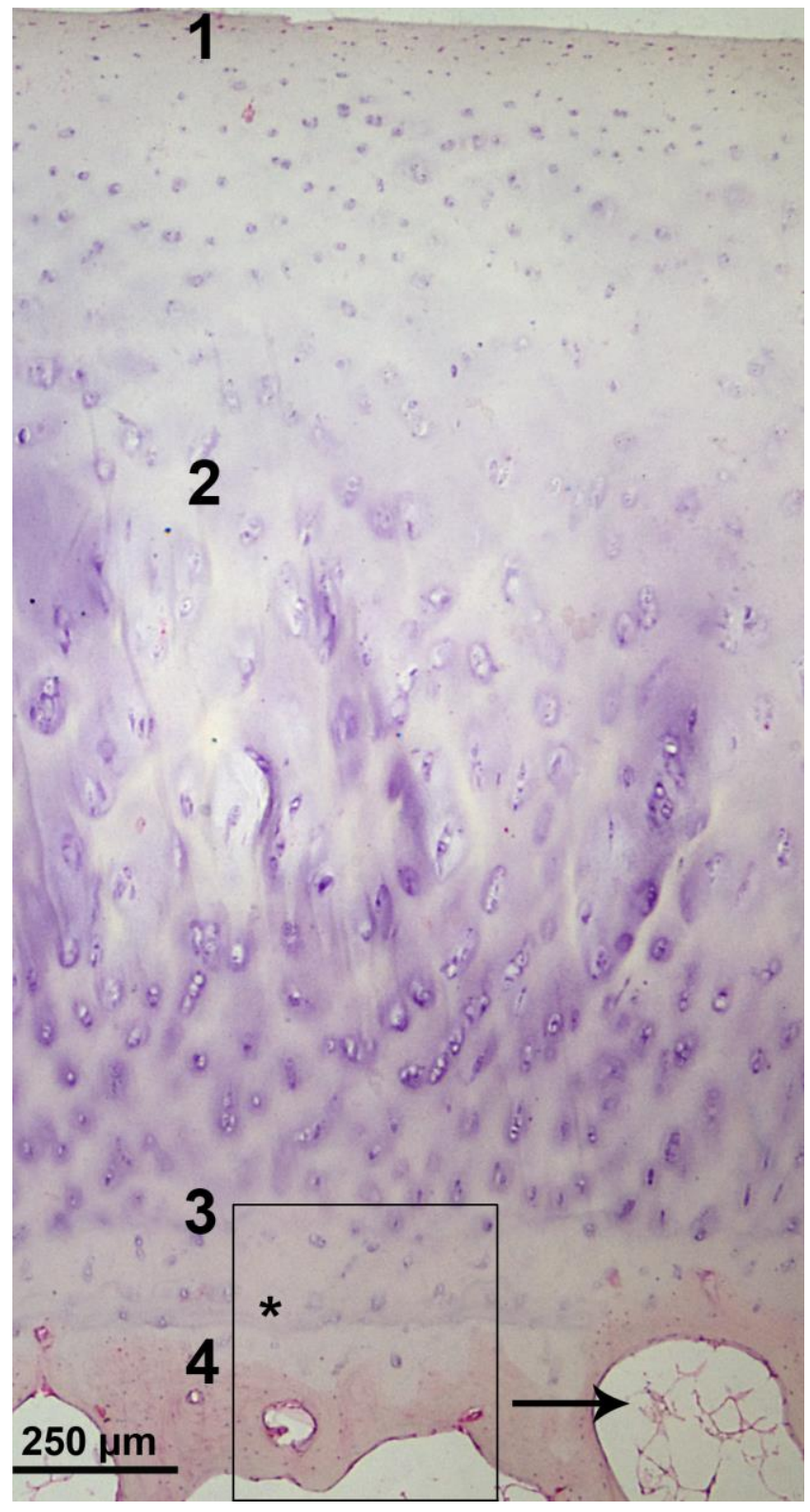

Abbildung 3.10: Tie-2-Expression im gesunden Knorpel. Hundertfache Vergrößerung und Gegenfärbung mit Hämalaun. An der Knorpeloberfläche zeigen sich Tie-2-positive Zellen (1). In tieferen Schichten zeigen sich keine Tie-2-positiven Zellen (2). Die Tidemark ist intakt und es sind keine Einsprossungen vorhanden (3). Im subchondralen Knochen können Tie-2-positive Zellen entlang des Knochens, im Knochenmarksbereich und bei Kapillaren beobachtet werden (4). Der subchondrale Knochen zeigt eine Tie-2-positive Reaktion. Der mit (*)-markierte Bereich wird in Abbildung 3.11 besprochen. Der Pfeil zeigt auf Tie-2-positives Knochenmarkstroma.

In den darunterliegenden Knorpelschichten konnten keine Tie-2-positiven Zellen beobachtet werden. Im Bereich des subchondralen Knochens zeigten sich Tie-2-positive Zellen entlang des Knochens zum Knochenmarksraum hin und im Stroma des Knochenmarks (Abbildung 3.10). Das Endothel der Kapillaren im subchondralen Knochen zeigte sich Tie2-positiv (Abbildung 3.11). 


\begin{abstract}
Abbildung 3.11: Teilausschnitt * aus Abb. 3.10. Die Tie-2-Expression im subchondralen Knochen. Mit $\left(^{*}\right)$ wurde eine Kapillare gekennzeichnet, die ein Tie-2-positives Endothel zeigt. Der Pfeil weist auf Tie-2-positive Zellen entlang des subchondralen Knochens hin.
\end{abstract}
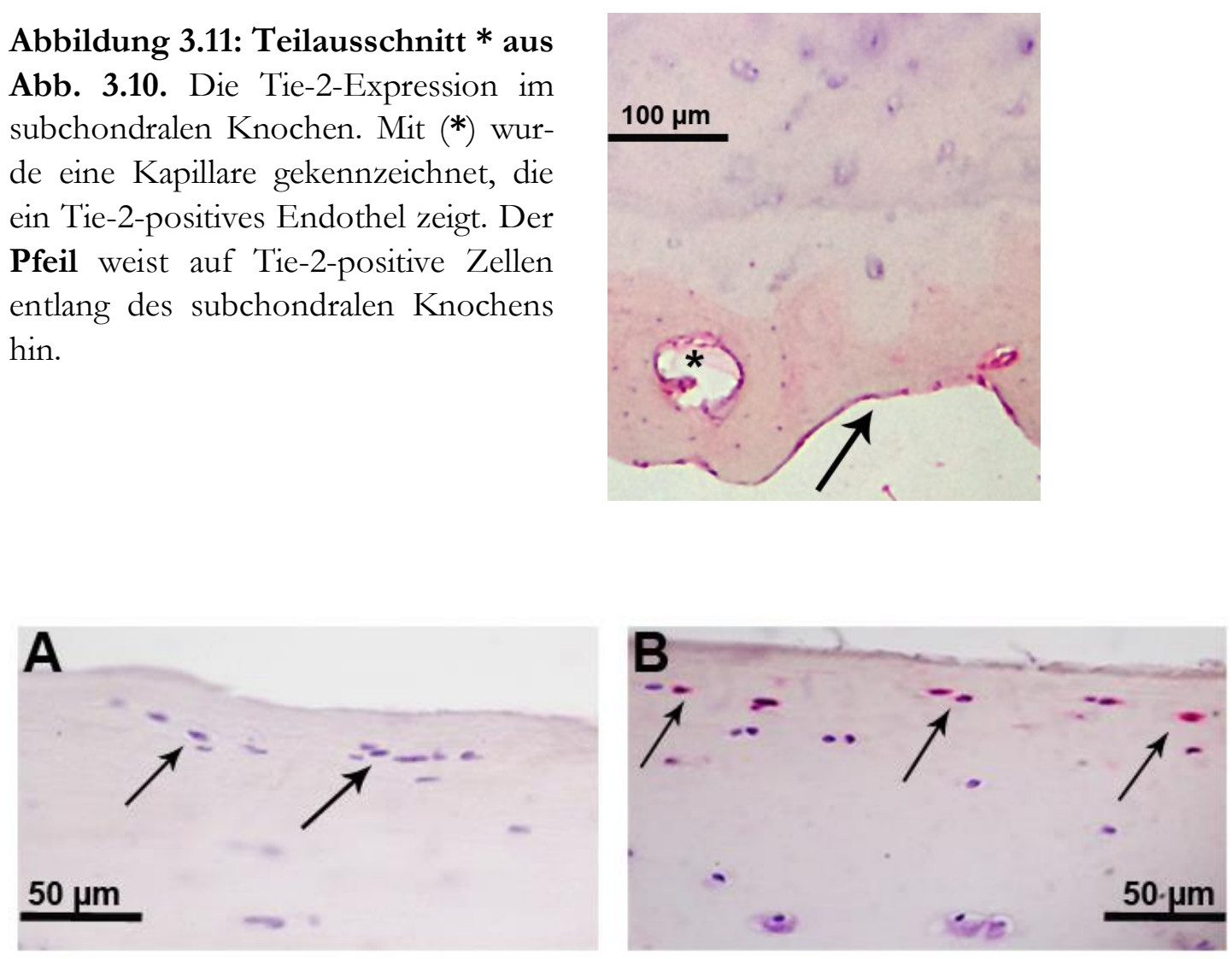

Abbildung 3.12: Tie-2-positive Zellen an der Knorpeloberfläche eines mikroskopisch gesunden Knorpels. Jeweils vierhundertfache Vergrößerung und HämalaunGegenfärbung. Die Knorpelprobe in Teilabbildung A wurde auf eine RGS-5-Expression hin untersucht. Die Pfeile zeigen auf die Zellen an der Knorpeloberfläche, die RGS-5negativ sind. In den histologischen Untersuchungen wurden bei mikroskopisch gesundem Kniegelenkknorpel keine PDGFR- $\beta$ - und RGS-5-positiven Zellen an der Knorpeloberfläche beobachtet. In Teilabbildung $\mathbf{B}$ zeigen die Pfeile auf Tie-2-positive Zellen an der Knorpeloberfläche. Darunter erkennt man im Gegensatz dazu Tie-2-negative Knorpelzellen.

In den frühen Stadien der Osteoarthrose bei noch intakter Tidemark, daher ohne beobachtete Einsprossungen, konnte in den oberflächennahen Knorpelschichten eine deutliche Fibrillenbildung beobachtet werden (Abbildung 3.14). Entlang dieser Fibrillen zeigten sich Tie-2-positive Zellen auch in tieferen Knorpelschichten (vergleiche Abbildung 3.12 und 3.13). Mit Voranschreiten der Pathogenese traten Tie-2-positive Einsprossungen im Knorpel auf (Abbildung 3.13 und 3.14). Im Bereich des subchondralen Knochens zeigte sich, wie bei den Untersuchungen mit den PDGFR- $\beta$ - und RGS-5-Antikörpern, eine Zunahme an Stroma zwischen den Knochentrabekeln, das Tie-2-positiv war (Abbildung 3.14). Ebenfalls traten in späteren Stadien der Osteoarthrose Tie-2-positive Cluster in den oberflächennahen Knorpelschichten auf (3.16). 

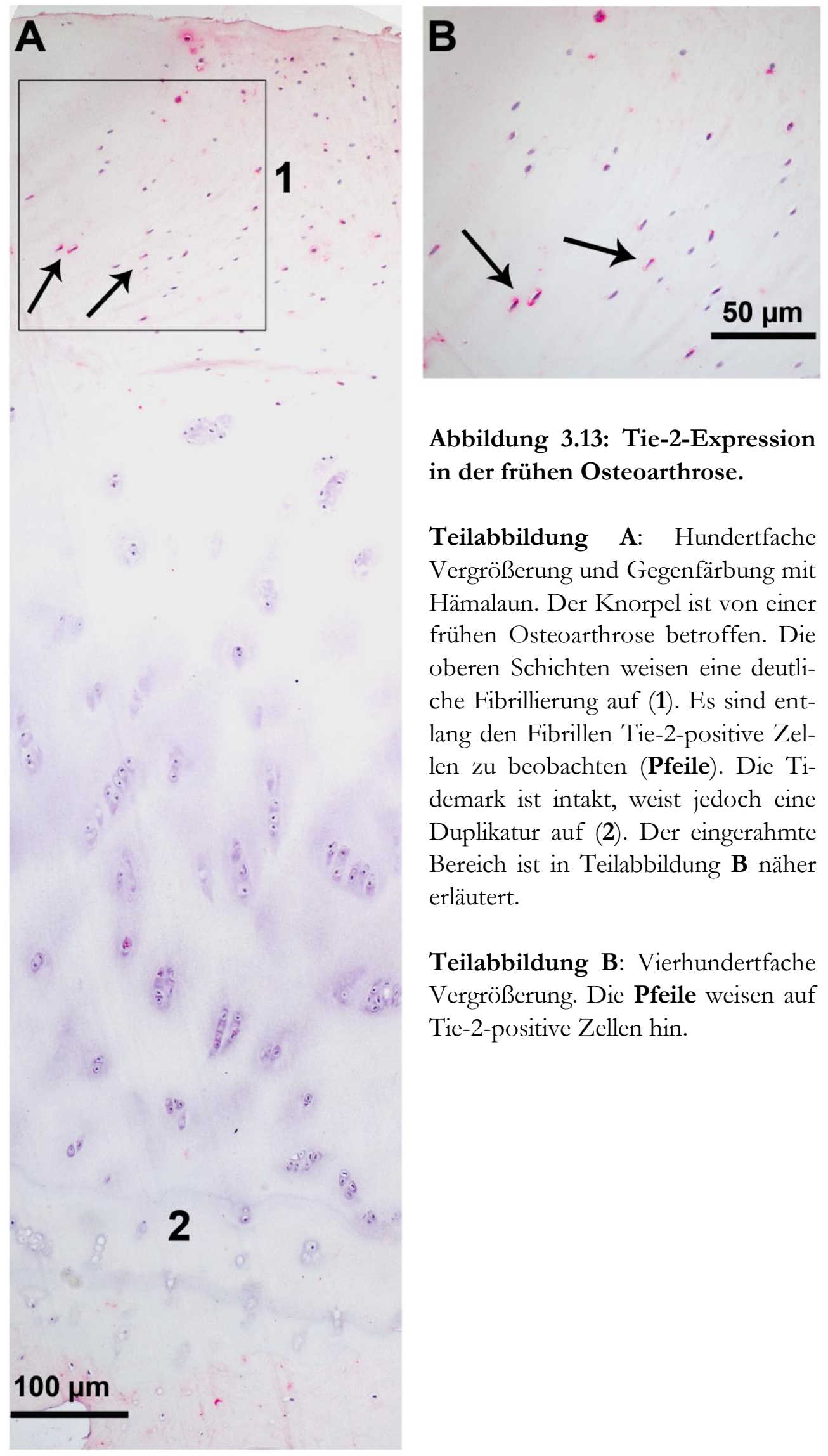

Abbildung 3.13: Tie-2-Expression in der frühen Osteoarthrose.

Teilabbildung A: Hundertfache Vergrößerung und Gegenfärbung mit Hämalaun. Der Knorpel ist von einer frühen Osteoarthrose betroffen. Die oberen Schichten weisen eine deutliche Fibrillierung auf (1). Es sind entlang den Fibrillen Tie-2-positive Zellen zu beobachten (Pfeile). Die Tidemark ist intakt, weist jedoch eine Duplikatur auf (2). Der eingerahmte Bereich ist in Teilabbildung $\mathbf{B}$ näher erläutert.

Teilabbildung B: Vierhundertfache Vergrößerung. Die Pfeile weisen auf Tie-2-positive Zellen hin. 


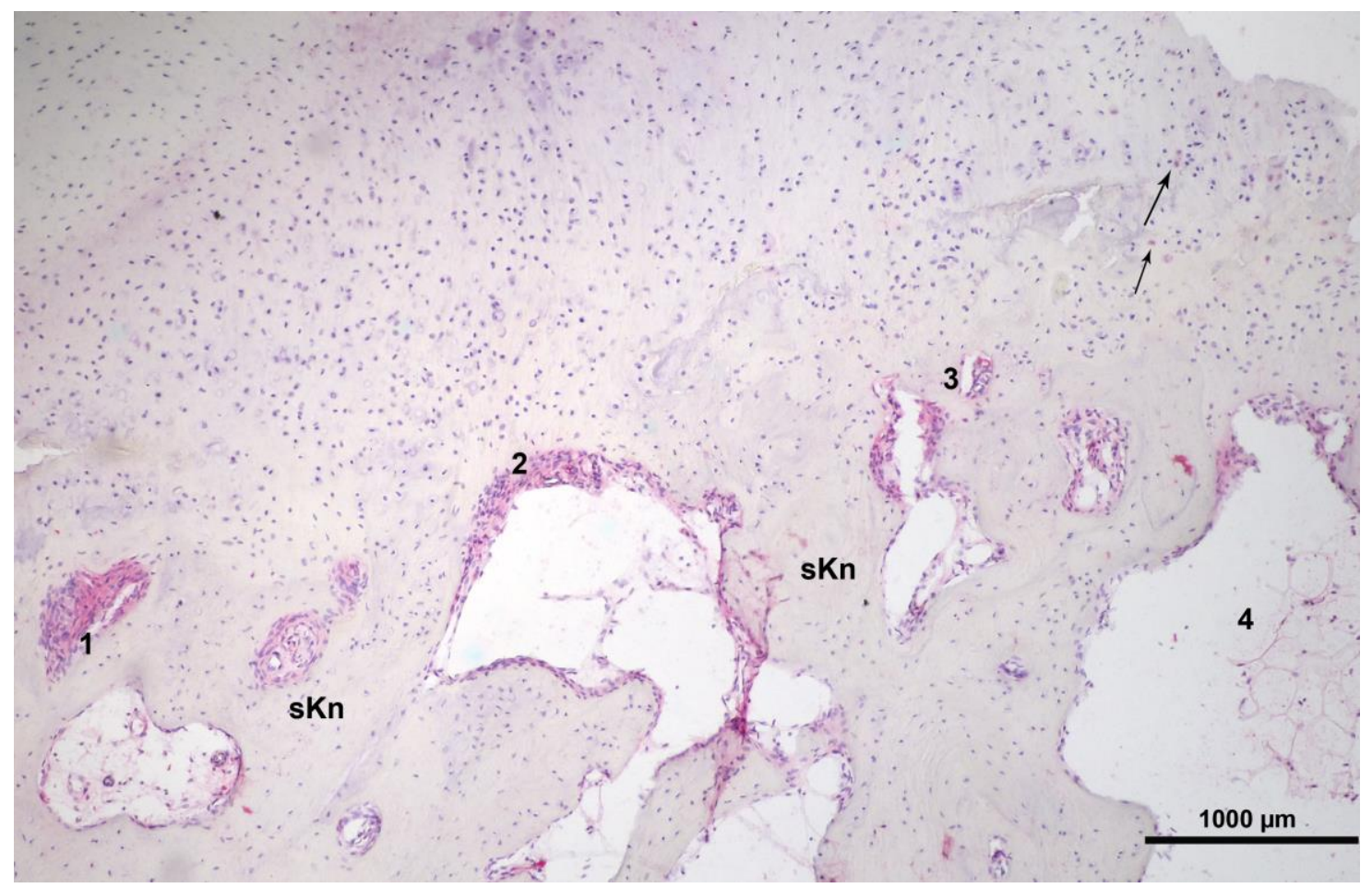

Abbildung 3.14: Untersuchung der Tie-2-Expression bei fortgeschrittener Osteoarthrose. Hundertfache Vergrößerung mit Hämalaun-Gegenfärbung. Im Bereich des subchondralen Knochens (sKn) zeigen sich Bereiche mit einer hohen Dichte an Tie-2positiven Zellen (1). Das an den subchondralen Knochen angrenzende Stroma des Knochenmarksbereichs ist deutlich vermehrt und Tie-2-positiv (2). Es treten Tie-2-positive Einsprossungen in den Knochen auf (3). Das Knochenmarkstroma weist eine leichte Tie2-Positivität auf (4). Die Pfeile zeigen auf vereinzelte Tie-2-positive Zellen im Knorpel.

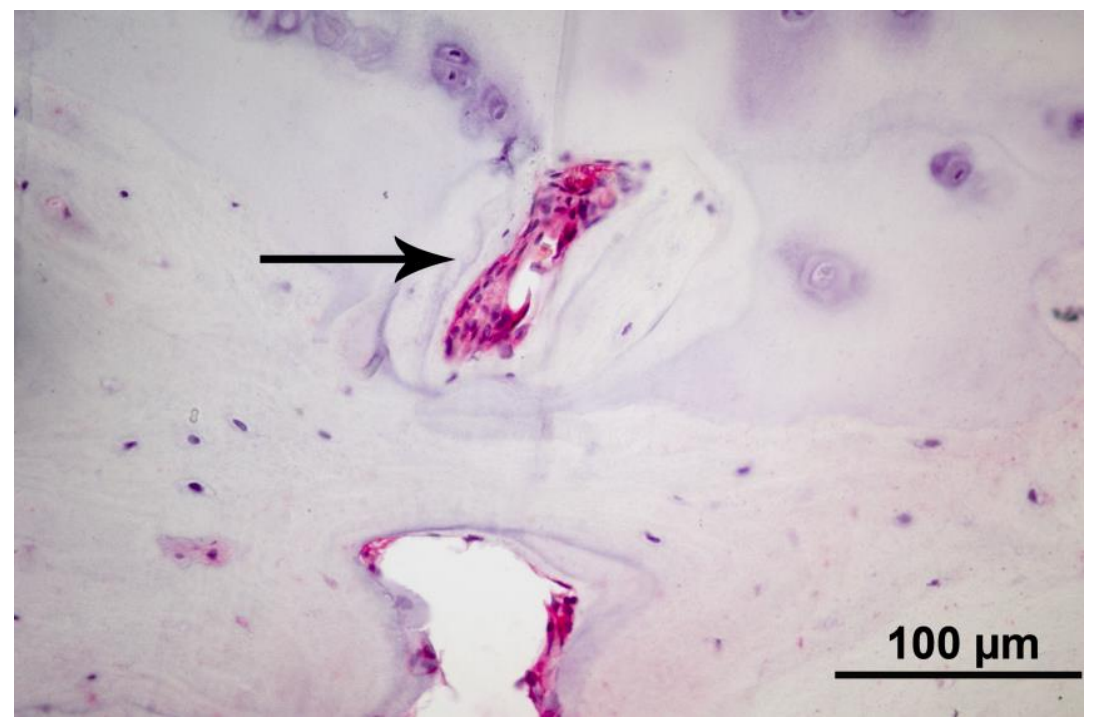

3.15: Tie-2-positive Einsprossung in den Knorpel. Vierhundertfache Vergrößerung und Gegenfärbung mit Hämalaun. Der Pfeil zeigt auf die Einsprossung. Darunter liegt der subchondrale Knochen. 


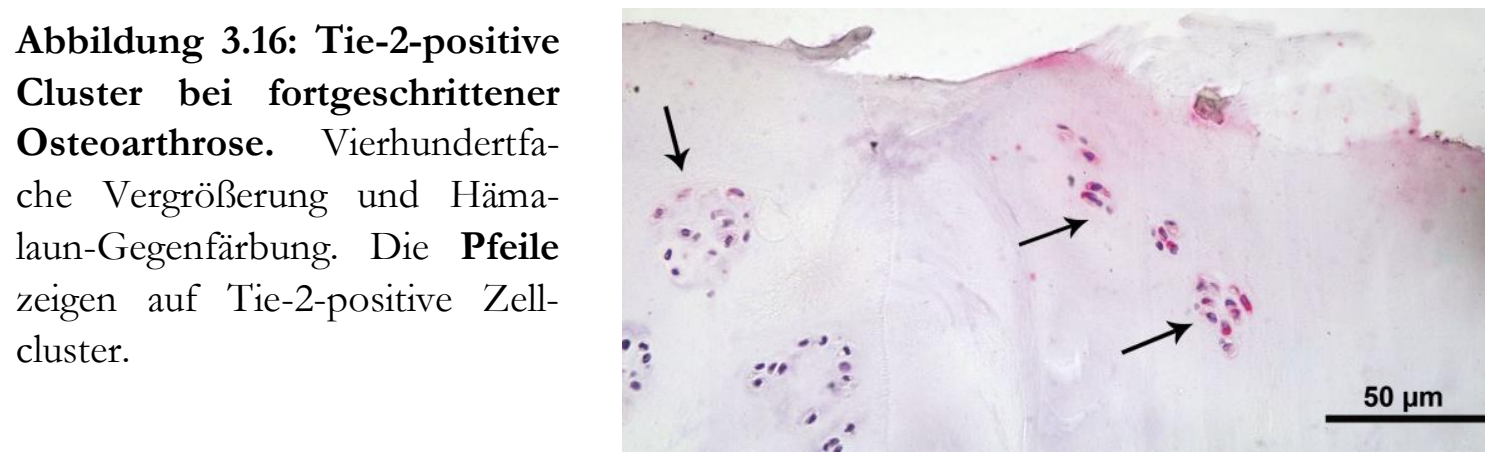

\subsection{Untersuchung von CPCs in Hinblick auf Perizyten- und mesenchymale Stammzellmarker}

\subsubsection{Durchflusszytometrie}

Es wurden CPCs von insgesamt 15 Patienten in den Passagen (kurz: P) P0, P1, P2, P4, P6, P8 und P10 mittels Durchflusszytometrie untersucht. Die Angaben in Prozent geben den ermittelten Mittelwert der Ergebnisse der Patienten in den jeweiligen Passagen an. In Bezug auf die Antigene PDGFR- $\beta$ und Tie-2 zeigte sich eine Tendenz zur Abnahme der Positivität über die Passagen. In der Passage P0 waren 28,0\% der Zellen positiv für das Antigen PDGFR- $\beta$, während in den späteren Passagen P8 1,93\% und in P10 1,6\% der Zellen für das Antigen positiv waren (Abbildung 3.17). Eine ähnliche Tendenz fand sich in Bezug auf das Antigen Tie-2. 12,0\% der Zellen waren in der Passage P0 positiv für Tie-2 und die Positivität nahm über die Passagen ab. In P8 waren 3,4\% der Zellen positiv für Tie-2 und in P10 0,8\% (Abbildung 3.17).

Die Ergebnisse für den mesenchymalen Stammzellmarker Stro-1 zeigten den höchsten Wert in der Passage P4 mit im Durchschnitt 68,3\% positiven Zellen. In den anderen Passagen waren die Zellen im Durchschnitt zu 49,9\% positiv für Stro-1 (Abbildung 3.17). Die Ergebnisse für den Perizytenmarker RGS-5 stellten sich relativ stabil über die Passagen dar mit im Durchschnitt 73,1\% positiven Zellen (Abbildung 3.17). Bei den Ergebnissen in der Durchflusszytometrie (siehe Abbildungen 3.17 und 3.18) traten hohe Standardabweichungen auf, auf die in der anschließenden Diskussion noch einmal eingegangen wird. 


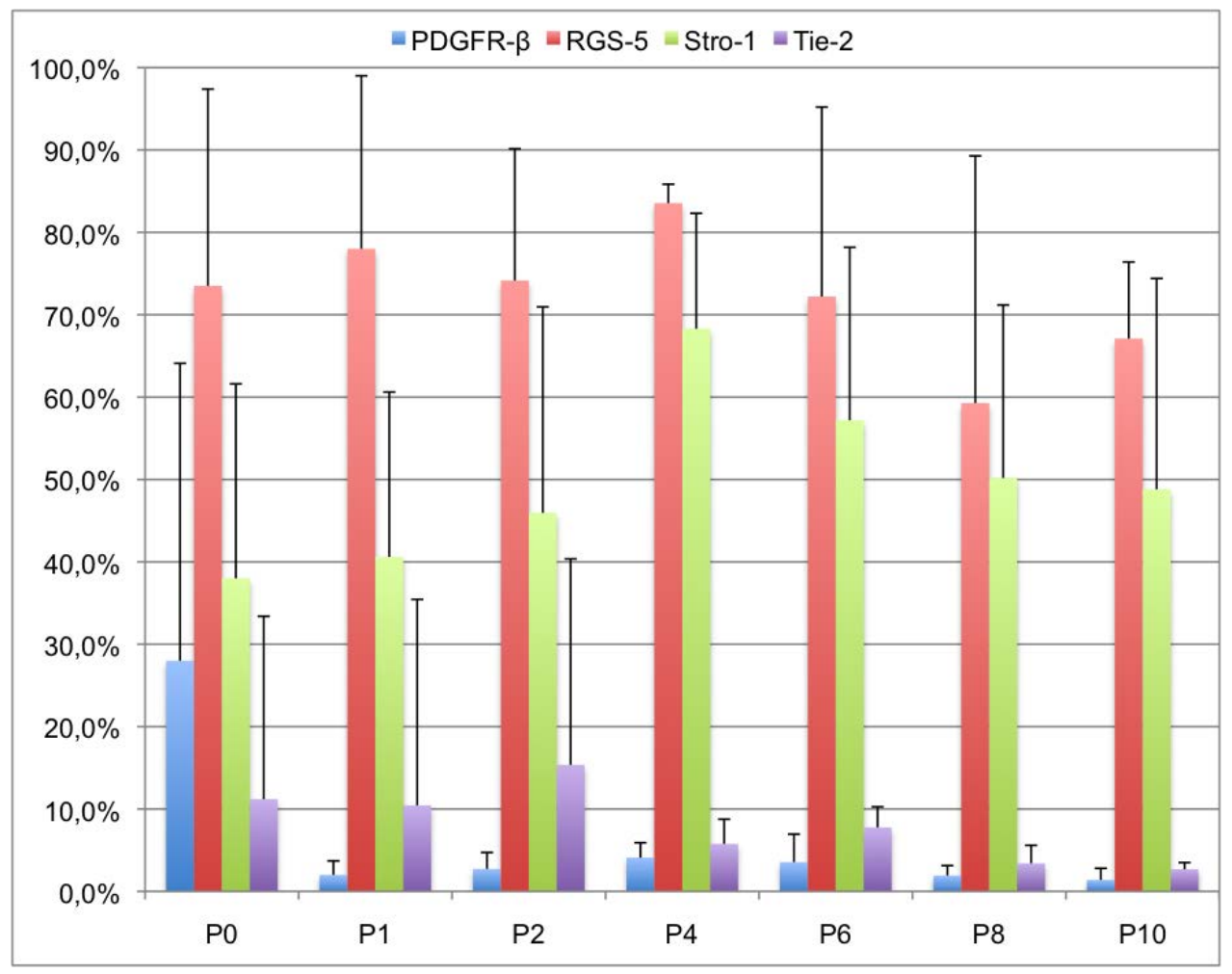

Abbildung 3.17: Durchflusszytometrische Untersuchung der CPCs auf Perizytenund mesenchymale Stammzellmarker. Es ist die durchschnittliche Anzahl der Zellen, die positiv für das jeweilige Antigen sind, in Prozent angegeben. Die CPCs zeigen sich in der Passage (P) P0 zu 28,0\% positiv für PDGFR- $\beta$ und zu 11,2\% positiv für Tie-2 und es findet sich eine leicht absteigende Tendenz über die Passagen. Relativ konstant über die Passagen sind die untersuchten CPCs im Durchschnitt zu 73,5\% für RGS-5 positiv. In Bezug auf den mesenchymalen Stammzellmarker Stro-1 sind die CPCs mit Ausnahme der Passage P4 im Durchschnitt zu 49,9\% positiv. In der Passage P4 zeigen sich 68,3\% der CPCs für Stro-1 positiv. Es sind hohe Standardabweichungen zu verzeichnen.

Es wurden die CPCs zusätzlich auf die Expression von CD 117 und in den Passagen P1 und P2 auf den Endothelzellmarker CD 31 hin untersucht. Im Durchschnitt waren 1,5\% der CPCs positiv für CD 117 (Abbildung 3.18). In Bezug auf den Endothelzellmarker CD 31 zeigten sich in der Passage P1 0,1\% der CPCs und in Passage P2 0,2\% positiv für das Antigen (Abbildung 3.18).

Eine Nebenbeobachtung wurde im Diagramm „Passagenintervalle“ basierend auf den Intervallen zwischen den einzelnen Passagen von CPCs dreier Patienten (Fall \#528, \#529 und \#537) zusammengefasst (Abbildung 3.19). Es fiel auf, dass es in den frühen Passagen durchschnittlich zehn beziehungsweise elf Tage bis zu einer 80\%igen Konfluenz dauerte und ab Passage P8 die Intervalldauer zwischen den Passagen auf bis zu 25 Tage zum Ende der Beobachtungsphase anstieg (Abbildung 3.19). 


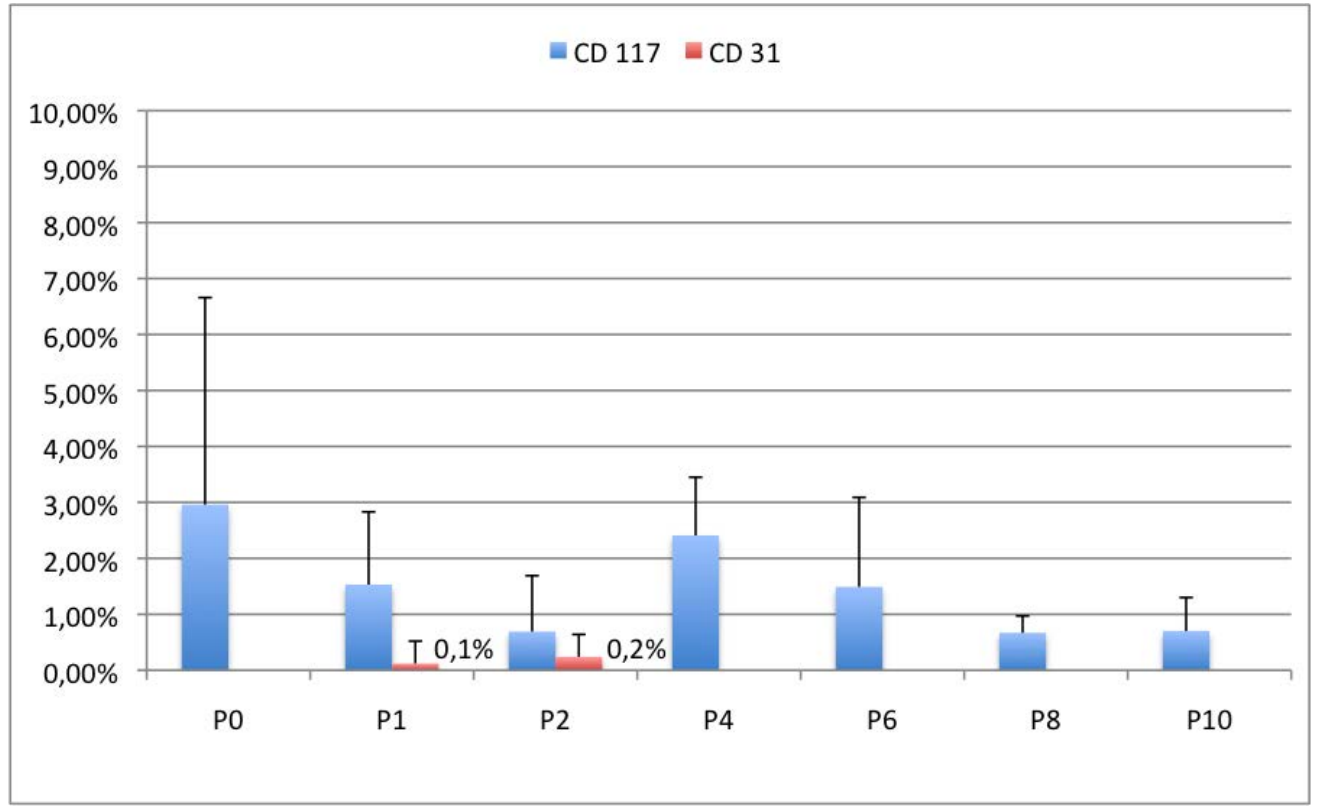

Abbildung 3.18: Durchflusszytometrische Untersuchung in Bezug auf die Antigene CD 31 und CD 117. Es ist die durchschnittliche Anzahl der Zellen, die positiv für das jeweilige Antigen sind, in Prozent angegeben. Im Durchschnitt waren die untersuchten CPCs zu 1,5\% für CD 117 positiv. Die höchsten Werte wurden in Passage P0 beobachtet. In den Passagen P1 und P2 wurden CPCs auf den Endothelmarker CD 31 getestet. Die Ergebnisse für CD 31 sind neben den roten Säulen dem Diagramm zu entnehmen.

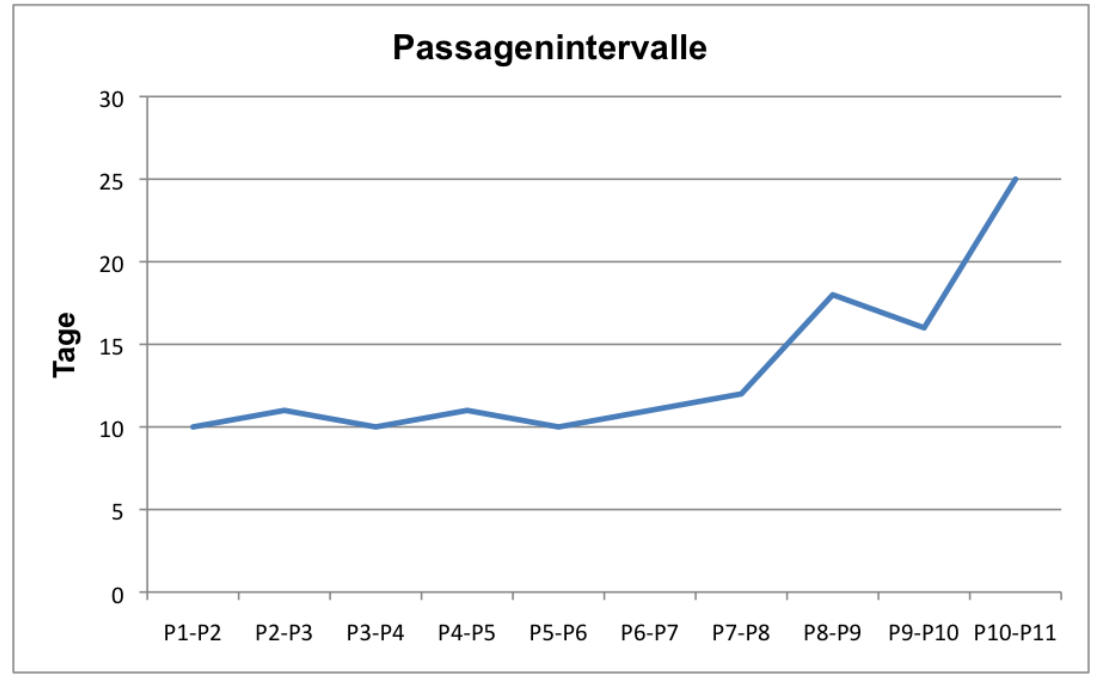

Abbildung 3.19: Passagenintervalle dreier CPC-Populationen. Die Zeitdauer zwischen den Passagen steigt ab Passage P8 deutlich an.

\subsubsection{Genexpressionsanalyse von CPCs über die Passagen}

Es wurde die isolierte mRNA von CPCs auf die Expression von PDGFR- $\beta$, RGS-5, Tie-2 und aSMA über die Passagen hin untersucht. Je Passage und Gen wurde die in cDNA um- 
geschriebene mRNA in drei Durchläufen mit jeweils drei Ansätzen untersucht. In Abbildung 3.20 wurden die Mittelwerte der ermittelten ct-Werte und die jeweiligen Standardabweichungen je Passage und Gen dargestellt.

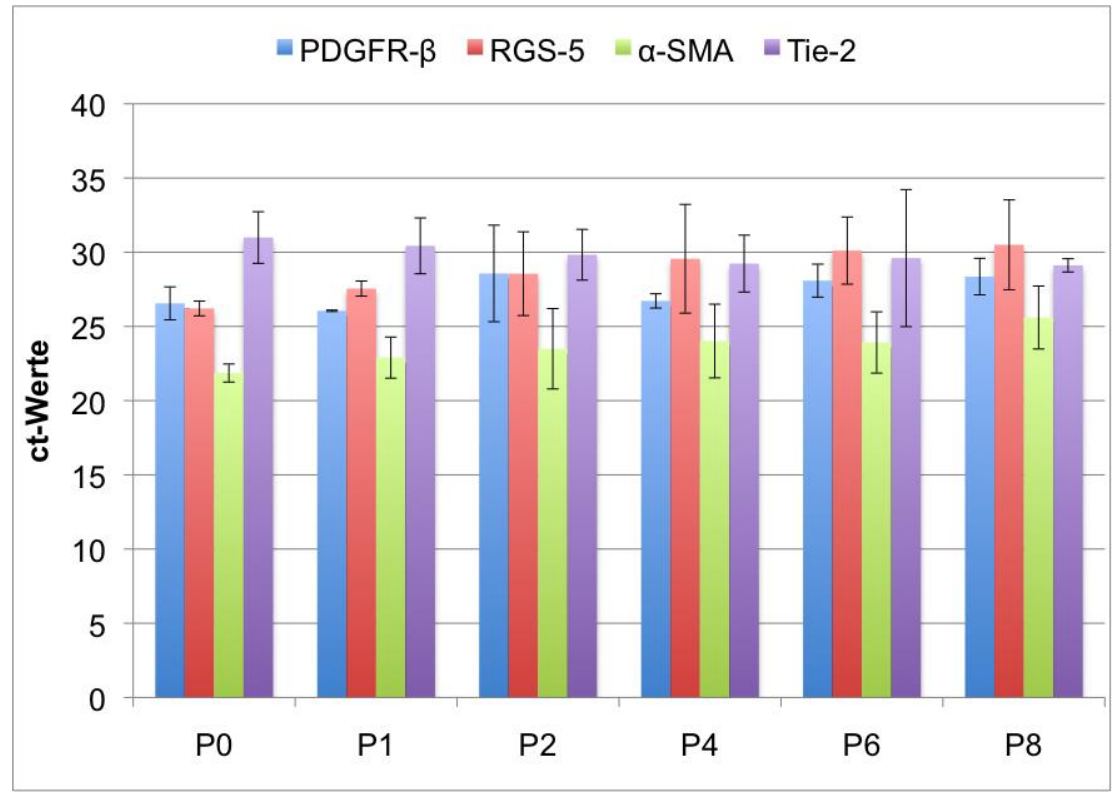

Abbildung 3.20: PCR-Untersuchung über die Passagen. Dargestellt sind die gemittelten ct-Werte nach drei Durchläufen je Passage und zugehörigen Standardabweichungen. Die ct-Werte der einzelnen Gene zeigten sich relativ konstant über die Passagen.

Bei der Untersuchung der Gene zeigten sich über die Passagen relativ konstante ct-Werte. Je niedriger der ct-Wert, desto höher war die korrespondierende Konzentration an mRNA in der Ausgangsprobe.

Es wurden im nächsten Schritt die ct-Werte der Passagen P1 bis P8 unter Bezug auf das house keeping gene $\beta 2-$ Mikroglobulin gegen die ct-Werte der Passage P0 normalisiert, um die Ratio nach Pfaffl (Pfaffl 2001) zu berechnen (Abbildung 3.21).

Die Effizienz der einzelnen Primer wurde bei der Etablierung der Primer im Labor über eine Verdünnungsreihe ermittelt. Der relative Expressionsunterschied über die Passagen zeigte bei den Genen PDGFR- $\beta$, RGS-5 und aSMA eine abnehmende Tendenz der Expression im Vergleich zu Tie-2, bei dem eine eher zunehmende Genexpression über die Passagen beobachtet wurde (Abbildung 3.21). Interessanter Weise wurde in der durchflusszytometrischen Untersuchung eine Abnahme der Tie-2-positiven Zellen über die Passagen hin beobachtet (Abbildung 3.17). 


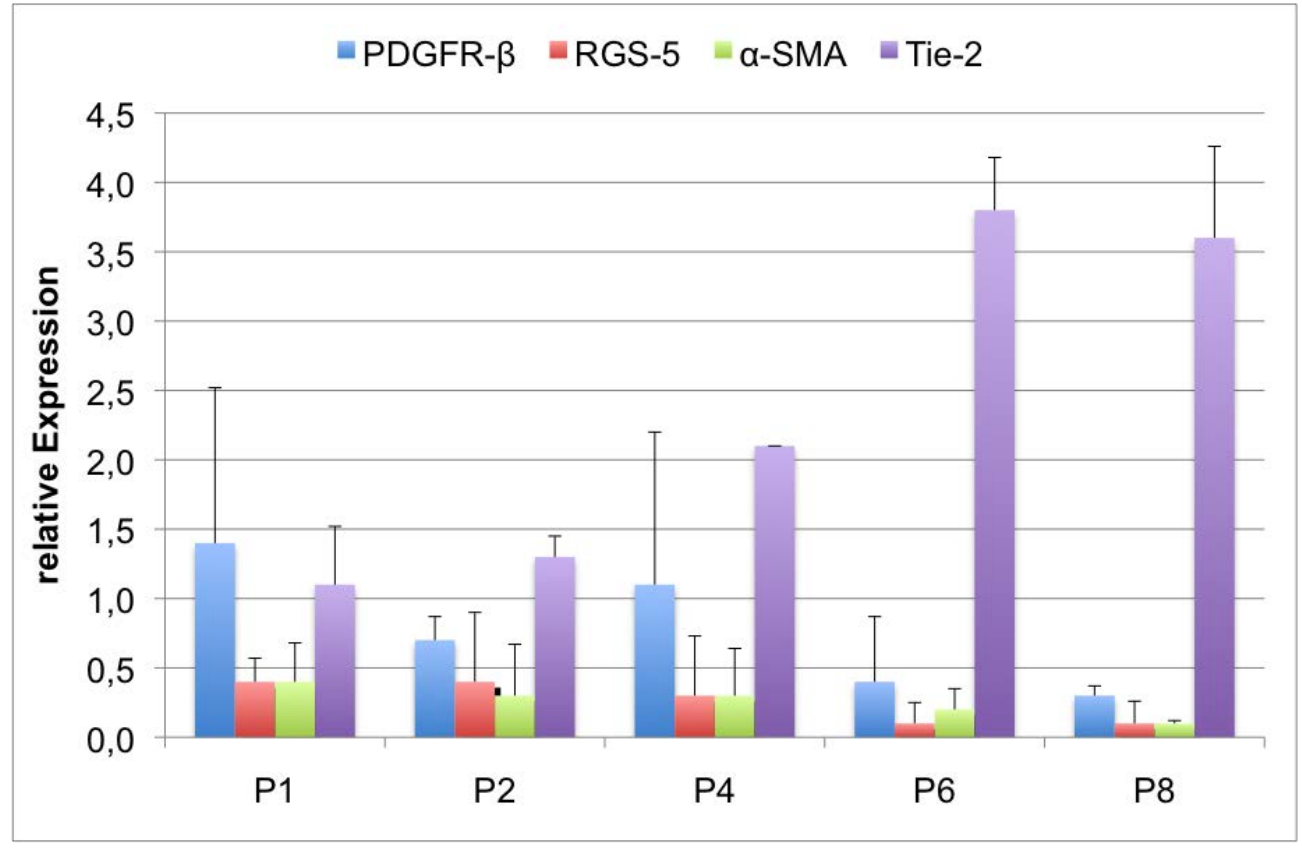

Abbildung 3.21: Relative Expression der untersuchten Gene über die Passagen. Normalisierte Werte nach Pfaffl (2001). Während bei den Genen PDGFR- $\beta$, RGS-5 und aSMA sich in den Passagen P1 bis P8 eine Tendenz zur Expressionsabnahme im Vergleich zu Passage P0 andeutet, zeigt sich in Bezug auf das Gen Tie-2 eine Tendenz zur erhöhten Genexpression über die Passagen. Die Standardabweichung wurde aus Übersichtsgründen nur nach oben abgetragen, gilt jedoch auch im negativen Bereich.

\subsubsection{Western Blot}

Es wurden CPCs von drei Patienten (\#334, \#340 und \# 346) in Hinblick auf die Expression von PDGFR- $\beta$, RGS-5 und Tie-2 auch mit Hilfe der Western-Blot-Methode untersucht. Die CPCs befanden sich in einer frühen Passage (Passage zwei und drei) und zeigten sich positiv für PDGFR- $\beta$, RGS-5 und Tie-2 (Abbildung 3.22-3.24). Bei der Untersuchung mit dem PDGFR- $\beta$-Antikörper zeigte sich die Bande bei $180 \mathrm{kDa}$ (Abbildung 3.22) und korrespondierte mit den Herstellerangaben und der Literatur (BD Pharmingen; He et al. 2015).

Bei der Untersuchung mit dem RGS-5-Antikörper zeigten sich drei Banden: bei 170 kDa, bei knapp über $70 \mathrm{kDa}$ und bei $40 \mathrm{kDa}$ (Abbildung 3.23). Im Diskussionsteil 4.2 wird auf dieses Phänomen genauer eingegangen. Die Bande bei 40 kDa dürfte dem RGS-5-Molekül zuzuordnen sein.

In der Western-Blot-Untersuchung der CPCs mit dem Tie-2-Antikörper stellte sich eine Bande bei circa 190 kDa dar (Abbildung 3.24). Laut Hersteller des Antikörpers (Santa Cruz Biotechnology, Texas, USA) und Literaturangaben (siehe zum Beispiel Makinde und Agrawal 2011) beträgt das Molekulargewicht von Tie-2 145 kDa. 
Abbildung 3.22: Western BlotUntersuchung auf eine PDGFR- $\beta$ Expression hin. Antikörperverdünnung 1:250 bei einer Belichtungszeit von 10 min. Die Bande, die durch die Antigen-Antikörper-Reaktion mit dem PDGFR- $\beta$-Antikörper bedingt ist, zeigt sich bei $180 \mathrm{kDa}$.

Links im Bild ist die Proteinleiter zu erkennen unter Angabe der vom Hersteller definierten Molekulargewicht-Schritte. Die Bande bei $55 \mathrm{kDa}$ ist unspezifisch.

\section{Abbildung 3.23: RGS-5-} Expression im Western-Blot. Antikörperverdünnung 1:250 und 10 min Belichtung. Zu erkennen sind drei Banden bei $40 \mathrm{kDa}, 80 \mathrm{kDa}$ und $150 \mathrm{kDa}$. Die Bande bei $40 \mathrm{kDa}$ wird dem RGS-5-Molekül zugeordnet (*). Auf das Auftreten dreier Banden wird in der Diskussion genauer eingegangen.

Abbildung 3.24: Western-BlotUntersuchung mit dem Tie-2Antikörper. Antikörperverdünnung 1:200 und 5 min Belichtungszeit. Bei circa $190 \mathrm{kDa}$ hat der Tie-2Antikörper mit dem Antigen reagiert.

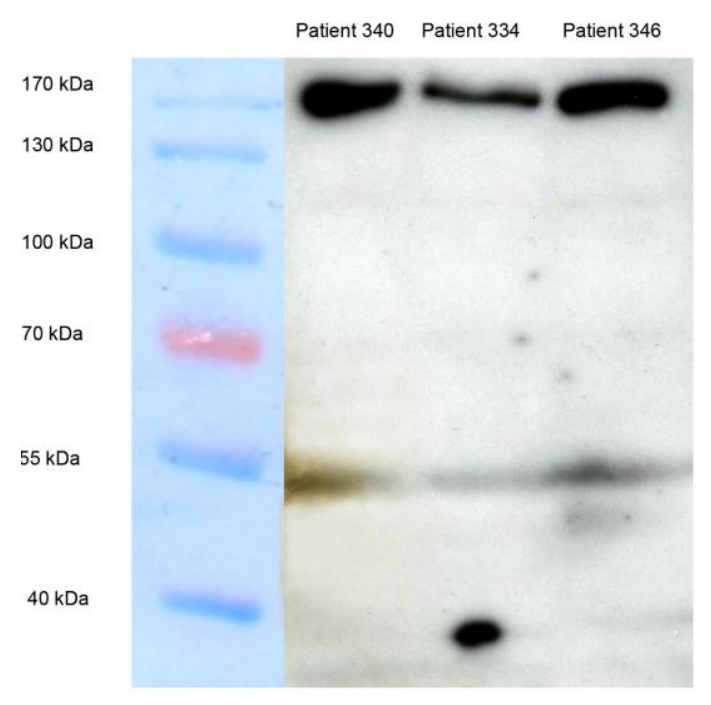

Western Blot PDGFR-ß

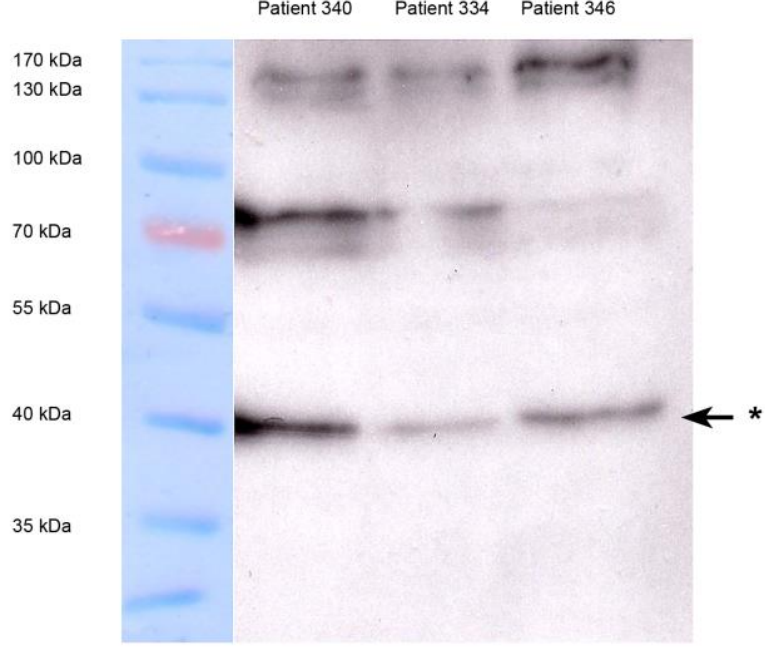

Western Blot für RGS5

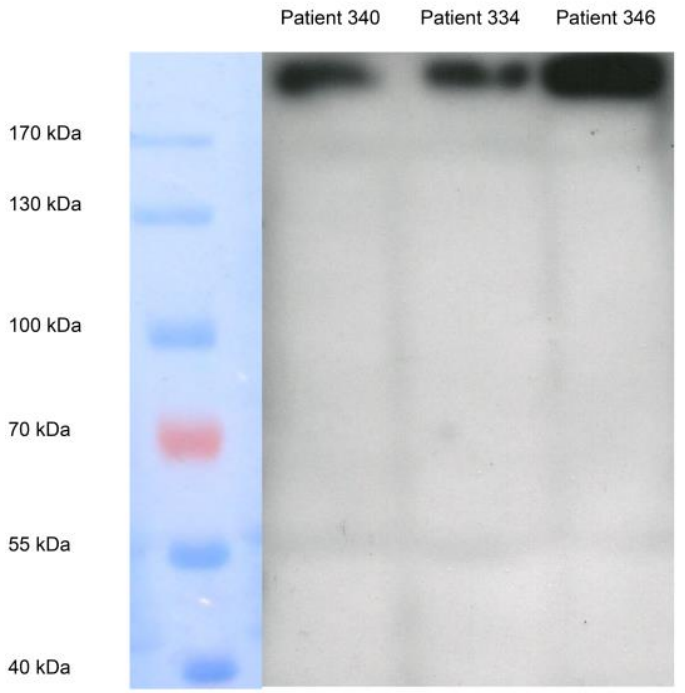

Western Blot Tie-2 


\subsection{Migrationsassay}

Im Rahmen dieser Arbeit wurden CPCs von insgesamt sieben Patienten im Rahmen von Migrationassay-Untersuchungen getestet. Je Zytokin und Konzentration wurden mehrere Durchläufe mit jeweils drei Ansätzen durchgeführt. Es wurden Entzündungsmediatoren, IL-6, IL-8, IL-17 und TNF-a, und die Wachstumsfaktoren VEGF ${ }_{165}$, PDGF-BB, Ang-1 und Ang-2, sowie die BMPs 2, 4, 6, 9, 12 und 13 in Bezug auf ihre chemotaktische Wirkung in verschiedenen Konzentrationen bei CPCs untersucht. Als Positivkontrolle diente Zellkulturmedium mit 10\% FCS-Zusatz und als Negativkontrolle wurde serumfreies (sf) Medium verwendet. Die mittels eines Fluoreszenzplattenlesers ermittelten Fluoreszenzsignale der gewanderten Zellen, die zuvor mit dem Fluoreszenzfarbstoff Calcein-AM markiert wurden und deren emittierte Fluoreszenzsignalstärke proportional zur gewanderten Zellzahl war, wurden ins Verhältnis zur gewanderten Zellzahl der Negativkontrolle gesetzt und die gewanderte Zellzahl bei der Negativkontrolle gleich eins gesetzt. Der Durchschnitt der ermittelten Vielfachen wurde in den Diagrammen mit den jeweiligen Standardabweichungen dargestellt (Abbildungen 3.25-3.27). Die ermittelten Mittelwerte wurden mit dem t-Test für zwei verbundene Stichproben und der Software SPSS statistics (25.0, IBM, USA) statistisch geprüft, ein $\mathrm{p}$-Wert $<0,05$ wurde als statistisch signifikant und $\mathrm{p}$-Werte $>0,05$ bis $<0,1$ als statistisch schwach signifikant gewertet.

Bei den Untersuchungen zeigte sich bei der Positivkontrolle eine signifikante chemotaktische Wirkung $(p=0,014)$. Es waren daher mehr als das 1,5-fache der Zellen im Vergleich zur Negativkontrolle durch die Membran des Migrationseinsatzes in Richtung der Probe gewandert (Abbildungen 3.25-3.27).

Bei den untersuchten Entzündungsmediatoren konnte bei IL-8 und IL-17 jeweils in der Konzentration $10 \mathrm{ng} / \mathrm{ml}$ eine tendenzielle Steigerung der Migrationsrate beobachtet werden, jedoch konnte die Wirkung in dieser Studie nicht signifikant nachgewiesen werden $(p=0,292$ und $p=0,258)$ (Abbildung 3.25). In abgeschwächter Form zeigte sich bei IL-6 und TNF- $\alpha$, jeweils in der Konzentration $10 \mathrm{ng} / \mathrm{ml}$, und bei IL-17 in der Konzentration $40 \mathrm{ng} / \mathrm{ml}$ eine nicht signifikante $(\mathrm{p}=0,313, \mathrm{p}=0,488$ und $\mathrm{p}=0,258)$ Tendenz zur positiven chemotaktischen Wirkung (Abbildung 3.25). IL-6 und IL-8 jeweils in der höheren Konzentration hatten keine signifikante chemotaktische Wirkung ( $p=0,885$ und $p=0,677)$ (Abbildung 3.25). TNF- $\alpha$ in der Konzentration $40 \mathrm{ng} / \mathrm{ml}$ zeigte eine signifikante Wirkung auf die Migration $(\mathrm{p}=0,005)$, jedoch ließ sich ein eher inhibitorischer Effekt in Hinblick auf die Migration der CPCs beobachten (Abbildung 3.25). 


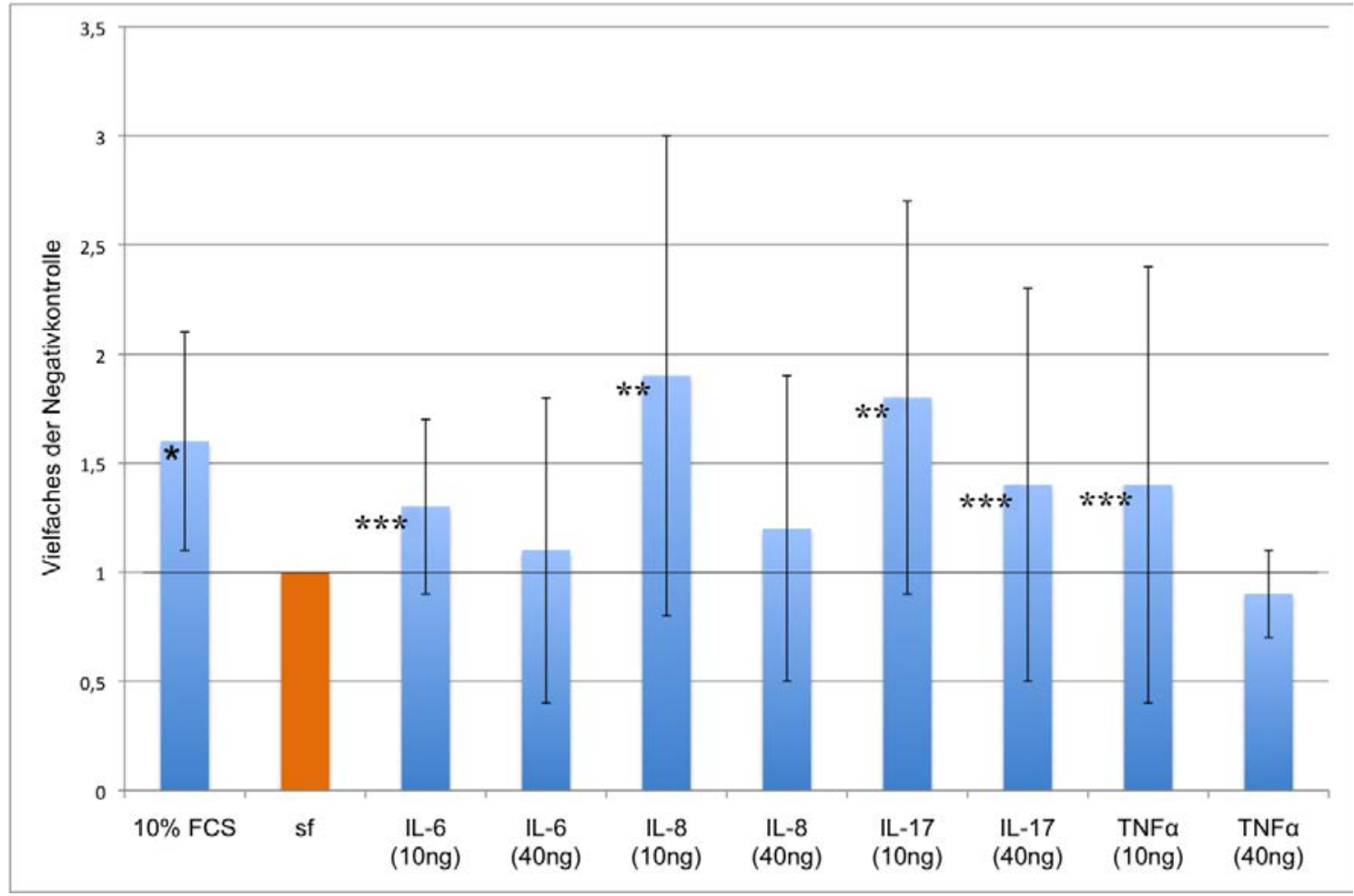

Abbildung 3.25: Migrationsassay mit Entzündungsfaktoren als Chemokine. Dargestellt sind die Ergebnisse für die Untersuchung der chemotaktischen Wirkung von IL-6, IL8, IL-17 und TNF- $\alpha$ auf CPCs in den Konzentrationen $10 \mathrm{ng} / \mathrm{ml}$ und $40 \mathrm{ng} / \mathrm{ml}$ als Säulendiagramm. Die gemessenen Werte der Proben wurden ins Verhältnis zur Negativkontrolle, serumfreies Medium (sf), gesetzt und das Vielfache in Bezug auf die Negativkontrolle als Faktor ermittelt. Der Durchschnitt der Ergebnisse wurde im Diagramm dargestellt und die jeweilige Standardabweichung eingezeichnet. Als Positivkontrolle diente Medium mit 10\% FCS $(\mathbf{1 0} \%$ FCS $)$. Bei der Positivkontrolle zeigt sich eine signifikante Steigerung $(p=0,014)$ der Migrationsrate $\left(^{*}\right)$ im Vergleich zur Negativkontrolle, bei IL-8 und IL-17 in den Konzentrationen $10 \mathrm{ng} / \mathrm{ml}$ wurde eine tendenzielle, in dieser Studie nicht signifikante $(\mathrm{p}=0,292$ und $\mathrm{p}=0,258)$, chemotaktische Wirkung beobachtet $\left.{ }^{* *}\right)$. Bei IL-6 und TNF- $\alpha$ in der Konzentration $10 \mathrm{ng} / \mathrm{ml}$ und IL-17 in der Konzentration $40 \mathrm{ng} / \mathrm{ml}$ kann ebenfalls, nicht signifikant $(p=0,313, p=0,488$ und $p=0,258)$, eine Tendenz zur Erhöhung der Migrationsrate beobachtet werden $(* * *)$. TNF- $\alpha$ in der Konzentration $40 \mathrm{ng} / \mathrm{ml}$ zeigte einen eher inhibitorischen Effekt $(p=0,005)$.

Bei der Untersuchung der chemotaktischen Wirkung der Wachstumsfaktoren VEGF ${ }_{165}$, PDGF-BB, Ang-1 und Ang-2 konnte keine signifikante Auswirkung auf die Migration der CPCs beobachtet werden (Abbildung 3.26). Am ehesten zeigte sich bei PDGF-BB in der Konzentration $40 \mathrm{ng} / \mathrm{ml}$ ein positiver, schwach signifikanter, chemotaktischer Effekt $(\mathrm{p}=0,061)$ (Abbildung 3.26). Bei Ang-1 in der Konzentration $40 \mathrm{ng} / \mathrm{ml}$ konnte im Gegensatz dazu ein eher inhibitorischer Effekt $(\mathrm{p}=0,024)$ beobachtet werden (Abbildung 3.26). 


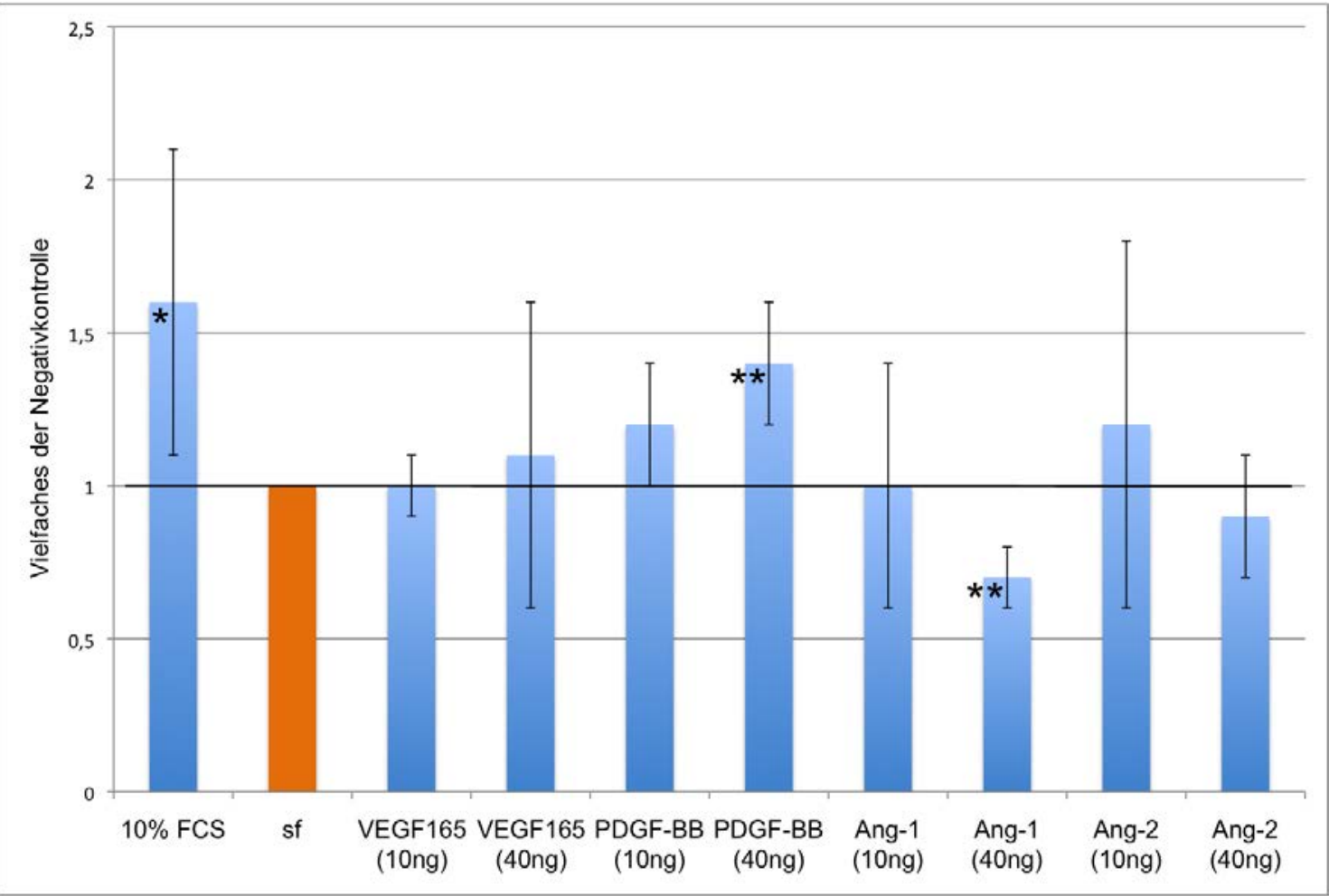

Abbildung 3.26: Migrationsassay mit Wachstumsfaktoren. Dargestellt sind die Ergebnisse für die Untersuchung der chemotaktischen Wirkung von VEGF ${ }_{165}$, PDGF-BB, Ang-1 und Ang-2 auf CPCs in den Konzentrationen $10 \mathrm{ng} / \mathrm{ml}$ und $40 \mathrm{ng} / \mathrm{ml}$ als Säulendiagramm. Die gemessenen Werte der Proben wurden ins Verhältnis zur Negativkontrolle, serumfreies Medium (sf), gesetzt. Als Positivkontrolle diente Kulturmedium mit 10\% FCS (10\% FCS). Bei der Positivkontrolle zeigt sich eine signifikante Steigerung der Migrationsrate $(p=0,014)$ (*) im Vergleich zur Negativkontrolle. Die untersuchten Wachstumsfaktoren in ihren jeweiligen Konzentrationen zeigen keinen signifikanten Einfluss auf die Migrationsrate der CPCs. Lediglich bei PDGF-BB in der Konzentration $40 \mathrm{ng} / \mathrm{ml}$ findet sich eine starke, schwach signifikante, Tendenz zur Erhöhung der Migrationsrate $(p=0,061)$, während bei Ang-1 in der Konzentration $40 \mathrm{ng} / \mathrm{ml}$ eine inhibitorische Wirkung festgestellt werden kann $(\mathrm{p}=0,024)(* *)$.

Die Wachstumsfaktoren BMP-2, -4, -6, -9, -12 und -13 wurden in der Konzentration $5 \mathrm{ng} / \mathrm{ml}$ und in Bezug auf BMP-4 und BMP-6 auch in der Konzentration $40 \mathrm{ng} / \mathrm{ml}$ untersucht (Abbildung 3.27). Bei den untersuchten BMPs zeigte sich nur bei BMP-4 in der Konzentration $5 \mathrm{ng} / \mathrm{ml}$ und in abgeschwächter Form bei $40 \mathrm{ng} / \mathrm{ml}$ eine nicht signifikante $(p=0,245$ und $p=0,383)$ Tendenz zur Erhöhung der Migrationsrate (Abbildung 3.27). Bei den anderen untersuchten BMPs konnte ebenfalls keine signifikante Erhöhung der Migrationsrate beobachtet werden (Abbildung 3.27) 


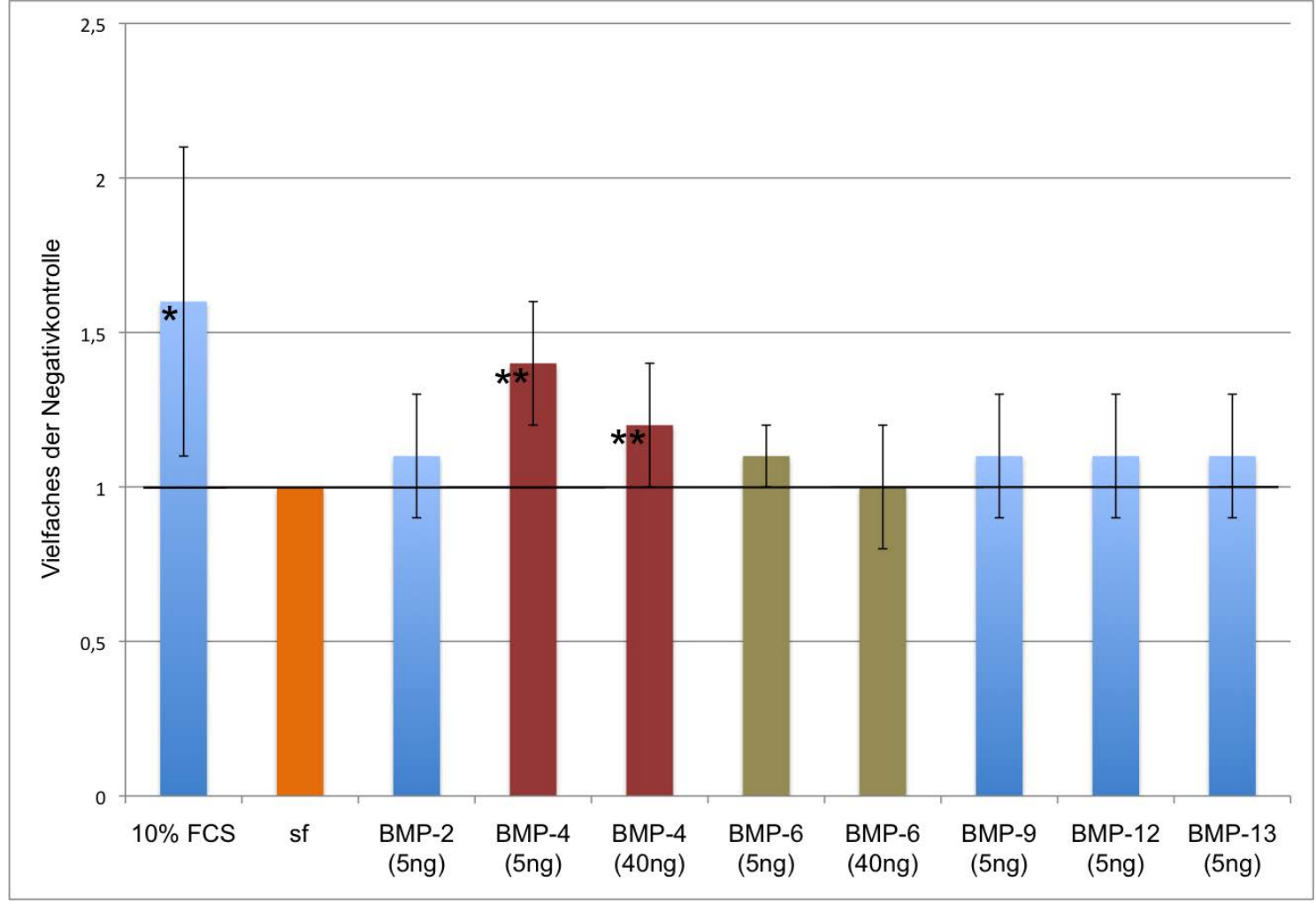

Abbildung 3.27: Migrationsassay mit BMPs. Dargestellt sind die Ergebnisse für die Untersuchung der chemotaktischen Wirkung der Wachstumsfaktoren BMP-2, BMP-4, BMP-6, BMP-9, BMP-12 und BMP-13 auf CPCs in den Konzentrationen $5 \mathrm{ng} / \mathrm{ml}$ und zum Teil $40 \mathrm{ng} / \mathrm{ml}$ als Säulendiagramm. Die gemessenen Werte der Proben wurden ins Verhältnis zur Negativkontrolle, serumfreies Medium (sf), gesetzt und das Vielfache in Bezug auf die Negativkontrolle als Faktor ermittelt. Der Durchschnitt der Messungen wurde im Diagramm abgetragen und die jeweilige Standardabweichung eingezeichnet. Als Positivkontrolle diente Kulturmedium mit zehnprozentigem Anteil FCS (10\% FCS). Bei der Positivkontrolle zeigt sich eine signifikante Steigerung der Migrationsrate $(p=0,014)(*)$ im Vergleich zur Negativkontrolle. Die untersuchten Wachstumsfaktoren in ihren jeweiligen Konzentrationen zeigen keinen signifikanten Einfluss auf die Migrationsrate der CPCs. Lediglich bei BMP-4 in der Konzentration $5 \mathrm{ng} / \mathrm{ml}$ und abgeschwächter in der Konzentration $40 \mathrm{ng} / \mathrm{ml}$ findet sich eine erhöhte, in dieser Studie nicht signifikante ( $\mathrm{p}=0,245$ und $\mathrm{p}=0,383)$ Migrationsrate (**). 


\section{Diskussion}

\subsection{Osteoarthrose und Stammzellen - Histologische Beobachtungen}

Osteoarthroseforschung im Bereich zellbiologischer Therapie kommt ohne mesenchymale Stammzellen (MSCs) nicht aus, auch wenn noch einige Hürden genommen werden müssen. Derzeitige und zukünftige Forschung wird einen Fokus auf die Applikation der MSCs und Optimierung der Wachstum- und Differenzierungsbedingungen für die MSCs am Bestimmungsort, gegebenenfalls mit Unterstützung von spezifischen Wachstumsfaktoren wie BMP-6 (Sekiya et al. 2001), legen müssen (Caplan und Bruder 2001).

Bereits heutzutage gibt es therapeutische Ansätze, die das an MSCs reiche Knochenmark (Tuan et al. 2002) nutzen. Die eingangs beschriebenen Methoden Pridie drilling und Microfracturing erzeugen auf künstliche Weise Brüche der Tidemark und bereiten so mesenchymalen Vorläuferzellen mit chondrogenem Differenzierungspotential den Weg in den defekten Knorpel (Pridie 1955; Steadman et al. 2001; Simon und Jackson 2006). Die chondrogenen Vorläuferzellen wandern entlang des Fibrinnetzwerks im entstandenen Blutgerinnsel aus dem Knochenmarkraum in den Knorpel (Dorotka et al. 2005). Das „Reparatur“- Gewebe entspricht jedoch nicht physiologischem, hyalinem Knorpel, sondern ist ein fibrokartiläres Gewebe mit eingeschränkter Funktionalität (Chen et al. 2009).

Es treten auch physiologische Reparaturmechanismen auf, die jedoch ebenfalls fibrokartiläres Ersatzgewebe liefern und den Verlauf der Erkrankung nicht aufhalten können (Sandell 2007; Tesche und Miosge 2005). In diesem Zusammenhang wurden fibroblastenförmige (spindelförmig) Zellen, die im fortgeschrittenen Stadium einer Osteoarthrose vom subchondralen Knochen aus in den Knorpel migrieren, und auch Einsprossungen in den Knorpel beschrieben, die von mesenchymalen Zellen begleitet werden (Koelling et al. 2009; Tesche und Miosge 2005).

In den histologischen Untersuchungen im Rahmen dieser Arbeit konnte die Expression der Perizytenmarker PDGFR- $\beta$ und RGS-5 im Knorpel einer fortgeschrittenen Osteoarthrose gezeigt werden, jedoch nicht im mikroskopisch gesunden Knorpel oder in frühen Stadien der Osteoarthrose, wenn die Tidemark noch intakt ist. Die PDGFR- $\beta$ - und RGS-5positiven Zellen waren in Clustern und auch als einzelne Zellen von spindelförmiger Gestalt zu beobachten. Von den PDGFR- $\beta$ - und RGS-5-positiven Clustern ließen sich die 
residenten Chondrozyten abgrenzen. Außerdem war das mesenchymale Begleitgewebe der beobachteten Einsprossungen PDGFR- $\beta$ - und RGS-5-positiv. Interessanterweise konnte zwischen den Trabekeln des subchondralen Knochens eine erhöhte Dichte an PDGFR- $\beta$ und RGS-5-positiven Zellen im Vergleich zu Proben, die mikroskopisch gesund sind oder sich in einer frühen Phase der Osteoarthrose befanden, beobachtet werden. Vermutlich könnte diese Beobachtung auf einer proliferativen Reaktion des Knochenmarkstromas, darunter MSCs und mesenchymale Progenitorzellen, auf das osteoarthrotische Geschehen im Knorpel hindeuten.

Es gibt anscheinend einen Zusammenhang zwischen den PDGFR- $\beta$ - und RGS-5-positiven Einsprossungen und dem Auftreten der PDGFR- $\beta$ - und RGS-5-positiven Zellen im Knorpel während einer fortgeschrittenen Osteoarthrose. Dies lässt sich dadurch begründen, dass die Kapillaren in den Einsprossungen von Perizyten begleitet sind, die PDGFR- $\beta$ - und RGS-5-positiv sind. Arnold Caplan vertritt die Hypothese, dass Perizyten eine MSC-Nische darstellen (Caplan 2008; Caplan 2010). Diese Hypothese basiert unter anderem auf den publizierten Ergebnissen namhafter Forscher über das perivaskuläre Vorkommen von MSCs und mesenchymalen Progenitorzellen vor allem im Knochenmark (Crisan et al. 2008; Crisan et al. 2009; Gronthos et al. 2003; Shi und Gronthos 2003) und dem direkten Nachweis von mesenchymalem Differenzierungspotential bei Perizyten, die auch für mesenchymale Stammzellmarker wie Stro-1 positiv sind (Doherty et al. 1998; Farrington-Rock et al. 2004; Howson et al. 2005). Auf Grund des Nicht-Vorhandenseins von PDGFR- $\beta$ - und RGS-5-positiven Zellen in mikroskopisch gesundem Knorpel und in Knorpelproben aus den frühen Stadien der Osteoarthrose mit intakter Tidemark wird im Rahmen dieser Arbeit postuliert, dass die PDGFR- $\beta$ - und RGS-5-positiven Zellen, die in den späten Stadien der Osteoarthrose im Knorpel auftreten, mesenchymale Progenitorzellen sind, die von MSC und/oder Perizyten abstammen, die im Rahmen der beobachteten Einsprossungen Zugang zum osteoarthrotischen Knorpel erlangen. Diese mesenchymalen Progenitorzellen entstehen wahrscheinlich durch asymmetrische Zellteilungen (David et al. 2009) von MSCs und/oder Perizyten entweder im Knorpel oder bereits im Knochenmarkraum. Spätestens im Knorpel migrieren diese mesenchymalen Progenitorzellen auch einzeln oder proliferieren und bilden Zellcluster. Die möglichen chemotaktischen Reize für die Einsprossungen und die Migration von mesenchymalen Progenitorzellen im Knorpel werden in Abschnitt 4.3 diskutiert. Eine Abstammung der PDGFR- $\beta$ - und RGS-5-positiven Zellen von residenten Chondrozyten wird für weniger wahrscheinlich gehalten, da solange keine Einsprossungen in den Knorpel auftreten, keine PDGFR- $\beta$ - und RGS-5-positiven Zellen beobachtet werden und auch in den späten Stadien im Knorpel die neu auftretenden PDGFR- $\beta$ - 
und RGS-5-positiven Zellen von den residenten Chondrozyten, die nicht PDGFR- $\beta$ - und RGS-5-positiv sind, differenzierbar sind. Der Ursprung der PDGFR- $\beta$ - und RGS-5positiven Progenitorzellen liegt im Bereich zwischen den Knochentrabekeln des subchondralen Knochens und im Knochenmark. Diese These stützt sich auf die histologischen Ergebnisse im Rahmen dieser Arbeit. So konnte in allen Stadien der Osteoarthrose PDGFR$\beta$ - und RGS-5-positives Stroma zwischen den Knochentrabekeln beobachtet werden. Diese Annahme ist konkordant zu bereits veröffentlichten Ergebnissen, die das Vorkommen von MSCs und mesenchymalen Progenitorzellen im Stroma des Knochenmarks sowohl in Tierversuchen (Johnstone et al. 1998) als auch beim Menschen (Dezawa et al. 2005; Friedenstein et al. 1970; Prockop et al. 2001) beschrieben. Auch wurden Hinweise auf das explizite Vorkommen von PDGFR- $\beta$-positiven Perizytenprogenitor-Zellen im Knochenmark publiziert (Lamagna und Bergers 2006).

Eine separate Betrachtung benötigt die beobachtete Expression von Tie-2 im osteoarthrotischen Knorpel. Im Gegensatz zu der ausführlich beleuchteten Expression von PDGFR- $\beta$ und RGS-5 im Knorpel konnten Tie-2-positive-Zellen an der Oberfläche von mikroskopisch gesunden Knorpel und Knorpel in Stadien der frühen Osteoarthrose beobachtet werden. Jedoch waren in diesen Stadien keine Tie-2-positiven Zellen in tiefer liegenden Knorpelschichten zu beobachten. In Knorpelproben mit fortgeschrittener Arthrose und Tidemarkbrüchen ließ sich ein ähnliches Verteilungsmuster wie bei den beiden anderen Markern feststellen: Es fanden sich Tie-2-positive Zellen in allen Knorpelschichten als einzelne Zellen, in Clustern, und auch die Einsprossungen zeichneten sich Tie-2-positiv. In allen Stadien konnte im intertrabekulären Raum und im Knochenmark Tie-2-positives Stroma beobachtet werden. Es stellt sich nun die Frage, ob die Tie-2-positiven Zellen, die im mikroskopisch gesunden Knorpel und in den sehr frühen Stadien an der Knorpeloberfläche beobachtet wurden, die gleichen sind wie die Tie-2-positiven Zellen der Einsprossungen in den späten Stadien der Osteoarthrose. Basierend auf den Beobachtungen im Rahmen dieser Arbeit, dass im mikroskopisch gesunden Knorpel an der Oberfläche des Knorpels und im Knochenmarkraum Tie-2-positive Zellen vorliegen und keine positiven Zellen dazwischen auftreten, kann die Hypothese aufgestellt werden, dass es sich hier um zwei Zellpopulationen handeln könnte. Die Beobachtung von Tie-2-positiven Zellen an der Knorpeloberfläche des mikrokopisch gesunden Knorpels ist konkordant zu publizierten Ergebnissen, die ebenfalls eine Population an mesenchymalen Progenitorzellen an der Knorpeloberfläche beobachtet haben (Dowthwaite et al. 2004; Hiraoka et al. 2006). Diese oberflächlichen mesenchymalen Progenitorzellen wurden auch mit den beobachteten Zellclustern in späteren Stadien der Osteoarthrose in Verbindung gebracht (Lotz et al. 2010). 
Es wurde in weiteren Studien das Genexpressionsmuster der untersuchten Zellclus-tern untersucht. Unter den exprimierten Genen fand sich auch Stro-1, aber es wurde bisher keine RGS-5- oder PDGFR- $\beta$-Expression in Zellclustern beschrieben (Lotz et al. 2010). In den in dieser Arbeit vorgestellten histologischen Untersuchungen konnten PDGFR- $\beta$ - und RGS-5-positive Zellcluster in Nachbarschaft zu chondrozytären Zellclustern, die nicht PDGFR- $\beta$ - bzw. RGS-5-positiv waren, dargestellt werden. Die untersuchten Zellcluster werden vermutlich von verschiedenen Zelltypen gebildet und müssen daher differenziert betrachtet werden. Die von unserer Arbeitsgruppe beschriebenen CPCs, die sich aus osteoarthrotischem Knorpel isolieren lassen, stammen vermutlich von den MSCs und/oder Perizyten ab, die durch die Tidemarkbrüche aus dem Knochenmarkraum in den Knorpel migrieren. Es ist jedoch auch möglich, dass es sich um eine Mischpopulation aus eingewanderten Perizytenabkömmlingen und von der Knorpeloberfläche stammenden mesenchymalen Progenitorzellen handelt. Um diese Thesen zu prüfen, wurden die beschriebenen Marker PDGFR- $\beta$, RGS-5 und Tie-2 und weitere MSC-Marker bei CPCs untersucht. Die Ergebnisse dieser Untersuchungen werden im folgenden Abschnitt 4.2 diskutiert.

\subsection{CPCs und Stammzellen}

Die in unserer Arbeitsgruppe untersuchten CPCs weisen charakteristische Stammzellmarker wie CD 29, CD 44, CD 73 oder CD 90 auf und wurden bereits positiv auf ihr mesenchymales Differenzierungspotential untersucht (Koelling et al. 2009). Im Rahmen dieser Arbeit wurden die aus osteoarthrotischen Knorpel isolierten CPCs auch auf die Perizytenmarker PDGFR- $\beta$, RGS-5, aSMA und Tie-2 sowie auf den MSC-Marker Stro-1 hin untersucht. Der Marker Tie-2 wird auch von Perizytenprogenitor-Zellen exprimiert, die, wenn sie sich in aSMA-positive Perizyten differenziert haben, nicht mehr Tie-2-positiv sind (Lamagna und Bergers 2006).

CPCs sind positiv für PDGFR- $\beta$, RGS-5, aSMA und Stro-1. Außerdem sind sie negativ für CD 117 und CD 31, was eine Kontamination mit anderen Progenitorzellen (Psaltis et al. 2011) und Endothelzellen ausschließen lässt. Zusätzlich ist es wahrscheinlich, dass eine Chemotaxis über eine Stammzellfaktor/CD 117-Signalkaskade, wie sie bei Hatzistergos et al. (2016) beschrieben wurde, bei den hier untersuchten CPCs ohne Relevanz ist. In Bezug auf den Marker Tie-2 zeigte sich, dass ein Teil der CPCs positiv für diesen Marker sind. In der durchflusszytometrischen Untersuchung waren in der Passage P0 circa 10\% der CPCs für Tie-2-positiv, wobei der Anteil über die Passagen hin abnahm. Interessanterweise zeigte sich im Gegensatz dazu bei der Genexpression von Tie-2 eine Zunahme über die Passage. 
Die vorgestellten Ergebnisse dieser Arbeit sind konkordant zu Expressionsuntersuchungen bei MSCs (siehe zum Beispiel da Silva Meirelles 2008). In mehreren Publikationen wurde bereits darauf hingewiesen, dass sowohl MSCs als auch Perizyten positiv für Stro-1, aSMA und PDGFR- $\beta$ sind und MSCs/Perizyten wie die hier untersuchten CPCs CD 31 und CD 117 negativ sind (Caplan 2008; da Silva Meirelles 2008). Diese Übereinstimmungen unterstützen die weiter oben beschriebene These, dass die von Koelling et al. beschriebenen CPCs von MSCs/Perizyten aus dem Knochenmark abstammen könnten, die im Rahmen der chemotaktisch induzierten Migration aus dem Knochenmarkraum in den osteoarthrotischen Knorpel migrieren. Die Beobachtung von aSMA- und Stro-1-positiven Zellclustern im osteoarthrotischen Knorpel (Lotz et al. 2010) unterstützt die These von aSMA- und Stro-1-positiven MSCs und/oder Perizyten, die im Rahmen der Osteoarthrose in den Knorpel migrieren und sich dort zu CPCs differenzieren.

Die Expression von Tie-2 bei einer Subpopulation der untersuchten CPCs könnte darauf beruhen, dass hier eine heterogene Gruppe vorliegt, die von mesenchymalen Progenitorzellen aus dem Knochenmark und von einer Population von Tie-2-positiven Zellen von der Knorpeloberfläche abstammt. In aufbauenden Studien müsste diese These geprüft werden und auch festgestellt werden, inwiefern sich diese beiden Populationen zum Beispiel in Bezug auf ihr chondrogenes Differenzierungspotential unterscheiden. Perizyten wurden widersprüchlich zum Teil als Tie-2-negativ (da Silva Meirelles 2008) und zum Teil auch als Tie-2-positiv beschrieben (Cai et al. 2008), während Perizyten-Progenitorzellen als Tie-2positiv charakterisiert worden sind (Lamagna und Bergers 2006). Es wäre demnach auch zu prüfen, ob über die Passagen hinweg eine Dedifferenzierung von Zellen zu Tie-2-positiven Progenitorzellen stattfindet, was eine vorsichtige Erklärung für die Zunahme der Genexpression von Tie-2 über die Passagen hinweg sein könnte.

Mit der erfolgten Untersuchung der CPCs auf Stammzellmarker über die Passagen sollte auch das Verhalten der CPCs in vitro geprüft werden. Eine der Hypothesen lautete hierbei, dass sich CPCs über die Passagen hinweg immer weiter von den beeinflussenden Faktoren aus dem osteoarthrotischen Knorpelmilieu und ihren Ursprungszellen entfernen würden. Außerdem konnten bei den Untersuchungen über die Passagen hinweg, Parallelen zu bereits publizierten Ergebnissen von MSCs in vitro gezogen werden. So nehmen bei MSCs in vitro die Proliferationsrate und das Differenzierungspotential ab (Caplan und Dennis 1996; Kassem und Abdallah 2008; Tuan et al. 2002), und es zeigte sich bei den hier untersuchten CPCs ebenfalls eine Reduzierung der Proliferationsrate und eine Abnahme der Genexpression von den Perizyten- und MSC-Marker PDGFR- $\beta$, RGS-5, Stro-1 und aSMA über die Passagen. Es wäre interessant zu prüfen, ob es, ähnlich wie bei MSCs (Kassem und Abdal- 
lah 2008; Tuan et al. 2002), eine Korrelation zwischen Seneszenz unserer CPCs und dem Alter der Patienten besteht.

Im Folgenden soll ein Augenmerk auf den Perizytenmarker RGS-5 gerichtet werden. Es wurden in einer veröffentlichten Arbeit verschiedenen RGS-Molekülen, darunter auch RGS-5, eine wichtige Rolle bei der Chondrozyten-Differenzierung zugesprochen (Appleton et al. 2006). Dabei war auffällig, dass die jeweiligen untersuchten RGS-Gene RGS-2, -4, -5, -7 und -10 bei der etablierten chondrogenen Zelllinie ATDC5 während der chondrogenen Differenzierung zu unterschiedlichen Zeitpunkten eine Rolle spielten. Vor allem RGS-10 war in der frühen Phase der chondrozytären Differenzierung mit einer starken Steigerung der Sox-9- und Kollagen Typ II-Expression von entscheidender Bedeutung (Appleton et al. 2006). Auch RGS-5 scheint einen positiven Einfluss auf Proliferation und während der frühen Differenzierung zu haben. Die Expression von RGS-5 nimmt über die chondrozytären Diffferenzierung hinweg ab. Das kann auch daran liegen, dass RGS-5 ein Marker für chondrogene Progenitorzellen ist, der mit der Reifung zum Chondrozyten an Bedeutung verliert. Appleton et al. zeigte mittels der In situ-Hybridization, dass RGS-5 nur in der Reservezone der Wachstumsplatte exprimiert wird (Appleton et al. 2006) und dort befinden sich die chondrogenen Progenitorzellen (Lefebvre und Bhattaram 2016). Dies ist auch konkordant zu den Ergebnissen dieser Arbeit, die eine starke Positivität der CPCs für RGS-5 gezeigt hat. Eine Überexpression von RGS-5 resultierte zusätzlich in einer deutlich erhöhten Expression vom Indian Hedgehog-Gen, das ansonsten in prähypertrophen und hypertrophen Chondrozyten aktiv ist (Appleton et al. 2006). RGS-7 wurde als wichtiger Faktor in der späteren Differenzierung beschrieben und erhöhte die Expression von Markern späthypertropher Chondrozyten (Appleton et al. 2006). Es bleibt spannend abzuwarten, was die zukünftige Forschung über das Zusammenspiel von RGS-5, RGS-10 und anderen Transkriptionsfaktoren wie Sox-9 bei der chondrozytären Differenzierung ans Tageslicht bringen wird.

Das Auftreten von drei Banden bei der Untersuchung von RGS-5 im Western Blot wurde bereits in der Literatur beschrieben (Yang et al. 2007). Die Autoren beschrieben bei 23 kDa die RGS-5-Bande, bei circa $42 \mathrm{kDa}$ postulierten sie ein Dimer von RGS-5 und vermuteten, dass die bei $87 \mathrm{kDa}$ auftretende Bande ein unspezifisches kreuzreaktives Protein sei. Unterschiede in der kDa-Größe der aufgetretenen Banden in Vergleich zu den kDa-Größen in dieser Arbeit, könnte in der Glykolisierung der Proteine in menschlichen Zellen liegen, während Proteine aus prokaryotischer oder niederer eukaryotischer Quelle nicht oder abweichend glykolysiert sind (Gerngross 2004; Wells und Robinson 2017). 
Hohe Standardabweichungen, wie zum Beispiel bei den durchflusszytometrischen Untersuchungen, können auf der Heterogenität der CPCs beruhen (Koelling et al. 2009). Auch bei den bisher untersuchten und beschriebenen Populationen von MSCs handelt es sich um eine heterogene Gruppe (Somoza et al. 2014; Tuan et al. 2002). Verschiedene Forscher haben bereits über spezifische Antigene wie Stro-1 versucht, eine homogene MSC-Population aus dem Knochenmarksstroma zu isolieren und hatten dabei erste Erfolge (Tuan et al. 2002). In Bezug auf MSCs steht es jedoch noch eine allgemeingültige Charakterisierung aus (Tuan et al. 2002).

\subsection{Migration - Was könnte der Antrieb sein?}

Wenn Reize, z.B. chemotaktischer Natur, eine Mobilisierung der MSCs in Gang setzen, finden asymmetrische Zellteilungen statt, indem einige Tochterzellen als Progenitorzelle für Regenerationsprozesse zur Verfügung stehen und die übrigen Tochterzellen den Stammzellpool erhalten (David et al. 2009).

Wie in der Einleitung bereits beschrieben (siehe 1.2.2) und auch im Rahmen dieser Arbeit in den histologischen Untersuchungen beobachtet (siehe Abbildung 3.2 und 3.7), treten im Rahmen der pathologischen Veränderungen bei einer fortschreitenden Osteoarthrose Einsprossungen in den Gelenkknorpel auf. Diese Einssprossungen gehen vom subchondralen Knochen aus. Es wurden auch Zytokine getestet, die einen möglichen chemotaktischen Reiz für die Migration von Zellen, in dieser Arbeit bei CPCs untersucht, in den osteoarthrotischen Knorpel bieten können. Hierbei zeigte sich bei den untersuchten inflammatorischen Zytokinen, dass bei einer Konzentration von $10 \mathrm{ng} / \mathrm{ml}$ eine größere Migrationsrate zu verzeichnen war, als bei der höheren Konzentration von $40 \mathrm{ng} / \mathrm{ml}$. Im Falle von TNF- $\alpha$ ließ sich in der Konzentration von $40 \mathrm{ng} / \mathrm{ml}$ sogar eine Tendenz zur Repression einer Migration im Vergleich zur Negativkontrolle verzeichnen. Die ausgeprägtesten Migrationsraten über die der Positivkontrolle hinaus konnten bei IL-8 und IL-17 jeweils in der Konzentration $10 \mathrm{ng} / \mathrm{ml}$ beobachtet werden. Dies ist eine interessante Beobachtung vor dem Hintergrund der inflammatorischen Komponente im Rahmen der Osteoarthrose. Hier wäre ein Grund für die Migration von MSCs/Perizyten bzw. CPCs in den osteoarthrotischen Knorpel zu sehen. Caplan vertritt unter anderem die These, dass Perizyten als Antwort auf eine Verletzung oder eine Entzündung ihren Kontakt zur Basalmembran der Blutgefäße verlören, aktiviert würden und zum betroffenen Ort migrierten. Infolge der Aktivierung und des Kontaktverlustes zur Basalmembran würden Perizyten zu MSCs und erlangten das mesenchymale Differenzierungspotential (Caplan 2015; da Silva Meirelles 
2008). In Hinblick auf eine erniedrigtere Migrationsrate bei einer hohen Konzentration von Entzündungsmediatoren wäre es interessant zu prüfen, in welcher Konzentration Entzündungsfaktoren im osteoarthrotischen Knorpel sezerniert werden und ob eine milde lokale anti-inflammatorische Therapie, die Migration von CPCs und MSCs in den Knorpel unterstützt. Interleukine scheinen neben der chemotaktischen Komponente auch eine weitere Funktion bei MSCs auszuüben. MSCs weisen Rezeptoren für TNF- $\alpha$ und diverse Interleukine, darunter auch IL-6, auf (da Silva Meirelles 2008) und sezernieren selbst die Interleukine IL-6, IL-7, IL-8 und IL-11 (Caplan 2009; da Silva Meirelles 2008; Prockop 1997). IL-6 scheint dabei ein wesentlicher Faktor zu sein, der die Proliferation von MSCs kontrolliert (Caplan 2009; Charbord et al. 2011).

Bei den untersuchten Wachstumsfaktoren VEGF $_{165}$ und PDGF-BB zeigte sich eine umgekehrte Tendenz, hier führte die Konzentration von $40 \mathrm{ng} / \mathrm{ml}$ zu einer erhöhten Migrationsrate, vor allem bei PDGF-BB. Beachtenswert ist, dass Chondrozyten-Kulturen unter Zugabe von 10 ng/ml PDGF-BB eine deutlich erhöhte Proliferationsrate als Kulturen nur mit 10\% FCS und $5 \mathrm{ng} / \mathrm{ml}$ fibroblast growth factor-2 (FGF-2) zeigten (Hardingham et al. 2002). Dies wäre ein zu überlegender therapeutischer Ansatz für eine synergetische Unterstützung von endogener Geweberegeneration: Appliziertes PDGF-BB könnte im Zusammenspiel mit weiteren Faktoren die Migration von chondrogenen Progenitorzellen (CPCs) in den osteoarthrotischen Knorpel fördern und könnte gleichzeitig die Proliferation von differenzierten Chondrozyten erhöhen. Hierbei kann auch RGS-5 eine Rolle spielen. Es hat sich gezeigt, dass RGS-5 eine entscheidende Funktion bei der Proliferation und Rekrutierung von PDGFR- $\beta$-positiven Perizyten als Antwort auf eine PDGF-BB-Sekretion inne hält (Cho et al. 2003). Es muss untersucht werden, inwiefern RGS-5 einen Einfluss auf Proliferation, Migration und chondrogene Differenzierung (siehe Abschnitt 4.2) bei PDGFR- $\beta$ positiven MSCs und den hier untersuchten PDGFR- $\beta$-positiven CPCs hat.

Interessanterweise konnte bei den Liganden des Rezeptors Tie-2 eine andere Tendenz beobachtet werden: Während Ang-1 in der Konzentration $10 \mathrm{ng} / \mathrm{ml}$ keinen signifikanten Einfluss auf die Migrationsrate hatte, konnte in der Konzentration $40 \mathrm{ng} / \mathrm{ml}$ eine deutliche Herabsetzung der Migrationsrate im Vergleich zur Negativkontrolle beobachtet werden. Bei Ang-2 zeigte sich in der Konzentration $10 \mathrm{ng} / \mathrm{ml}$ im Vergleich zur Negativkontrolle eine Tendenz zur Erhöhung der Migrationsrate und in der Konzentration von $40 \mathrm{ng} / \mathrm{ml}$ eine tendenziell erniedrigte Migrationsrate in Relation zur Negativkontrolle. Es wurde in der Literatur beschrieben, dass Ang-1 und -2 bei Perizyten auf Standard-Zellkulturplatten keine signifikante Erhöhung der Migrationsrate erzielten, jedoch nach einer Beschichtung mit Basalmembrankomponenten Ang-1 eine konzentrationsabhängige signifikante Erhö- 
hung der Migrationsrate stimulieren konnte (Cai et al. 2008). Auch die Effekte von Ang-2 sind umgebungsabhängig. So verstärkte Ang-2 die apoptotische Wirkung von TNF- $\alpha$ auf Perizyten, bewirkte ohne TNF- $\alpha$ jedoch eine konzentrationsabhängige Erhöhung der Proliferationsrate (Cai et al. 2008). Interessanterweise konnte Ang-1 den apoptotischen Effekt von TNF- $\alpha$ auf Perizyten um mehr als 50\% reduzieren und erwies sich als stabilisierender und protektiver Faktor für Perizyten (Cai et al. 2008). Passend hierzu wurde bei Perizyten in der Zellkultur eine Ang-1-Expression festgestellt, aber keine Ang-2-Expression (da Silva Meirelles 2008). Im Rahmen der Angiogenese konnte eine Induzierung der Expression von Ang-1 und Ang-2 durch Hypoxie, VEGF und TNF- $\alpha$ beobachtet werden (Spiegel und Krukemeyer 2006).

Es wurden ebenfalls verschiedene BMPs auf ihr chemotaktisches Potential hin getestet. Hier zeigten sich nur bei BMP-4 und BMP-6 Tendenzen zur Beeinflussung der Migrationsrate, und zwar in ähnlicher Weise wie bei den zuvor beschriebenen inflammatorischen Mediatoren. In der Konzentration $5 \mathrm{ng} / \mathrm{ml}$ konnte vor allem bei BMP-4 eine erhöhte Migrationsrate beobachtet werden, während in einer Konzentration von $40 \mathrm{ng} / \mathrm{ml}$ eine reduzierte, aber dennoch erhöhte Migrationsrate im Vergleich zur Negativkontrolle zu verzeichnen war. BMP-2, -6 und -9 wurden als positive Initiatoren und Unterstützer von chondrogener Differenzierung von MSCs in 3D-Kulturen beschrieben (Tuan et al. 2002). Daher könnten diese Faktoren in geeigneter Konzentration Migration von MSCs/CPCs in den Knorpel, aber vor allem die chondrogene Differenzierung unterstützen.

\subsection{Einordnung der Ergebnisse dieser Arbeit in den biologischen und medizinischen Kontext mit Schlussbetrachtungen}

Es ist abzusehen, dass es nicht nur notwendig sein wird, MSCs und chondrogene Progenitorzellen in einer geeigneten künstlichen Matrix einzubetten, sondern auch Cofaktoren wie Ascobinsäure, BMP-6, Dexamethason und TGF- $\beta$ (Transforming Growth Factor- $\beta$ ) zu applizieren, die eine Chondrogenese unterstützen (David et al. 2009). Von Vorteil ist ebenfalls, dass MSCs immunpriviligiert sind und immunsupressive und anti-inflammatorische Eigenschaften aufweisen (David et al. 2009). Letztere Eigenschaft ist vor dem Hintergrund der inflammatorischen Komponente der Osteoarthrose (Fernandes et al. 2002; Goldring und Goldring 2007; Sun 2010) von entscheidender Relevanz.

Es gibt jedoch auch Hinweise, dass Chondrozyten, die von MSCs abstammen, Hypertrophie-Gene exprimieren, die zu frühzeitigem Zelltod führen können, und im Gegensatz zu originären Gelenk-Chondrozyten zu Kalzifikationen und Vaskulationsförderung neigen 
(Koga et al. 2009). In der Literatur lassen sich auch Hinweise finden, das MSCs aus dem Knochenmark von Patienten mit fortgeschrittener Osteoarthrose eine erniedrigte Proliferationsrate und ein herabgesetztes chondrogenes Differenzierungspotential aufwiesen (Murphy et al. 2002). Diese Punkte stellen eine große Herausforderung für eine autologe Geweberegeneration dar und sollte in Zukunft weiter untersucht werden.

Die endogenen Regenerationsmechanismen, die mit Kapillareinsprossungen in den Knorpel verbunden sind, könnten auch ihren Teil zur Destruktion des Knorpels beitragen. Einer der Wege, um MSCs bzw. Perizyten und mesenchymale Progenitorzellen aus dem Knochenmark zu rekrutieren, erfolgt über die Gewebe-Sekretion von VEGF, das wiederum die Synthese von aktiviertem MMP-9 im Knochenmark zur Folge hat. MMP-9 katalysiert die Freisetzung von löslichen Kit-Liganden, die die Zellteilung von MSCs und ihre Mobilisierung fördert (Lamagna und Bergers 2006). Es lässt sich vermuten, dass nach erfolgter Einsprossung in den Knorpel dieser Rekrutierungsmechanismus und damit auch Mobilisationsmechanismus weiterhin Bestand hat, da der osteoarthrotische Knorpel über seine VEGF-Sekretion (Pufe et al. 2001) die Einsprossung bereits induziert hat und VEGF bei Perizyten eine Proliferation und Migration auslösen kann (Diaz-Flores et al. 2009; Witmer et al. 2004). Im Rahmen des oben beschriebenen Rekrutierungsmechanismuses würde jedoch im Knorpel weiteres MMP-9 sezerniert werden, was die Destruktion des Knorpels weiterhin befördern könnte. Ähnliche Zusammenhänge wurden bereits im Rahmen der Pathophysiologie von Rheumatoider Arthritis und Arthritis Psoriatica beschrieben (Fraser et al. 2001).

Diese punktuellen Hinweise auf die Herausforderungen im Rahmen von zellbiologischen Therapien mit MSCs sollen verdeutlichen, dass es nötig ist unter Berücksichtigung von Nutzen-Risiko-Bilanzen einen Ansatz zu finden, der eine geeignete chondrogene Zellpopulation in einem geeigneten chondrogenem Milieu in den Knorpel zu integrieren.

Die erstmals von Koelling et al. 2009 beschriebenen und im Rahmen dieser Arbeit untersuchten CPCs zeigen ein vielversprechendes Potential für zukünftige zellbiologische Therapien. Doch sie können im osteoarthrotischen Knorpel noch nicht ihr volles chondrogenes und regeneratives Potential ausschöpfen (Koelling et al. 2009; Koelling und Miosge 2009; Kruegel et al. 2008). Ihr chondrogenes Potential konnte gesteigert werden durch einen Runx-2-Knock down mit einer konsekutiven Erhöhung der Expression von Sox-9, Aggrecan und Kollagen Typ II (Koelling et al. 2009; Koelling und Miosge 2009). Zwar konnte man auch schon durch retrovirale Transduktion von Sox-9 in 3D-Kultur von humanen osteoarthrotischen Gelenkknorpelzellen eine gesteigerte Kollagen Typ II-Expression und unter 
Zugabe von unter anderem TGF- $\beta_{3}$ eine zusätzliche Verbesserung der Morphologie erzielt werden (Tew et al. 2005), es wird jedoch zu bedenken gegeben, dass im Stadium einer fortgeschrittenen Osteoarthrose die affektierten Chondrozyten zunehmend in Apoptose gehen und die genetische Behandlung womöglich nur in frühen Stadien sinnvoll ist - wenn man als Patient wahrscheinlich noch keine Kenntnis über seine Erkrankung besitzt. In Hinblick auf Transkriptionsfaktoren gestützte Modifizierung von Zellen, um das chondrogene Potential zu verbessern, scheint auch das Forkhead Box Protein O1A (FOXO1A) von Interesse zu sein. Die Über-Expression von FOXOA1 allein, ohne Zugabe von weiteren Differenzierungsfaktoren, konnte bei MSCs eine chondrogene Differenzierung induzieren (Charbord et al. 2011). Es sollte auch untersucht werden, ob eine begleitende pharmakologische Therapie das chondrogene Potential unterstützt. So konnte ein chondroprotektiver Effekt von Ibuprofen (Gineyts et al. 2004) und vom Antibiotikum Doxycyclin beim Meerschweinchen (Bowyer et al. 2009), aber auch beim Menschen (Brandt et al. 2005; Lohmander et al. 2005) gezeigt werden.

Um Osteorthrose in Zukunft zu therapieren und möglichst einen prothetischen Gelenkersatz zu verzögern, sollte zunächst im Rahmen prophylaktischer Maßnahmen die Entstehung einer Osteoarthrose vermieden werden. Dazu gehörten neben Gewichtsreduktion und optimaler chirurgischer Versorgung von Gelenksverletzungen auch von der Krankenkasse finanzierte frühzeitige Umstellungsosteotomien, um nur einige Beispiele zu nennen. Sollten pharmakologische Therapien nicht mehr greifen, ist ein Ansatz, die endogenen zellbiologischen Mechanismen zu nutzen, attraktiv.

Ein neuer Ansatz wäre es, nicht wie vielfach in der Literatur beschrieben, starre ex vivo gezüchtete Scaffolds mit MSCs und/oder bereits differenzierten Chondrozyten besetzt in ein inflammatorisches und osteoarthrotisches Milieu einzusetzen (Frenkel et al. 1997; Schlegel et al. 2008), sondern den betroffenen Knorpel komplett abzutragen und auf dem freiliegenden Knochen eine anti-inflammatorische und anti-angiogenetische Matrix aufzutragen. Diese sollte sich im nächsten Schritt mit der nun aufgetragenen vormodellierter Matrix, die mit vordifferenzierten CPCs versetzt und noch plastisch formbar ist, verbinden. Der Reiz liegt hier in der intraoperativen plastischen Ausformung der „Knorpel-Matrix“ an anatomische Verhältnisse angepasst und in der Aushärtung und Ausreifung der neuen Knorpelschicht in vivo möglichst ohne ein inflammatorisches Milieu. Einen ähnlichen Ansatz mit injizierbarem Knorpelersatz auf Basis von Polymeren für minimal invasive Einsätze wurde bereits beschrieben (Dobratz et al. 2009) und auch der Einsatz von Polymeren am Kniegelenk wurde schon diskutiert (Galaois et al. 2004). Durch Zugabe geeigneter Cofaktoren, genetischer Vorbehandlung der CPCs und geeignete Wahl der Einbettungsmatrix könnte 
sich in einer mehr oder weniger fernen Zukunft ein adäquater Knorpelersatz erzeugen lassen. Davon ausgenommen sind genetisch bedingte Osteoarthrose-Formen, die einen differenzierteren therapeutischen Ansatz benötigen.

Die im Rahmen dieser Arbeit erzielten Erkenntnisse leisten hoffentlich einen kleinen Beitrag zum nötigen Erkenntnisgewinn für zukünftige zellbiologische Therapien. 


\section{$5 \quad$ Zusammenfassung}

Im Rahmen der vorliegenden Arbeit wurde die potentielle Ableitbarkeit von chondrogenen Progenitorzellen (CPCs), die im Gelenkknorpel mit einer fortgeschrittenen Osteoarthrose auftreten, von Perizyten bzw. mesenchymalen Stammzellen untersucht, sowie die chemotaktische Wirkung von relevanten Entzündungs- und Wachstumsfaktoren auf das Migra-tionsverhalten der CPCs.

Knorpelproben, die vom Einsatz einer Knie-Totalendoprothese auf Grund einer fortgeschrittenen Osteoarthrose stammten, wurden histologisch auf das Auftreten der Perizytenbzw. mesenchymalen Stammzellmarker PDGFR- $\beta$, RGS-5 und Tie-2 untersucht. Es zeigte sich hierbei, dass in Knorpelproben mit einer fortgeschrittenen Osteoarthrose und durchbrochener Tidemark PDGFR- $\beta$ - und RGS-5-positive Zellen und Einsprossungen im Knorpel beobachtet werden konnten, während im mikroskopisch gesunden Knorpel mit intakter Tidemark keine PDGFR- $\beta$ - und RGS-5-positiven Zellen im Knorpel auftraten. In Hinblick auf Tie-2 zeigte sich ein ähnliches Verteilungsmuster mit der Ausnahme, dass an der Knorpeloberfläche von mikroskopisch gesundem Knorpel Tie-2-positive Zellen beobachtet wurden. In weitergehenden immunzytologischen und molekularbiologischen Untersuchungen wurde das Vorkommen dieser und weiterer mesenchymaler Stammzellmarker auch bei den CPCs direkt untersucht. CPCs zeigten sich positiv für PDGFR- $\beta$, RGS-5, aSMA , Stro-1 und zu einem geringen Prozentsatz für Tie-2. Sie waren negativ in Bezug auf hämatopoetische Stammzellmarker.

Darüber hinaus wurde mit einem Migrationsassay die chemotaktische Wirkung der Entzündungsfaktoren IL-6, IL-8, IL-17 und TNF- $\alpha$ und des Wachstumsfaktors VEGF ${ }_{165}$, deren Auftreten im osteoarthrotischen Knorpel beschrieben wurde, auf CPCs untersucht. Vor allem IL-8 und IL-17 erzielten hierbei eine tendenzielle Steigerung der Migrationsrate. Zusätzlich wurden Liganden der untersuchten Rezeptoren unter den Stammzellmarkern PDGF-BB und Angiopoeitin-1 und -2 auf ihre chemotaktische Wirkung hin geprüft sowie Vertreter der Familie der Bone Morphogenetic Proteins BMP-2, -4, -6, -9, -12 und -13, bei denen zum Teil ein positiver chondrogener Einfluss auf mesenchymale Stammzellen beschrieben wurde. Am ehesten konnte hier bei PDGF-BB und bei BMP-4 ein positiver chemotaktischer Effekt festgestellt werden.

Durch die Erkenntnisse in dieser Arbeit wurde ein besseres Verständnis über die Herkunft der CPCs und ihre Rolle bei endogenen Reparaturmechanismen im Rahmen der Osteo- 
arthrose gewonnen. Zusätzlich könnten die Ergebnisse des Migrationsassays Hinweise für eine Weiterentwicklung von Strategien im Rahmen von zellbiologischen Therapien liefern. 


\section{$6 \quad$ Literaturverzeichnis}

Aigner T, McKenna L (2002): Molecular pathology and pathobiology of osteoarthritic cartilage. Cell Mol Life Sci $\underline{59}(1)$, 5-18

Aigner T, Finger F, Zien A, Bartnik E (2004): [cDNA-microarrays in cartilage research functional genomics of osteoarthritis]. Z Orthop Ihre Grensgeb 142(2), 241-247

Allen KD, Golightly YM (2015): Epidemiology of Osteoarthritis: state of evidence. Curr Opin Rheumatol 27(3), 276-283

Allt G, Lawrenson JG (2001): Pericytes: cell biology and pathology. Cells Tissues Organs $\underline{169}(1), 1-11$

Alsalameh S, Amin R, Gemba T, Lotz M (2004): Identification of mesenchymal progenitor cells in normal and osteoarthritic human articular cartilage. Arthritis Rheum 50(5), 1522 1532

Altman R, Asch E, Bloch D, Bole G, Borenstein D, Brandt K, Christy W, Cooke TD, Greenwald R, Hochberg M, et al. (1986): Development of criteria for the classification and reporting of osteoarthritis. Classification of osteoarthritis of the knee. Diagnostic and Therapeutic Criteria Committee of the American Rheumatism Association. Arthritis Rheum 29(8), 1039-1049

Angelo LS, Kurzrock R (2007): Vascular endothelial growth factor and its relationship to inflammatory mediators. Clin Cancer Res $\underline{13}(10), 2825-2830$

Appleton CT, James CG, Beier F (2006): Regulator of G-protein signaling (RGS) proteins differentially control chondrocyte differentiation. J Cell Physiol 207(3), 735-745

Armulik A, Abramsson A, Betsholtz C (2005): Endothelial/pericyte interactions. Circ Res $\underline{97}(6), 512-523$

Barleon B, Sozzani, S, Zhou D, Weich HA, Mantovani A, Marme D (1996): Migration of human monocytes in response to vascular endothelial growth factor (VEGF) is mediated

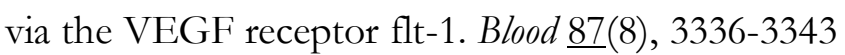

Bergers G, Song S (2005): The role of pericytes in blood-vessel formation and maintenance. Neuro Oncol $\underline{7}(4), 452-464$ 
Bobacz K, Gruber R, Soleiman A, Erlacher L, Smolen JS, Graninger WB (2003): Expression of bone morphogenetic protein 6 in healthy and osteoarthritic human articular chondrocytes and stimulation of matrix synthesis in vitro. Arthritis Rheum $\underline{48}(9), 2501-2508$

Bondjers C, Kalen M, Hellstrom M, Scheidl SJ, Abramsson A, Renner O, Lindahl P, Cho H, Kehrl J, Betsholtz C (2003): Transcription profiling of platelet-derived growth factor-Bdeficient mouse embryos identifies RGS5 as a novel marker for pericytes and vascular smooth muscle cells. Am J Pathol 162(3), 721-729

Bowyer J, Heapy CG, Flannelly JK, Waterton JC, Maciewicz RA (2009): Evaluation of a magnetic resonance biomarker of osteoarthritis disease progression: doxycycline slows tibial cartilage loss in the Dunkin Hartley guinea pig. Int J Exp Path $\underline{90}$, 174-181

Boyden S (1962): The chemotactic effect of mixtures of antibody and antigen on polymorphonuclear leucocytes. J Exp Med $\underline{115}$, 453-466

Brachvogel B, Moch H, Pausch F, Schlotzer-Schrehardt U, Hofmann C, Hallmann R, von der Mark K, Winkler T, Poschl E (2005): Perivascular cells expressing annexin A5 define a novel mesenchymal stem cell-like population with the capacity to differentiate into multiple mesenchymal lineages. Development 132(11), 2657-2668

Brandt KD, Mazzuca SA, Katz BP, Lane KA, Buckwalter KA, Yocum DE, Wolfe F, Schnitzer TJ, Moreland LW, Manzi S, et al. (2005): Effects of doxycycline on progression of osteoarthritis: results of a randomized, placebo-controlled, double-blind trial. Arthritis Rheum 52, 2015-2025

Bucher O, Wartenberg H: Cytologie, Histologie und mikroskopische Anatomie des Menschen. 12. Aufl.; Verlag Hans Huber, Bern 1997

Cai J, Kehoe O, Smith GM, Hykin P, Boulton ME (2008): The Angiopoietin/Tie-2 System Regulates Pericyte Survival and Recruitment in Diabetic Retinopathy. Invest Ophthalmol Vis Sci $\underline{49}(5), 2163-2171$

Caplan AI (2008): All MSCs are pericytes? Cell Stem Cell $\underline{3}$ (3), 229-230

Caplan AI (2009): Why are MSCs therapeutic? New data: new insight. J Pathol 217, 318 324

Caplan AI (2010): What's in a name? Tissue Eng Part A 16(8), 2415-2417

Caplan AI (2015): Adult Mesenchymal Stem Cells: When, Where, and How. Stem Cells Int $\underline{2015}, 628767$

Caplan AI, Dennis JE (1996): Mesenchymal stem cells: Progenitors, progeny, and pa- 
thways. J Bone Miner Metab 14, 193-201

Caplan AI, Bruder SP (2001): Mesenchymal stem cells: building blocks for molecular medicine in the 21st century. Trends Mol Med $\underline{7}(6), 259-264$

Carlevaro MF, Cermelli S, Cancedda R, Descalzi Cancedda F (2000): Vascular endothelial growth factor (VEGF) in cartilage neovascularization and chondrocyte differentiation: auto-paracrine role during endochondral bone formation. J Cell Sci 113(Pt 1), 59-69

Charbord P, Livne E, Gross G, Haupl T, Neves NM, Marie P, Bianco P, Jorgensen C (2011): Human bone marrow mesenchymal stem cells: a systematic reappraisal via the genostem experience. Stem Cell Rev 7, 32-42

Chen D, Zhao M, Mundy GR (2004): Bone morphogenetic proteins. Growth Factors 22(4), 233-241

Chen FH, Tuan RS (2008): Adult Stem Cells for Cartilage Tissue Engineering and Regeneration. Curr Rheumatol Rev $\underline{4}, 161-170$

Chen H, Sun J, Hoemann CD, Lascau-Coman V, Ouyang W, McKee MD, Shive MS, Buschmann MD (2009): Drilling and microfracture lead to different bone structure and necrosis during bone-marrow stimulation for cartilage repair. J Orthop Res 27(11), 1432 1438

Cho H, Kozasa T, Bondjers C, Betsholtz C, Kehrl JH (2003): Pericyte-specific expression of Rgs-5: implications for PDGF and EDG receptor signaling during vascular maturation. FASEB J 17(3), 440-2

Chopra H, Hans MK, Shetty S (2013): Stem cells-the hidden treasure: A strategic review. Dent Res J (Isfahan) 10(4), 421-427

Crisan M, Yap S, Casteilla L, Chen CW, Corselli M, Park TS, Andriolo G, Sun B, Zheng B, Zhang L, et al. (2008): A perivascular origin for mesenchymal stem cells in multiple human organs. Cell Stem Cell $\underline{3}(3), 301-313$

Crisan M, Chen CW, Corselli M, Andriolo G, Lazzari L, Peault B (2009): Perivascular multipotent progenitor cells in human organs. Ann N Y Acad Sci 1176, 118-123

da Silva Meirelles L, Chagastelles PC, Nardi NB (2006): Mesenchymal stem cells reside in virtually all post-natal organs and tissues. J Cell Sci $\underline{119}(\mathrm{Pt} 11), 2204-2213$

da Silva Meirelles L, Caplan AI, Nardi NB (2008): In search of the in vivo identity of mesenchymal stem cells. Stem Cells 26, 2287-2299 
Dai J, Rabie ABM (2007): VEGF: an essential mediator of both angiogenesis and endochondral ossification. J Dent Res $\underline{86}(10)$, 937-950

David JP, Zwerina J, Schett G (2009): Mesenchymale Stammzellen bei Arthritis. Z Rheumatol 68 , 228-233

Davis S, Aldrich TH, Jones PF, Acheson A, Compton DL, Jain V, Ryan TE, Bruno J, Radziejewski C, Maisonpierre PC, Yancopoulos GD (1996): Isolation of angiopoietin-1, a ligand for the TIE2 receptor, by secretion-trap expression cloning. Cell $\underline{\text { 87}(7), ~ 1161-1169 ~}$

De Vries L, Zheng B, Fischer T, Elenko E, Farquhar MG (2000): The regulator of G protein signaling family. Annu Rev Pharmacol Toxicol 40, 235-271

Debrunner AM: Orthopädie / Orthopädische Chirurgie. 4. Auflage; Verlag Hans Huber, Bern 2005

Dennis JE, Carbillet JP, Caplan AI, Charbord P (2002): The STRO-1+ marrow cell population is multipotential. Cells Tissues Organs $\underline{170}(2-3)$, 73-82

Dezawa M, Ishikawa H, Itokazu Y, Yoshihara T, Hoshina M, Takeda S, Ide C, Nabeshima Y (2005): Bone marrow stromal cells generate muscle cells and repair muscle degeneration. Science $\underline{309}, 314-317$

Diaz-Flores L, Gutierrez R, Madrid JF, Varela H, Valladares F, Acosta E, Martin-Vasallo P, Diaz-Flores L, Jr. (2009): Pericytes. Morphofunction, interactions and pathology in a quiescent and activated mesenchymal cell niche. Histol Histopathol 24(7), 909-969

Dobratz EJ, Kim SW, Voglewede A, Park SS (2009): Injectable Cartilage. Arch Facial Plast Surg 11(1), 40-47

Doherty MJ, Ashton BA, Walsh S, Beresford JN, Grant ME, Canfield AE (1998): Vascular pericytes express osteogenic potential in vitro und in vivo. J Bone Miner Res $\underline{13}$, 828-838

Dorotka R, Windberger U, Macfelda K, Bindreiter U, Toma C, Nehrer S (2005): Repair of articular cartilage defects treated by microfracture and a three-dimensional collagen matrix. Biomaterials $\underline{26}(17), 3617-3629$

Dowthwaite GP, Bishop JC, Redman SN, Khan IM, Rooney P, Evans DJ, Haughton L, Bayram Z, Boyer S, Thomson B, et al. (2004): The surface of articular cartilage contains a progenitor cell population. J Cell Sci $\underline{117}(\mathrm{Pt}$ ), 889-897

Dvorak AM, Feng D (2001): The vesiculo-vacuolar organelle (VVO). A new endothelial cell permeability organelle. J Histochem Cytochem 49(4), 419-432 
Edelman DA, Jiang Y, Tyburski J, Wilson RF, Steffes C (2006): Toll-like receptor-4 message is up-regulated in lipopolysaccharide-exposed rat lung pericytes. J Surg Res 134(1), 2227

Farrington-Rock C, Crofts NJ, Doherty MJ, Ashton BA, Griffin-Jones C, Canfield AE (2004): Condrogenic and adipogenic potential of microvascular pericytes. Circulation 110, 2226-2232

Fernandes JC, Martel-Pelletier J, Pelletier JP (2002): The role of cytokines in osteoarthritis pathophysiology. Biorbeology 39 (1-2), 237-246

Ferrara N, Gerber HP, LeCouter J (2003): The biology of VEGF and its receptors. Nat Med $\underline{9}(6), 669-676$

Fickert S, Fiedler J, Brenner RE (2004): Identification of subpopulations with characteristics of mesenchymal progenitor cells from human osteoarthritic cartilage using triple staining for cell surface markers. Arthritis Res Ther $\underline{6}(5)$, R422-432

Fish KM (2016): Mesenchymal Stem Cells Drive Cardiac Stem Cell Chemotaxis, Proliferation, and Phenotype via CXCR4 and cKit Signaling. Circ Res 119, 891-892

Fraser A, Fearon U, Reece R, Emery P, Veale DJ (2001): Matrix metalloproteinase 9, apoptosis, and vascular morphology in early arthritis. Arthritis Rheum 44(9), 2024-2028

Frenkel SR, Toolan B, Menche D, Pitman MI, Pachence JM (1997): Chondrozyte transplantation using a collagen bilayer matrix for cartilage repair. J Bone Joint $\operatorname{Surg} B r \underline{79}, 831-836$

Friedenstein AJ, Chailakhan RK, Lalykina KS (1970): The development of fibroblast colonies in monolayer cultures of guinea-pig bone marrow and spleen cells. Cell Tissue Kinet $\underline{3}$, 393-403

Fukui N, Zhu Y, Maloney WJ, Clohisy J, Sandell LJ (2003): Stimulation of BMP-2 expression by pro-inflammatory cytokines IL-1 and TNF-alpha in normal and osteoarthritic chondrocytes. J Bone Joint Surg Am 85-A Suppl 3, 59-66

Galois L, Freyria AM, Grossin L, Hubert P, Mainard D, Herbage D, Stoltz JF, Netter P, Dellacherie E, Payan E (2004): Cartilage repair: surgical techniques and tissue engineering using polysaccharide- and collagen-based biomaterials. Biorheology $\underline{41}$, 433-443

Gebhard S, Poschl E, Riemer S, Bauer E, Hattori T, Eberspaecher H, Zhang Z, Lefebvre V, de Crombrugghe B, von der Mark K (2004): A highly conserved enhancer in mammalian type $\mathrm{X}$ collagen genes drives high levels of tissue-specific expression in hypertrophic cartilage in vitro and in vivo. Matrix Biol 23(5), 309-322 
Gerhardt H, Wolburg H, Redies C (2000): N-cadherin mediates pericytic-endothelial interaction during brain angiogenesis in the chicken. Dev Dyn 218(3), 472-479

Gerngross TU (2004): Advances in the production of human therapeutic proteins in yeasts and filamentous fungi. Nat Biotechnol 22(11), 1409-1414

Goldring MB, Goldring SR (2007): Osteoarthritis. J Cell Physiol 213, 626-634

Goldring MB, Tsuchimochi K, Ijiri K (2006): The control of chondrogenesis. J Cell Biochem $\underline{97}(1), 33-44$

Goldring SR, Goldring MB (2004): The role of cytokines in cartilage matrix degeneration in osteoarthritis. Clin Orthop Relat Res 427 Suppl, S27-36

Gronthos S, Zannettino ACW, Hay SJ, Shi S, Graves SE, Kortesidis A, Simmons PJ (2003): Molecular and cellular characterisation of highly purfied stromal stem cells derived from human bone marrow. J Cell Sci 116, 1827-1835

Gineyts E, Mo JA, Ko A, Henriksen DB, Curtis SP, Gertz BJ, Garnero P, Delmas PD (2004): Effects of ibuprofen on molecular markers of cartilage and synovium turnover in patients with knee osteoarthritis. Ann Rheum Dis $\underline{63}$, 857-861

Hardingham T, Tew S, Murdoch A (2002): Tissue engineering: chondrozytes and cartilage. Arthritis Res 4(suppl 3), S63-S68

Hatzistergos KE, Quevedo H, Oskouei BN, Hu Q, Feigenbaum GS, Margitich IS, Mazhari R, Boyle AJ, Zambrano JP, Rodriguez JE, et al. (2010): Bone marrow mesenchymal stem cells stimulate cardiac stem cell proliferation and differentiation. Circ Res 107, 913-922

Hatzistergos KE, Saur D, Seidler B, Balkan W, Breton M, Valasaki K, Takeuchi LM, Landin AM, Khan A, Hare JM (2016): Stimulatory Effects of Mesenchymal Stem Cells on cKit+ Cardiac Stem Cells Are Mediated by SDF1/CXCR4 and SCF/cKit Signaling. Pathways Circ Res 119, 921-930

He C, Medley SC, Hu T, Hinsdale ME, Lupu F, Virmani R, Olson LE (2015): PDGFRbeta signalling regulates local inflammation and synergizes with hypercholesterolaemia to promote atherosclerosis. Nat Commun $\underline{6}, 7770$

Hedbom E, Hauselmann HJ (2002): Molecular aspects of pathogenesis in osteoarthritis: the role of inflammation. Cell Mol Life Sci $\underline{59}(1), 45-53$

Hellström M, Kalen M, Lindahl P, Abramsson A, Betsholtz C (1999): Role of PDGF-B and PDGFR-beta in recruitment of vascular smooth muscle cells and pericytes during embryonic blood vessel formation in the mouse. Development $126(14), 3047-3055$ 
Herbert SP, Stainier DYR (2011): Molecular control of endothelial cell behaviour during blood vessel morphogenesis. Nat Rev Mol Cell Bio 12, 551-564

Hidaka C, Goldring MB (2008): Regulatory Mechanisms of Chondrogenesis and Implications for Understanding Articular Cartilage Homeostasis. Curr Rheumatol Rev 4, 1-12

Hiraoka K, Grogan S, Olee T, Lotz M (2006): Mesenchymal progenitor cells in adult human articular cartilage. Biorheology $\underline{43}, 447-454$

Horwitz R, Webb D (2003): Cell migration. Curr Biol 13(19), R756-759

Howson KM, Aplin AC, Gelati M, Alessandri G, Parati EA, Nicosia RF (2005): The postnatal rat aorta contains pericyte progenitor cells that form spheroidal colonies in suspension culture. Am J Physiol Cell Physiol 289(6), C1396-1407

Johnstone B, Hering TM, Caplan AI, Goldberg VM, Yoo JU (1998): In Vitro chondrogenesis of bone marrow-derived mesenchymal progenitor cells. Exp Cell Res 238: 265-272

Jones EA, McGonagle D (2008): Human bone marrow mesenchymal stem cells in vivo. Rheumatology (Oxford) 47(2), 126-131

Jones EA, Kinsey SE, English A, Jones RA, Straszynski L, Meredith DM, Markham AF, Jack A, Emery P, McGonagle D (2002): Isolation and characterization of bone marrow multipotential mesenchymal progenitor cells. Arthritis Rheum 46 (12), 3349-3360

Kalka C, Masuda H, Takahashi T, Gordon R, Tepper O, Gravereaux E, Pieczek A, Iwaguro H, Hayashi SI, Isner JM, et al. (2000): Vascular endothelial growth factor(165) gene transfer augments circulating endothelial progenitor cells in human subjects. Circ Res $\underline{86}(12), 1198-1202$

Kassem M, Abdallah BM (2008): Human bone-marrow-derived mesenchymal stem cells: biological characteristics and potential role in therapy of degenerative diseases. Cell Tissue Res 331, 157-163

Khalil AA, Friedl P (2010): Determinants of leader cells in collective cell migration. Integr Biol 2 , 568-574

Koelling S, Miosge N (2009): Stem cell therapy for cartilage regeneration in osteoarthritis. Expert Opin Biol Ther $\underline{9}(11), 1-7$

Koelling S, Kruegel J, Irmer M, Path JR, Sadowski B, Miro X, Miosge N (2009): Migratory chondrogenic progenitor cells from repair tissue during the later stages of human osteoarthritis. Cell Stem Cell 4 (4), 324-335 
Kolf CM, Cho E, Tuan RS (2007) Mesenchymal stromal cells. Biology of adult mesenchymal stem cells: regulation of niche, self-renewal and differentiation. Arthritis Res Ther $\underline{9}(1), 204$

Koga H, Engebretsen L, Brinchmann JE, Muneta T, Sekiya I (2009): Mesenchymal stem cell-based therapy for cartilage repair: a review. Knee Surg Sports Traumatol Arthrosc 17, 12891297

Koskinen E, Eskelinen A, Paavolainen P, Pulkkinen P, Remes V (2008): Comparison of survival and cost-effectiveness between unicondylar arthroplasty and total knee arthroplasty in patients with primary osteoarthritis: a follow-up study of 50,493 knee replacements from the Finnish Arthroplasty Register. Acta Orthop 79 (4), 499-507

Krauss G: Biochemistry of signal transduction and regulation. 4. Auflage; Wiley-VCH Verlag, Weinheim 2008

Kruegel J, Miosge N, Koelling S (2008): The role of progenitor cells in osteoarthritis. Curr Rheum Rev $\underline{4}, 210-213$

Kuettner KE (1992): Biochemistry of articular cartilage in health and disease. Clin Biochem $\underline{25}, 155-163$

Kurz H, Fehr J, Nitschke R, Burkhardt H (2008): Pericytes in the mature chorioallantoic membrane capillary plexus contain desmin and alpha-smooth muscle actin: relevance for non-sprouting angiogenesis. Histochem Cell Biol 130, 1027-1040

Laemmli UK (1970): Cleavage of structural proteins during the assembly of the head of bacteriophage T4. Nature $\underline{227}$, 680-685

Lamagna C, Bergers G (2006): The bone marrow constitutes a reservoir of pericyte progenitors. J Leukoc Biol $\underline{80,}$ 677-681

Lamalice L, Le Boeuf F, Huot J (2007): Endothelial cell migration during angiogenesis. Circ Res 100, 782-794

Lauffenburger DA, Horwitz AF (1996): Cell migration: a physically integrated molecular process. Cell $\underline{84}(3), 359-369$

Lefebvre V, Bhattaram P (2016): SOXC Genes and the Control of Skeletogenesis. Curr Osteoporos Rep 14, 32-38

Lin G, Liu G, Banie L, Wang G, Ning H, Lue TF, Lin CS (2011): Tissue distribution of mesenchymal stem cell marker Stro-1. Stem Cells Dev 20(10), 1747-1752 
Lohmander LS, Brandt KD, Mazzuca SA, Katz BP, Larsson S, Struglics A, Lane KA (2005): Use of the plasma stromelysin (matrix metalloproteinase 3) concentration to predict joint space narrowing in knee osteoarthritis. Arthritis Rheum 52, 3160-3167

Lotz MK, Otsuki S, Grogan SP, Sah R, Terkeltaub R, D’Lima D (2010): Cartilage cell clusters. Arthr Rheum 62(8), 2206-2218

Mackay AM, Beck SC, Murphy JM, Barry FP, Chichester CO, Pittenger MF (1998): Chondrogenic differentiation of cultured human mesenchymal stem cells from marrow. Tissue Eng 4(4), 415-428

Maisonpierre PC, Suri C, Jones PF, Bartunkova S, Wiegand SJ, Radziejewski C, Compton D, McClain J, Aldrich TH, Papadopoulos N, et al. (1997): Angiopoietin-2, a natural antagonist for Tie2 that disrupts in vivo angiogenesis. Science $\underline{277}$ (5322), 55-60

Makinde TO, Agrawal DK (2011): Increased expression of angiopoietins and Tie2 in the lungs of chronic asthmatic mice. Am J Respir Cell Mol Biol 44(3), 384-393

Matsumoto T, Cooper GM, Gharaibeh B, Meszaros LB, Li G, Usas A, Fu FH, Huard J (2009): Cartilage repair in a rat model of osteoarthritis through intraarticular transplantation of muscle-derived stem cells expressing bone morphogenetic protein 4 and soluble Flt-1. Arthritis Rheum 60(5), 1390-1405

Miosge N, Hartmann M, Maelicke C, Herken R (2004): Expression of collagen type I and type II in consecutive stages of human osteoarthritis. Histochem Cell Biol 122(3), 229-236

Mishima Y, Lotz M (2008): Chemotaxis of human articular chondrocytes and mesenchymal stem cells. J Orthop Res $\underline{26}(10), 1407-1412$

Moran EM, Connolly M, Gao W, McCormick J, Fearon U, Veale DJ (2011): Interleukin$17 \mathrm{~A}$ induction of angiogenesis, cell migration, and cytoskeletal rearrangement. Arthritis Rhe-

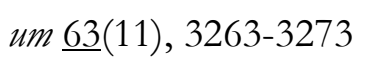

Murphy JM, Dixon K, Beck S, Fabian D, Feldmann A, Barry F (2002): Reduced chondrogenic and adipogenic activity of mesenchymal stem cells from patients with advanced osteoarthritis. Arthritis Rheum 46, 704-713

Nakatsu MN, Sainson RCA, Pérez-del-Pulgar S, Aoto JN, Aitkenhead M, Taylor KL, Carpenter PM, Hughes CCW (2003): VEGF 121 and $\mathrm{VEGF}_{165}$ regulate blood vessel diameter through vascular endothelial growth factor receptor 2 in an in vitro angiogenesis model. Lab Invest $\underline{\text { 83 }}$ (12), 1873-1885 
Ning H, Lin G, Lue TF, Lin CS (2011): Mesenchymal stem cell marker Stro-1 is a $75 \mathrm{kd}$ endothelial antigen. Biochem Biophys Res Commun 413(2), 353-357

Palmer GD, Steinert A, Pascher A, Gouze E, Gouze JN, Betz O, Johnstone B, Evans CH, Ghivizzani SC (2005): Gene-induced chondrogenesis of primary mesenchymal stem cells in vitro. Mol Ther $12(2), 219-228$

Pelletier JP, Martel-Pelletier J, Abramson SB (2001): Osteoarthritis, an inflammatory disease: potential implication for the selection of new therapeutic targets. Arthritis Rheum 44(6), $1237-1247$

Pfaffl MW (2001): A new mathematical model for relative quantification in real-time RTPCR. Nucleic Acids Res 29, e45

Pridie KH (1955): The development and nature of osteoarthritis of the hip joint. Rheumatism $\underline{11}(1), 2-7$

Pritzker KP, Gay S, Jimenez SA, Ostergaard K, Pelletier JP, Revell PA, Salter D, van den Berg WB (2006): Osteoarthritis cartilage histopathology: grading and staging. Osteoarthritis Cartilage 14(1), 13-29

Prockop DJ (1997): Marrow stromal cells as stem cells for nonhematopoietic tissues. Science 276, 71-74

Prockop DJ, Sekiya I, Colter DC (2001): Isolation and characterization of rapidly selfrenewing stem cells from cultures of human marrow stromal cells. Cytother $\underline{3}$ (5), 393-396

Psaltis PJ, Harbuzariu A, Delacroix S, Holroyd EW, Simari RD (2011): Resident vascular progenitor cells--diverse origins, phenotype, and function. J Cardiovasc Transl Res $\underline{4}, 161-176$

Pufe T, Petersen W, Tillmann B, Mentlein R (2001): The splice variants VEGF121 and VEGF189 of the angiogenic peptide vascular endothelial growth factor are expressed in osteoarthritic cartilage. Arthritis Rheum 44(5), 1082-1088

Ridley AJ, Schwartz MA, Burridge K, Firtel RA, Ginsberg MH, Borisy G, Parsons JT, Horwitz AR (2003): Cell migration: integrating signals from front to back. Science $\underline{302}$ (5651), 1704-1709

Rönnstrand L, Heldin CH (2001): Mechanisms of platelet-derived growth factor-induced chemotaxis. Int J Cancer $91(6), 757-762$

Rychlik W, Spencer WJ, Rhoads RE (1990): Optimization of the annealing temperature for DNA amplification in vitro. Nucleic Acids Res 18(21), 6409-6412 
Sandell LJ (2007): Modern molecular analysis of a traditional disease: progression in osteoarthritis. Arthritis Rheum 므, 2474-2477

Sandell LJ, Aigner T (2001): Articular cartilage and changes in arthritis. An introduction: cell biology of osteoarthritis. Arthritis Res $\underline{3}(2), 107-113$

Sekiya I, Colter DC, Prockop DJ (2001): BMP-6 enhances chondrogenesis in a subpopulation of human marrow stromal cells. Biochem Biophys Res Commun 284, 411-418

Schlegel W, Nurnberger S, Hombauer M, Albrecht C, Vecsei V, Marlovits S (2008): Scaffold-dependent differentiation of human articular chondrocytes. Int J Mol Med 22, 691-699

Shi S, Gronthos S (2003): Perivascular niche of postnatal mesenchymal stem cells in human bone marrow and dental pulp." J Bone Miner Res $\underline{18}$, 696-704

Simmons PJ, Torok-Storb B (1991): Identification of stromal cell precursors in human bone marrow by a novel monoclonal antibody, STRO-1. Blood 78 (1), 55-62

Simon TM, Jackson DW (2006): Articular cartilage: injury pathways and treatment options. Sports Med Arthrosc 14(3), 146-154

Singh H, Tahir TA, Alawo DO, Issa E, Brindle NP (2011): Molecular control of angiopoietin signalling. Biochem Soc Trans 39 (6), 1592-1596

Skalli O, Pelte MF, Peclet MC, Gabbiani G, Gugliotta P, Bussolati G, Ravazzola M, Orci L (1989): Alpha-smooth muscle actin, a differentiation marker of smooth muscle cells, is

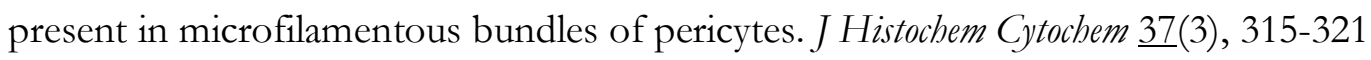

Somoza RA, Welter JF, Correa D, Caplan AI (2014): Chondrogenic differentiation of mesenchymal stem cells: Challenges and unfulfilled expectations. Tiss Eng 20(6), 596-608

Spiegel H-U, Krukemeyer MG: Chirurgische Forschung. Georg Thieme Verlag, Stuttgart 2006

Steadman JR, Rodkey WG, Rodrigo JJ (2001): Microfracture: surgical technique and rehabilitation to treat chondral defects. Clin Orthop Relat Res (391 Suppl), S362-369

Stoppiello LA, Mapp PI, Wilson D, Hill R, Scammell BE, Walsh DA (2014): Structural associations of symptomatic knee osteoarthritis. Arthritis Rheumatol $\underline{66}(11), 3018-3027$

Sun HB (2010): Mechanical loading, cartilage degradation, and arthritis. Ann N Y Acad Sci 1211, 37-50

Suzuki G, Iyer V, Lee TC, Canty JM, Jr. (2011): Autologous mesenchymal stem cells mobilize cKit+ and CD133+ bone marrow progenitor cells and improve regional function in 
hibernating myocardium. Circ Res $\underline{109}, 1044-1054$

Tesche F, Miosge N (2005): New aspects of the pathogenesis of osteoarthritis: the role of fibroblast-like chondrocytes in late stages of the disease. Histol Histopathol 20, 329-337

Tew SR, Li Y, Pothacharoen P, Tweats LM, Hawkins RE, Hardingham TE (2005): Retroviral transduction with SOX9 enhances re-expression of the chondrocyte phenotype in passaged osteoarthritic human articular chondrocytes. Osteoarthritis Cartilage $\underline{13}$, 80-89

Tuan RS, Boland G, Tuli R (2002): Adult mesenchymal stem cells and cell-based tissue engineering. Arthritis Res Ther $\underline{5}(1), 32-45$

Umlauf D, Frank S, Pap T, Bertrand J (2010): Cartilage biology, pathology, and repair. Cell Mol Life Sci 67, 4197-4211

Wells EA, Robinson AS (2017): Cellular engineering for therapeutic protein production: product quality, host modification, and process improvement. Biotechnol J 12(1), 1-12

Westermark B, Siegbahn A, Heldin CH, Claesson-Welsh L (1990): B-type receptor for platelet-derived growth factor mediates a chemotactic response by means of ligand-induced

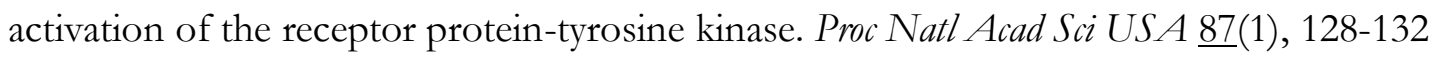

Witmer AN, van Blijswijk BC, van Noorden CJ, Vrensen GF, Schlingemann RO (2004): In vivo angiogenic phenotype of endothelial cells and pericytes induced by vascular en-

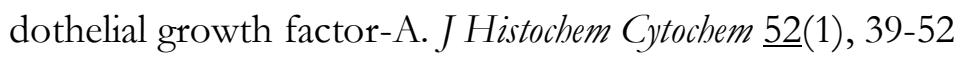

Yang Z, Gaudio S, Song W, Greenwood M, Jean-Baptiste G, Greenwood MT (2007): Evidence for the dimerization of human regulator of G-protein signaling 5 (RGS5). Cell Pbysiol Biochem 20(5), 303-310 


\section{Danksagung}

Zu großem Dank bin ich Herrn Prof. Miosge für die sehr gute Betreuung meiner Dissertation verpflichtet. Nicht nur für die Betreuung, sondern auch für den breiten Einblick in die Wissenschaft danke ich ihm recht herzlich.

Ebenso möchte ich von Herzen Christa Bode, Boguslawa Sadowski und Elke Henze für ihre Unterstützung während meiner Promotion danken.

Meinen Mitdoktoranden möchte ich für die Diskussionen, Anregungen, die gegenseitigen Hilfestellungen und die schöne Zeit im Labor danken. Hier möchte ich besonders erwähnen: Dr. Jenny Frese, Dr. Sebastian Kölling, Dr. Gökhan Cingöz und Dr. Boris Schminke. 
